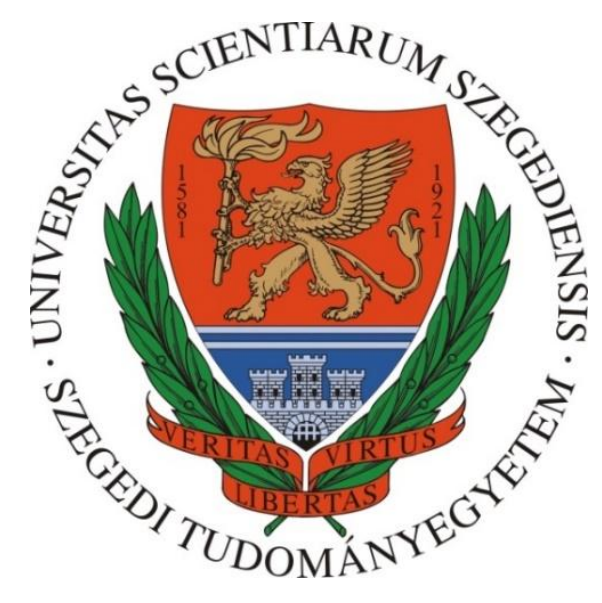

\title{
EVALUATION OF \\ NOVEL RADIOTHERAPY APPROACHES \\ IN BRAIN TUMOUR MANAGEMENT
}

PhD Thesis

Ágnes Dobi MD

Supervisor:

Prof. Katalin Hideghéty, MD, PhD, Habil.

Department of Oncotherapy

Faculty of Medicine, University of Szeged

Szeged, Hungary

Doctoral School of Clinical Medicine

University of Szeged

Szeged 
List of full papers that served as the basis of the $\mathrm{PhD}$ thesis

I) Dobi Á, Darázs B, Fodor E, Cserháti A, Együd Z, Maráz A, László S, Dodd L, Reisz Z, Barzó P, Oláh J, Hideghéty K. (2020) Low Fraction Size Re-irradiation for Large Volume Recurrence of Glial Tumours. Pathol Oncol Res. 26(4):2651-2658. doi: 10.1007/s12253$\underline{020-00868-2}$

(IF: 2.826, Q2)

II) Dobi Á, Fodor E, Maráz A, Együd Z, Cserháti A, Tiszlavicz L, Reisz Z, Barzó P, Varga Z, Hideghéty K. (2018) Boost Irradiation Integrated to Whole Brain Radiotherapy in the Management of Brain Metastases. Pathol Oncol Res. 2020 26(1):149-157. doi: 10.1007/s12253-018-0383-y (Epub 2018 Jan 17.)

(IF: 2.826, Q2) 


\section{List of other full papers}

I) Végváry Z, Darázs B, Paczona V, Dobi Á, Reisz Z, Varga Z, Fodor E, Cserháti A, Oláh J, Kis D, Barzó P, Hideghéty K. (2020) Adaptive Radiotherapy for Glioblastoma Multiforme - The Impact on Disease Outcome. Anticancer Res. 40(8):4237-4244. doi: $\underline{10.21873 / \text { anticanres. } 14425}$

$(I F: 1.994, Q 2)$

II) Darázs B, Ruskó L, Végváry Z, Ferenczi L, Dobi Á, Paczona V, Varga Z, Fodor E, Hideghéty K. (2019) Subventricular zone volumetric and dosimetric changes during postoperative brain tumour irradiation and its impact on overall survival. Phys Med. 68:35-40. doi: 10.1016/j.ejmp.2019.10.039

(IF: 2.485, Q1)

III) Rusz O, Kószó R, Dobi Á, Csenki M, Valicsek E, Nikolényi A, Uhercsák G, Cserháti A, Kahán Zs. (2018) Clinical benefit of fulvestrant monotherapy in the multimodal treatment of hormone receptor and HER 2 positive advanced breast cancer: a case series. Oncotargets and Therapy 11: 5459-5463. doi: 10.2147/OTT.S170736

$(I F: 3.046, Q 2)$

IV) Valicsek E, Kószó R, Dobi Á, Uhercsák G, Varga Z, Vass A, Jebelovszky É, Kahán Zs. (2015) Cardiac Surveillance Findings During Adjuvant and Palliative Trastuzumab Therapy in Patients with Breast Cancer. Anticancer Res. 35(9): 4967-73.

(IF: 1.895, Q2)

V) Hideghéty K, Cserháti A, Besenyi Z, Zag L, Gaál S, Együd Zs, Mózes P, Szántó E, Csenki M, Rusz O, Varga Z, Dobi Á, Maráz A, Pávics L, Lengyel Z. (2015) Role of 18FDG-PET/CT in the management and gross tumour volume definition for radiotherapy of head and neck cancer; single institution experiences based on long-term follow-up. Magy Onkol. 59(2):103-10.

(Q3)

VI) Hideghéty K, Dobi Á, Mózes P, Cserháti A. (2014) Sürgősségi sugárkezelés az onkológiában. Klin Onkol. 1: 4: 273-280. 
VII) Uhercsák G, Dobi Á, Gyulai R, Oláh J, Kaizer L, Ormándi K, Cserháti A, Lázár G, Farkas Gy, Kahán Zs. (2013) Management of the case of a young female patient with multiple malignancies and germline R24P CDKN2A gene mutation. Journal of Cancer Therapy 4: 7A 18-20. doi:10.4236/jct.2013.47A004

VIII) Dobi Á, Kelemen Gy, Kaizer L, Weiczner R, Thurzó L, Kahán Zs. (2011) Breast cancer under 40 years of age: increasing number and worse prognosis. Pathol Oncol Res. 17(2):425-8. doi: 10.1007/s12253-010-9305-3

$(I F: 1.366, Q 2)$

Cumulative impact factor (full papers) $=16.438$ 


\section{Table of contents}

List of full papers that served as the basis of the $\mathrm{PhD}$ thesis ............................................... 2

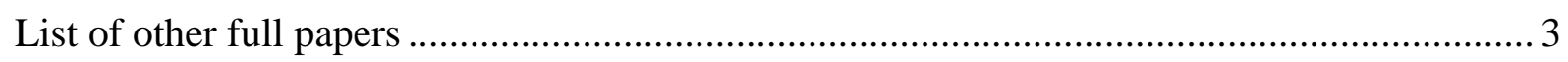

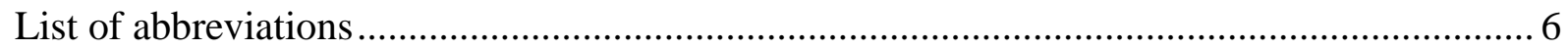

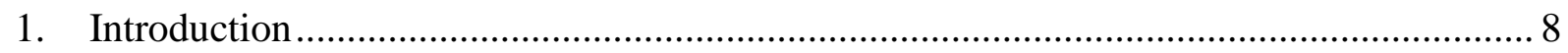

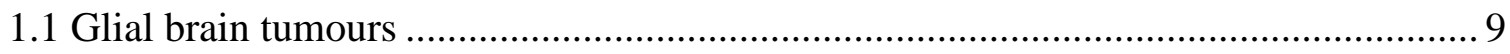

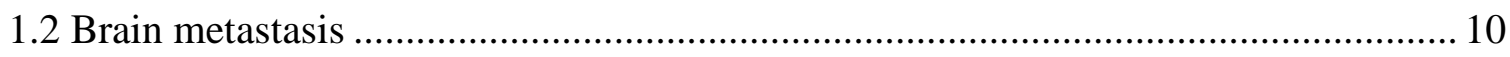

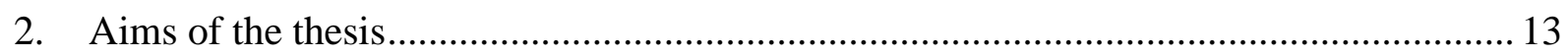

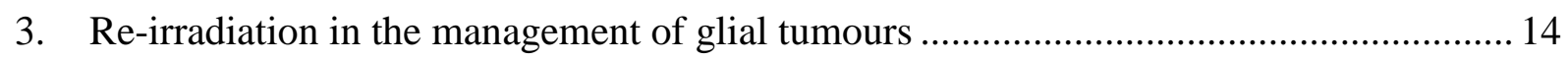

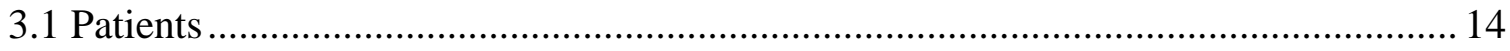

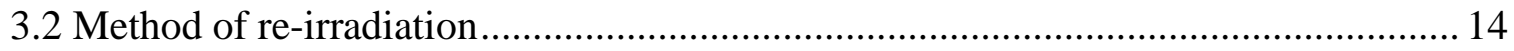

3.3 Management of side effects during radiotherapy in both studies ............................ 15

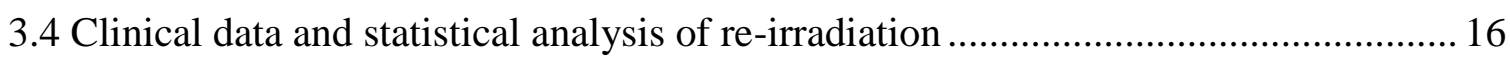

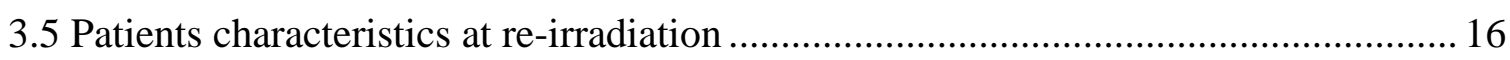

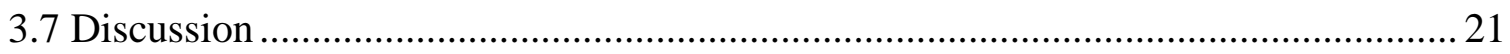

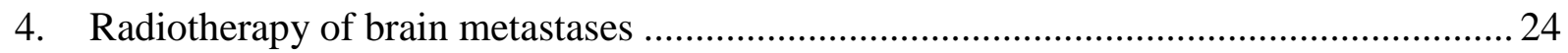

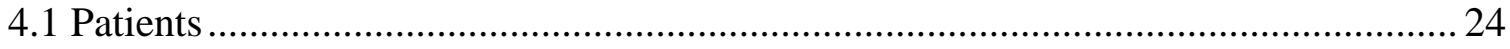

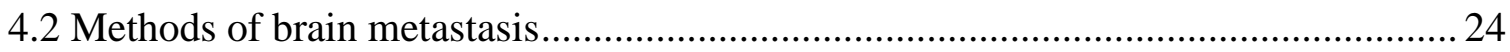

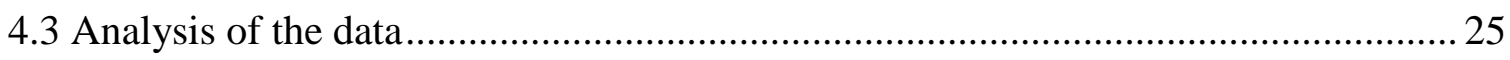

4.4 Characteristics of the malignant disease and brain metastases ................................ 27

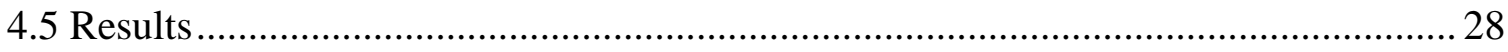

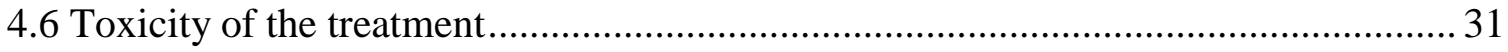

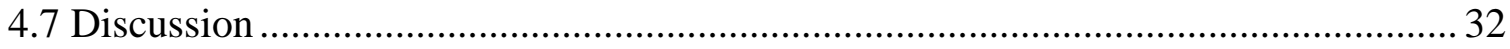

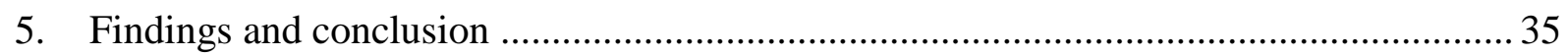

5.1 Main points derived from the analysis of glial tumour re-irradiation.......................... 35

5.2 Main points of dose escalation in the radiation treatment of brain metastases........... 36

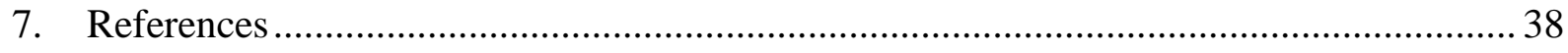


List of abbreviations

ALK anaplastic lymphoma kinase

ALL acute lymphoblastic leukaemia

ATRX ATP-dependent helicase

BBB blood-brain barrier

BM brain metastasis

BRAF a human gene that encodes a protein called B-Raf

BSC best supportive care

CT computed tomography

ChT chemotherapy

CI confidence interval

CNS central nervous system

CT computed tomography

DCRT 3D conformal radiation therapy

DG diagnosis

EBRB external beam radiotherapy boost

EGFR epidermal growth factor receptor

EQD2 2 Gy equivalent dose

FSRT hypofractionated stereotactic radiosurgery

GBM glioblastoma multiforme

GPA graded prognostic assessment

Gy Gray

GTV gross tumour volume

$\mathbf{H}_{2}$ histamine $\mathrm{H}_{2}$ receptor

HER2 human epidermal growth factor receptor 2

HFRT hypofractionated radiotherapy

HR hazard ratio

ICRU International Commission on Radiation Units \& Measurements, Inc.

IDH isocitrate dehydrogenase

IMRT intensity-modulated radiotherapy

KPS Karnofsky performance score

MGMT $O[6]$-methylguanine-DNA methyltransferase 
MM melanoma malignum

MMS Mini Mental Score

MRI magnetic resonance imaging

NSCLC non- small cell lung cancer

OS overall survival

PCI prophylactic cranial irradiation

PFS progression free survival

PPI proton pump inhibitor

PS performance score

PTV palling target volume

RANO response assessment in neuro-oncology

HGG high-grade glioma

RChT radio-chemotherapy

re-RT re-irradiation

RPA recursive partitioning analysis

RT radiotherapy

SCLC small cell lung cancer

SIB simultaneous integrated boost

SRS stereotactic radiosurgery

TMZ temozolomide

TTF tumour treating field

VMAT volumetric modulated arc therapy

WBRT whole-brain irradiation 


\section{Introduction}

Brain tumours are arising from different cells of the central nervous system or originating from various primary cancers all over the body. The incidence of gliomas is rising, peaking between the fifth and sixth decades of life [1]. The same steadily increasing tendency can be observed in the incidence of brain metastases (BMs), ranging 9-40\% worldwide, alongside the improved efficacy of systemic treatments, providing longer survival for cancer patients in disseminated status $[2,3]$. The treatment of primary and secondary brain tumours is highly challenging due to the special characteristics of CNS neoplasms. The prognosis of the patients with glioblastoma or with intracranial metastases remained dismal in spite of all common interdisciplinary efforts. On the other hand, due to the vulnerability of the CNS, longer survivals frequently affected by the serious consequences of the tumour and of exposing the brain to medical interventions, including surgery, radiotherapy and chemotherapy [4,5].

The classical rules of onco-surgery cannot be applied to the brain. In cases of tumour invasion of the eloquent regions or affecting the corticospinal tracts or with unfavourable deep midline localization and also in cases of diffuse, multifocal tumours, only a biopsy could be performed. By using sophisticated techniques, such as neuronavigation, endoscopic neurosurgery, intraoperative electrophysiology, i.e. brain mapping, the main aim is to achieve as much tumour mass removal as possible, without causing serious sequelae. Nevertheless, even in the case of complete removal fast recurrence occurs frequently. Further limit to the successful treatment is the blood-brain barrier (BBB) - a system of tight junctions and transport proteins that protect delicate neural tissues from toxic compounds in the bloodstream, therefore also blocking the cross of chemotherapeutic, anticancer agents with molecular targeting. Moreover, the highly special genetic, epigenetic, developmental and micro-environmental characteristics of the human brain frequently manifest in cancers, which are resistant to routine and new therapeutic modalities, as well $[6,7,8]$.

Due to the unsuccessful BBB crossing of many drugs, thus their inability to reach the therapeutic concentration locally, the majority of systemic therapies have poor treatment responses in patients with brain tumours [9].

Radiotherapy plays a central role in the management of brain malignancies, leading to survival prolongation and symptom relieve. However, damage to the healthy brain tissue could result in serious acute side effects like brain oedema, increase of intracranial pressure, 
and late sequelae such as cognitive deterioration or brain function disturbance. Radiotherapy has progressed rapidly over the past decades, and apart of implementation of the novel techniques, further methods for improvement of the therapeutic index, i.e. increased efficacy and decreased brain damage, could contribute to better outcome.

Therefore we focused our research on introduction and evaluation of novel radiotherapy approaches in the complex management of primary and secondary brain tumours.

\subsection{Glial brain tumours}

Gliomas, with incidence of 5/100 000 in adults, are the most common primary central nervous system malignancies, peaking between the fifth and sixth decades of life [1]. After initial multimodal treatment, at least $70 \%$ recurrence rate of gliomas can be expected $[10,11,12]$. By surgical therapy alone, the disease has a very poor prognosis (median survival 4-6 months) [13], whereas surgery accompanied by radiotherapy (RT) ameliorates the median survival data to 8-9 months. Together with concomitant and sequential temozolomide (TMZ), an alkylating agent crossing through the blood brain barrier, better median survival values can be expected, such as 15 months for glioblastomas, or even 2-5 years for anaplastic gliomas [14].

In the case of recurrence with its considerable limitations, surgical treatment has the highest efficacy [15]. In certain good performance status patients with good anatomical access to tumours, surgery is applicable, but the resection outcome could be definitely limited by considerable infiltration of nervous tissue and by higher morbidity risk [16, 17]. As for other low grade and grade 3 cases, TMZ is the treatment of choice, if it was not administered during the initial management. Thereafter and for GBM second-line systemic treatment (such as chemo- or biological therapy) and re-irradiation is optional, in the lack of standardised treatment for recurrent gliomas [18]. Recently, Tumour Treating Field (TTF), a novel therapeutic option emerged, prolonging the survival with further 6 months [1]. For systemic treatment, monoclonal antibody (bevacizumab), chemotherapy (nitrosurea, lomustine, dose dense TMZ [17], immune checkpoint blockade (nivolumab, pembrolizumab) [19], or even vaccines (DCVax) [20, 21, 22] are the options to consider. For recurrent tumours, salvage reirradiation could be selected. The typical re-irradiation techniques and strategies for recurrent gliomas are conventionally fractionated RT, brachytherapy, hypofractionated stereotactic 
radiosurgery (FSRT), stereotactic radiosurgery (SRS) alone, or combination treatment with RT and systemic therapy, and palliative RT [23,24].

On reviewing several clinical trials, the 6- and 12-month overall survival (OS-6 and OS-12), calculated from the time of re-irradiation, were $73 \%$ and $36 \%$, respectively, whereas the 6and 12-month of progression free survival (PFS-6 and PFS-12) were 43\% and 17\%, respectively [25]. Median OS (mOS) was 7.4-12.7 months in other studies [26, 27, 28, 29, 30]. On the basis of these encouraging results, the re-irradiation for recurrent gliomas was introduced in our Department a decade ago. However, large volume recurrence could develop and contrast enhancement often appears along the ventricle wall or along the entire border of the surgical cavity. In these cases, if the planning target volume is $>80 \mathrm{~cm}^{3}$, the applicability of stereotactic irradiation is limited, the fraction size could be reduced for retaining the cognitive function. In the first part of the thesis, the prospectively implemented 32 Gy reirradiation in 20 fractions was evaluated in order to confirm the feasibility and to investigate the outcome influencing factors and potential benefit for patients with recurrent glial tumour after the first/second line tumour management.

\subsection{Brain metastasis}

Alongside the improved efficacy of systemic treatments, the incidence of brain metastases (BMs) steadily increases, ranging 9-40\% worldwide [2, 3]. The most common cancers that metastasise to the brain include lung, breast, melanoma, renal cell, and colorectal cancers [31]. In the case of brain metastasis, though, the overall prognosis remains poor: without any treatment 1-2 months, with palliative methods, 4-6 months of median survival can be expected with WBRT [32], depending (1) on the age and functional status of the patient, (2) the extent of the underlying systemic disease, and (3) the number of metastases [33].

The era of immunotherapy and targeted therapies gives a new emphasis for medical therapy of malignancies. The vast majority of currently available treatment experience about targeted therapies concerns patients with melanoma, breast cancer, and lung cancer [34]. The ameliorated response rates of $45-78 \%$ in cases of the newcomer drugs such as alectinib [35], ceritinib [36], and (a combined ALK and EGFR inhibitor) brigatinib [37, 38] can be traced back to their better BBB crossing ability [39]. Targeted agents have been applied primarily in HER2-positive breast cancer patients with brain metastases [40]. The lapatinib-capecitabine combination therapy resulted in response rates of $66 \%$ (patients with no prior radiotherapy) 
20\% (radiation refractory patients); according to recent phase II studies [41, 42, 43]. The efficacy of neratinib remained strictly limited (responses rates of 8\% in HER2-positive brain metastases) [44]; nevertheless, in combination with capecitabine, the rates increased up to $49 \%[45]$.

BRAF mutations can be detected in $40-50 \%$ of melanoma patients with brain metastases, whilst the BRAF inhibitor vemurafenib has only $18-20 \%$ response rates and dabrafenib treatment comes with 30-40\% response rates [46, 47]. Better response rates are associated with radiation naive patients, this could be applied to breast cancer patients, as well. The dabrafenib/trametinib combination has response rates of 55\% [48], and the duration of good response is around six months.

Immunotherapies also serve as stimulating research field for brain metastases. In case of brain metastatic melanoma, the ipilimumab/nivolumab combination achieved $45-57 \%$ response rates (in some studies, stable disease also included) [49, 50, 51].

Contrary to our gradually better scientific understanding of the genetic background of brain metastases, it remains still unanswered, whether brain metastases, compared to their primary tumours, are genetically heterogeneous, and if it is so, then this genetic heterogeneity could also explain the different clinical responses. According to a detailed genomic study of 104 matched brain metastases and primary tumours; coming from different histological types and treatment regimens, the researchers established the phylogenetic relationship between brain metastases and primary tumours [52]. In above $50 \%$ of cases, clinically targetable alterations were present in the brain metastasis, which have been not diagnosed in the primaries [34].

These novel targeted therapies represent an encouraging approach against brain metastases, but they have still certain limitation both in efficacy and response duration. As common therapeutic mean is the radiotherapy with different possible methods to choose from. In case of multiple BMs, palliative whole-brain irradiation (WBRT) is usually performed with the dose of 10x3 Gy [53], whilst the cases with less than three metastatic lesions (i.e. oligometastases) are considered for surgery and/or radiosurgery with or without WBRT [54, 55]. In the last decade, conclusions from relevant clinical studies demonstrated the superiority of multimodal approaches over the single treatment method of neurosurgery, stereotactic radiosurgery (SRS), and WBRT $[56,57,58]$. The conformational fractionated external beam boost, instead of SRS for BMs arising from lung cancer (as it has been recently demonstrated in a multi-institutional study [59]), results in a remarkable estimated 1-year local control rate 
of $>75 \%$. Such dose escalation can be also carried out with intensity-modulated radiotherapy (IMRT) or volumetric modulated arc therapy (VMAT), using the simultaneous integrated boost (SIB) technique $[60,61]$, or, if the above mentioned techniques are not available, with external beam radiotherapy boost (EBRB) [59].

Several technical and logistical advantages of SIB over other modalities (such as radiosurgery) makes SIB a plausible choice. SIB includes WBRT and boost on BM in the same session with optimised dose distribution, requires a single simulation protocol, reducing the waiting and dose delivery time, therefore costs and inconvenience, as well [62]. Using single fraction protocols, the re-oxygenation and re-assortment benefits accompanying fractionated modalities, cannot be exploited. The treatment of more than 3 metastases with radiosurgery may require long or multiple sessions, or may lead to the impossibility of radiosurgery, as well. The substantial time break between radiosurgery and WBRT may enhance the probability of tumour cell repopulation or subletal repair processes [63]. The optimal selection of SRS versus WBRT in the management of brain metastasis remains to be answered [34].

In the case of multiple and/or large volume brain metastases, if the extracranial disease could be well controlled by means of simultaneous WBRT with $<2.5 \mathrm{~Gy} /$ fraction and focal boost to each metastatic lesion in 15 fractions. This promising approach provides the same or superior efficacy and less neurocognitive deterioration probability in a reasonable timeframe, than the conventional WBRT \pm boost. We have implemented this technique in our Department and evaluated the outcome.

In the present thesis we summarise our results on two separate clinical investigations addressing relevant clinical questions on enhancement of radiotherapy for patients with recurrent primary brain tumours, and with brain metastases.

Both studies have been carried out in accordance with The Code of Ethics of the World Medical Association (Declaration of Helsinki) for experiments involving humans. Informed consent was obtained from the patients at their first clinical admission for the anonymised use of their patient data for research purposes. 


\section{Aims of the thesis}

In the present thesis,

1) we aimed to investigate

- the feasibility of re-irradiation with low fraction size in large volume recurrent gliomas,

- the safety and clinical efficacy of re-irradiation for the patients affected, and

- the clinical factors influencing the outcome of re-RT.

2) Our goal was by introducing the SIB into the management of brain metastases to find a balance in improving the survival with dose escalation to the macroscopic metastases, maintaining the intracranial control and reducing the probability of treatment-related cognitive decline; meanwhile keeping the treatment duration reasonable for patients even with multiple brain metastases.

In this thesis the outcome of escalated dose irradiation (SIB and WBRT+boost) was compared to WBRT in order to evaluate

- whether the above defined main goal could be achieved in real-life clinical setting;

- whether the applicability and safety of dose escalation for radiotherapy of brain metastases could be proven;

- the patient groups with the highest benefit from SIB according to the primary tumour;

- further clinical factors which provide improved outcome for appropriate patient selection; and

- whether this concept is also feasible for patients with poor performance status. 


\section{Re-irradiation in the management of glial tumours}

\subsection{Patients}

Between 2007 and 2018, at the Department of Oncotherapy, altogether 55 patients with recurrent glial tumours were subjected to re-irradiation. The whole present study was carried out according to the ethical permission No. 4209/2018-SZTE, issued by the Ethical Committee of our University.

The initial care consisted of surgery in each case. The patients with grade 2 and grade 3 brain tumours received radiotherapy only postoperatively and for GBM we applied adjuvant chemoradiation therapy followed by temozolomide monotherapy up to progression. Magnetic resonance imaging (MRI) were performed three monthly. Disease progression was defined independently by two experts. At the time of diagnosis, the tumour grading was based on histological assessment. At the time of re-RT, histological evaluation was performed only in the re-operated cases, in the case of the remaining patients (without re-operation), the grading was based on clinical and radiological evaluation.

The majority of the patients (32 over 23) received bevacizumab therapy after the re-RT, and these patients were controlled in a bi-weekly fashion, with physical examination up to progression and 3-months intervals MRIs were performed, whereas for the remaining group without bevacizumab treatment after re-RT, the check-ups were scheduled in 4-6 weeks. Two experts evaluated the images according to the RANO HGG (Response Assessment in NeuroOncology High-grade glioma) criteria [64].

\subsection{Method of re-irradiation}

The re-irradiation volume was defined on the basis of planning CT (computed tomography) and MRI fusion. Patients were immobilised with a 3-point thermoplastic mask (ORFIT Industries, NL). The planning target volume encompassed the GTV (gross tumour volume) plus $0.3-1 \mathrm{~cm}$ margin. The shapes of the recurrent tumours were frequently highly irregular, sometimes with multiple manifestations, and with spread to the contralateral hemisphere through the corpus callosum; or spreading along the wall of the previous surgical cavity and/or ventricle wall, resulting in larger PTV. The normal structures were contoured 
including the lens, optic chiasm, optic nerve, brain, and brainstem. Treatment planning was performed with Eclipse (version 5, Varian Medical Systems, Palo Alto, USA) [Figure \#1]. The re-RT dose was 32 Gy in 1.6 Gy daily fractions in all cases, in order to avoid serious neurotoxicity. Dependent on the location and extent of the recurrent glioma, 3 DCRT or IMRT or VMAT (Rapid Arch) therapy-plans (VMAT) were generated according to the ICRU (International Commission on Radiation Units \& Measurements, Inc.) 52 recommendation [65].

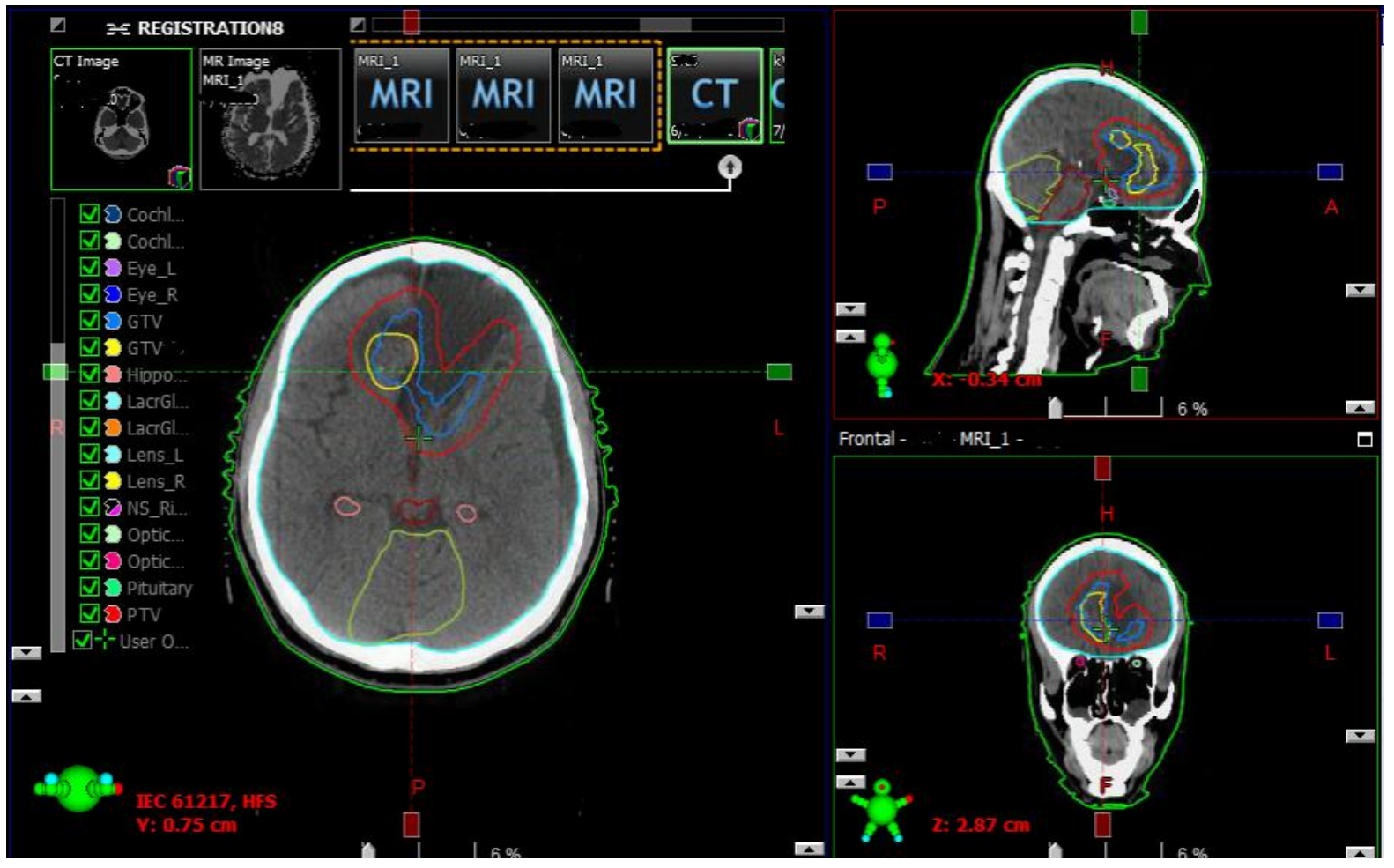

Figure\#1 Contouring of target and organs at risk for re-irradiation treatment planning. (yellow: GTV by radiation oncologist, blue: GTV by radiologist, red: PTV, turquoise: brain, pink: hippocampus, dark red: brain stem, light yellow: cerebellum)

\subsection{Management of side effects during radiotherapy in both studies}

During brain irradiation patients received $12 \mathrm{mg}$ methyl-prednisolone for prevention of brain oedema (with $\mathrm{PPI} / \mathrm{H}_{2}$ receptor inhibitor and potassium chloride, if needed), with gradually decreased dosing after radiotherapy. The dose of methyl-prednisolone was adjusted according to the symptoms of intracranial pressure elevation due to brain oedema. 


\subsection{Clinical data and statistical analysis of re-irradiation}

We assessed retrospectively the overall survival (OS) from the diagnosis, and from the first day of the re-irradiation according to the age, Karnofsky performance score (KPS), primary tumour grade and histopathology type, the primary tumour removal, size of GTV, size of PTV, time interval between two irradiations, time elapsed between diagnosis and $2^{\text {nd }} R T$, second line bevacizumab treatment.

The data were evaluated by Kaplan-Meier statistical analysis with IBM SPSS Statistics for Windows, Version 20.0 (Armonk, NY: IBM Corp.) p value <0.05 was considered as statistically significant. COX regression was used for univariate, as well as multivariate analysis. Factors with significance in univariate analysis were included into a multivariate analysis. After the re-irradiation we recorded the KPS, Mini Mental Score (MMS) and daily activity in every visit.

\subsection{Patients characteristics at re-irradiation}

The mean age of the population at the time of the primary diagnosis detection was 39 years (range: $11-71$ years); $49 \%$ of them was male and $51 \%$ female. The mean age at the time of the re-irradiation was 42 years (range: 13-72 years). The KPS was over $70 \%$ in $40 \%$ of this population. At the beginning of the re-irradiation, majority of the patients had minor neurological symptoms, such as hemiparesis, facial paresis, focal seizure partly controlled by antiepileptic medication, more frequently motor and sensory aphasia. Besides these symptoms, the patients preserved the ability of self-caring, except 5 patients with serious paresis needing regular help in their daily life. Out of 23 cases with repeated surgery, only four initially grade 2-3 tumours showed malignant transformation to grade 3-4. In the majority of the cases, though, reoperation took place relatively early during the course of the disease. Usually in the case of initially low grade tumours; surgery was performed prior to the first oncological management; and also grade 3 tumours were as well as re-operated some years prior to re-irradiation. In $84 \%$ of the cases, based on the clinical behaviour of the tumour, their malignant transformation was highly probable at the time of re-irradiation, but no regular biopsy was performed in order to confirm it. The average time interval between the diagnosis and re-irradiation was 47.4 months (range: 7.3-228 months) first and the re- 
irradiation was 36 months (range: 7.7-232 months) respectively. All patients received firstline systemic temozolomide treatment, either as part of initial postoperative management (GBM), or at the first relapse. 23 patients were treated with bevacizumab monotherapy, as second-line treatment. The re-irradiation was performed after the first-line systemic treatment in 45 cases, and after second-line therapy in 10 cases.

The primary histological type was grade 2 astrocytoma in 15 cases, grade 3 glial tumour (anaplastic astrocytoma or oligodendroglioma) in 12 cases, and glioblastoma multiforme (GBM) in 28 cases. MGMT (O-6-methylguanine-DNA methyltransferase) methylation status was known in 28 cases. 18 patients were methylated, and in 9 cases MGMT was nonmethylated [Table \#1].

\begin{tabular}{|l|c|}
\hline Variables & No. of the patients \\
\hline Number of the patients & 55 \\
\hline Sex & \\
\hline Male & 27 \\
\hline Female & 28 \\
\hline KPS & \\
\hline $\mathbf{> 7 0} \%$ & 22 \\
\hline $\mathbf{5 7 0 \%}$ & 33 \\
\hline Primary histopathology type & \\
\hline astrocytoma grade 2 & 15 \\
\hline oligodendroglioma grade 3 & 6 \\
\hline anaplastic astrocytoma grade 3 & 6 \\
\hline glioblastoma multiforme & 28 \\
\hline Salvage surgery & 23 \\
\hline Prior temozolomide treatment & 55 \\
\hline MGMT methylation status & \\
\hline methylated & 18 \\
\hline unmethylated & 9 \\
\hline unknown & 28 \\
\hline
\end{tabular}

Table\#1 Characteristics of re-irradiated patients.

\subsection{Results}

Median survival was altogether 42.6 months, as calculated from the date of the first diagnosis [Table \#2]. Regarding histology, cases with lower, grade 2 malignancies had the most favourable survival values (111.0 months), whereas this value was 23 months $(p<0.001)$ in cases with GBM. We found a strong correlation to histological type: grade 2 astrocytoma 
cases had the longest survival (114.8 months), whereas the worst survival was detected of grade 4 cases (30.7 months; $\mathrm{p} \leq 0.001)$.

The most important factors significantly influencing the outcome of re-RT were the time interval between the diagnosis and the re-RT, histology grade, GTV, and KPS at the reirradiation.

\begin{tabular}{|c|c|c|c|c|}
\hline Variable & $\mathbf{n}$ & $\begin{array}{l}\text { OS (months) } \\
\text { from initial } \\
\text { diagnosis }\end{array}$ & $\pm \mathbf{S E}$ & p-value \\
\hline entire group & 55 & 42.6 & 2.6 & \\
\hline \multicolumn{5}{|l|}{ initial histopathology type } \\
\hline grade 2 & 15 & 114.8 & 40.2 & \multirow[b]{3}{*}{$\mathbf{p}<0.001 *$} \\
\hline grade 3 & 12 & 52.2 & 9.8 & \\
\hline grade 4 & 28 & 30.7 & 1.3 & \\
\hline Variable & n & $\begin{array}{l}\text { OS (months) } \\
\text { from re-RT }\end{array}$ & $\pm \mathbf{S E}$ & p-value \\
\hline entire group & 55 & 8.37 & 1.9 & \\
\hline \multicolumn{5}{|l|}{ histopathology type at re-RT } \\
\hline $\operatorname{grade} 2(n=12)+\operatorname{grade} 3(n=14)$ & 26 & 10 & 1.2 & \multirow[b]{2}{*}{$\mathrm{p}=\mathbf{0 . 0 3 1} *$} \\
\hline grade 4 & 29 & 6 & 2 & \\
\hline \multicolumn{5}{|l|}{ GTV re-RT mean $118 \mathrm{~cm}^{3}$} \\
\hline$\leq$ mean & 29 & 12.9 & 3.9 & \multirow[b]{2}{*}{$\mathrm{p}=0.006^{*}$} \\
\hline$>$ mean & 23 & 5.5 & 0.3 & \\
\hline \multicolumn{5}{|l|}{ KPS at re-RT } \\
\hline$\leq 70 \%$ & 33 & 5.6 & 0.7 & \multirow[b]{2}{*}{$\mathbf{p}=0.009 *$} \\
\hline$>70 \%$ & 22 & 10.4 & 1.9 & \\
\hline \multicolumn{5}{|c|}{ Time between diagnosis (DG) and re-RT } \\
\hline$\leq 47$ months & 18 & 6.7 & 1.6 & \multirow[b]{2}{*}{$\mathbf{p}=0.029 *$} \\
\hline$>47$ months & 37 & 10.2 & 0.7 & \\
\hline \multicolumn{5}{|l|}{ Time between the $1^{\text {st }}$ and the $2^{\text {nd }}$ RT } \\
\hline$\leq 37$ months & 31 & 6.7 & 1.5 & \multirow{2}{*}{$\mathrm{p}=0.05^{*}$} \\
\hline$>37$ months & 24 & 10.2 & 3.7 & \\
\hline \multicolumn{5}{|l|}{ PTV re-RT $316 \mathrm{~cm}^{3}$} \\
\hline$\leq$ mean & 33 & 10.1 & 1.5 & \multirow[b]{2}{*}{$\mathrm{p}=0.246$} \\
\hline$>$ mean & 22 & 5.5 & 0.4 & \\
\hline \multicolumn{5}{|l|}{ Age at re-irradiation } \\
\hline$\leq 40$ year & 27 & 8.3 & 2.2 & \multirow[b]{2}{*}{$\mathrm{p}=0.704$} \\
\hline$>40$ year & 28 & 6.6 & 2.7 & \\
\hline \multicolumn{5}{|l|}{ bevacizumab therapy before re-RT } \\
\hline no & 32 & 6.5 & 1.1 & \multirow{2}{*}{$\mathrm{p}=0.35$} \\
\hline yes & 23 & 10.2 & 0.3 & \\
\hline
\end{tabular}

Table\#2 Survival data. Asterisk denotes significant difference $(\mathbf{p} \leq \mathbf{0 . 0 5})$, $* * \operatorname{In} 3$ cases, the former GTV data were not available due to transfer incompatibility to the new treatment planning system. 
The median OS from the re-RT of the entire cohort was 8.4 months; 6 patients survived more than 10 months and 2 patients more than 2 years. The 6-month and the 12-month OS rate was $64 \%$ and $31 \%$ respectively.

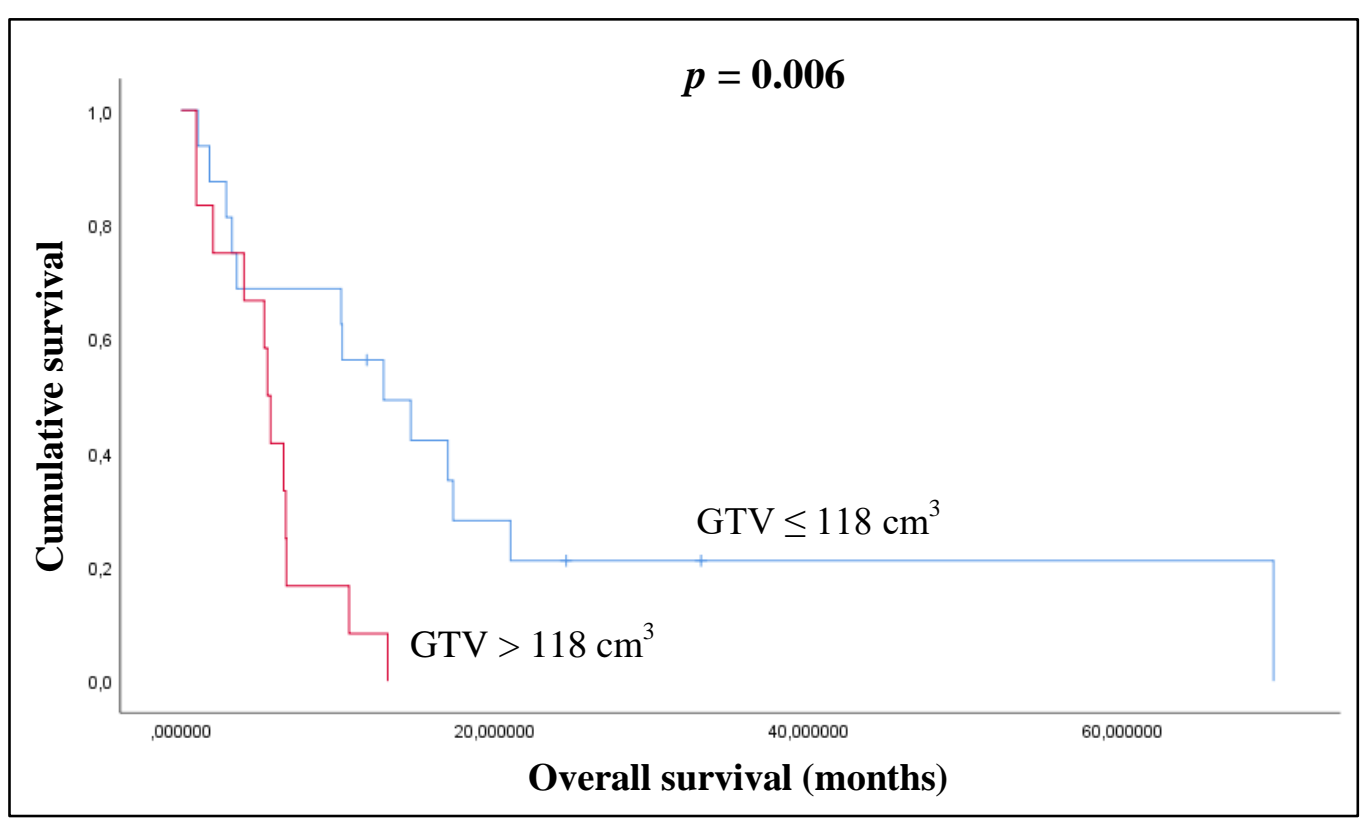

Figure\#2 Kaplan-Meier plot of the correlation between GTV-re-RT and OS (p=0.006).

The mean volume of GTV, as contoured during re-RT, was $118.0 \mathrm{~cm}^{3}$ (range: $4.5-304 \mathrm{~cm}^{3}$ ). Patients with lesser than average GTV at re-RT had 12.9 months, patients with greater than average GTV at re-RT had 5.5 month of median survival ( $\mathrm{p}=0.006)$ [Figure \#2].

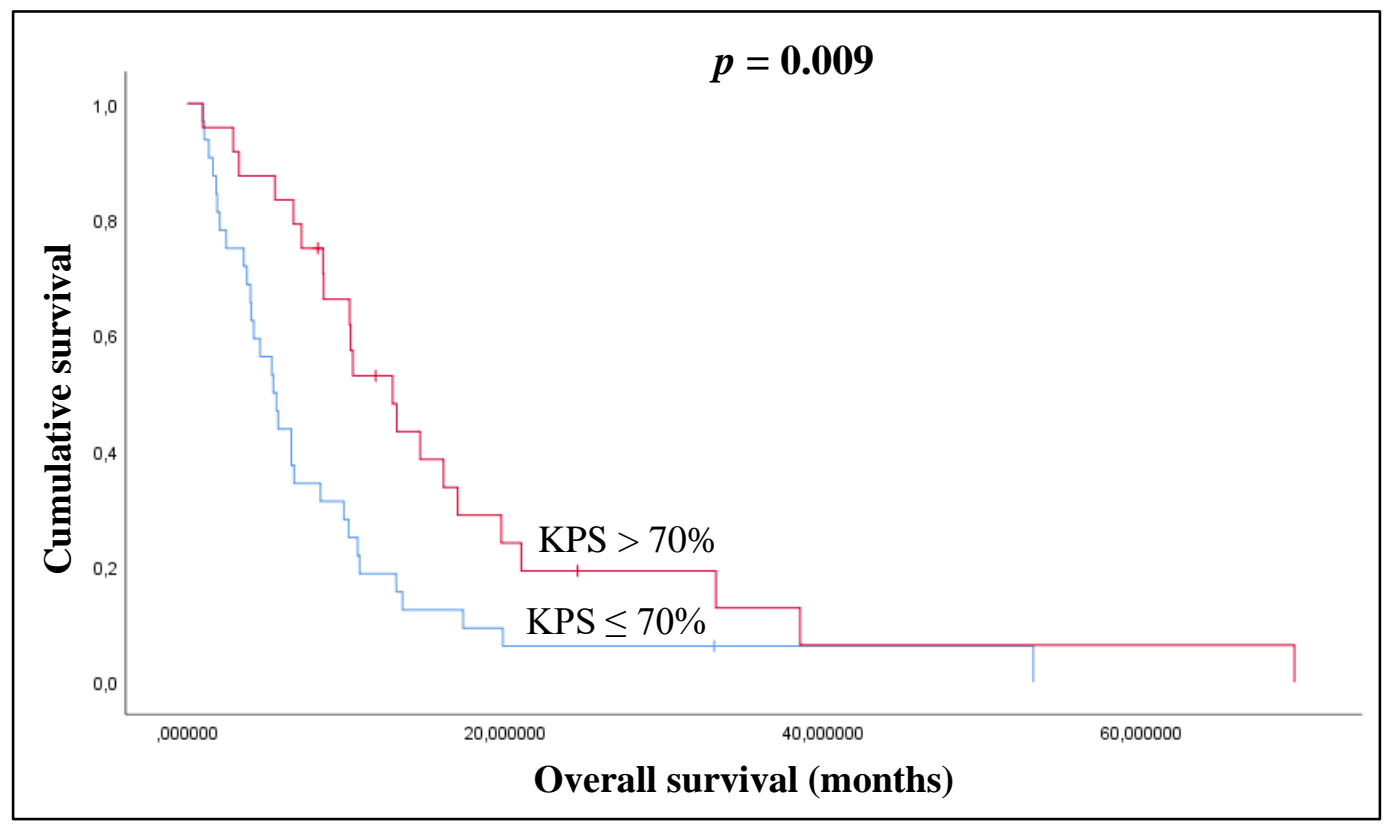

Figure\#3 Kaplan-Meier plot of the correlation between KPS and OS ( $p=0.009)$. 
Patients with KPS $>70 \%$ at the beginning of re-RT had significantly better survival values (10.4 months, $\mathrm{p}=0.009)$, than those ones with poorer general conditions (5.6 months) [Figure \#3].

Comparing time interval (between diagnosis and second radiotherapy) with OS on univariate analysis, patients with an interval of more than 47 months from diagnosis to the $2^{\text {nd }}$ course of RT, had better survival than those with lesser than 47 months between diagnosis and re-RT (mOS 10.2 vs. 6.7 months, hazard ratio (HR) 0.99; 95\% confidence interval $(\mathrm{CI}) \mathrm{p}=0.029$ ) [Figure \#4].

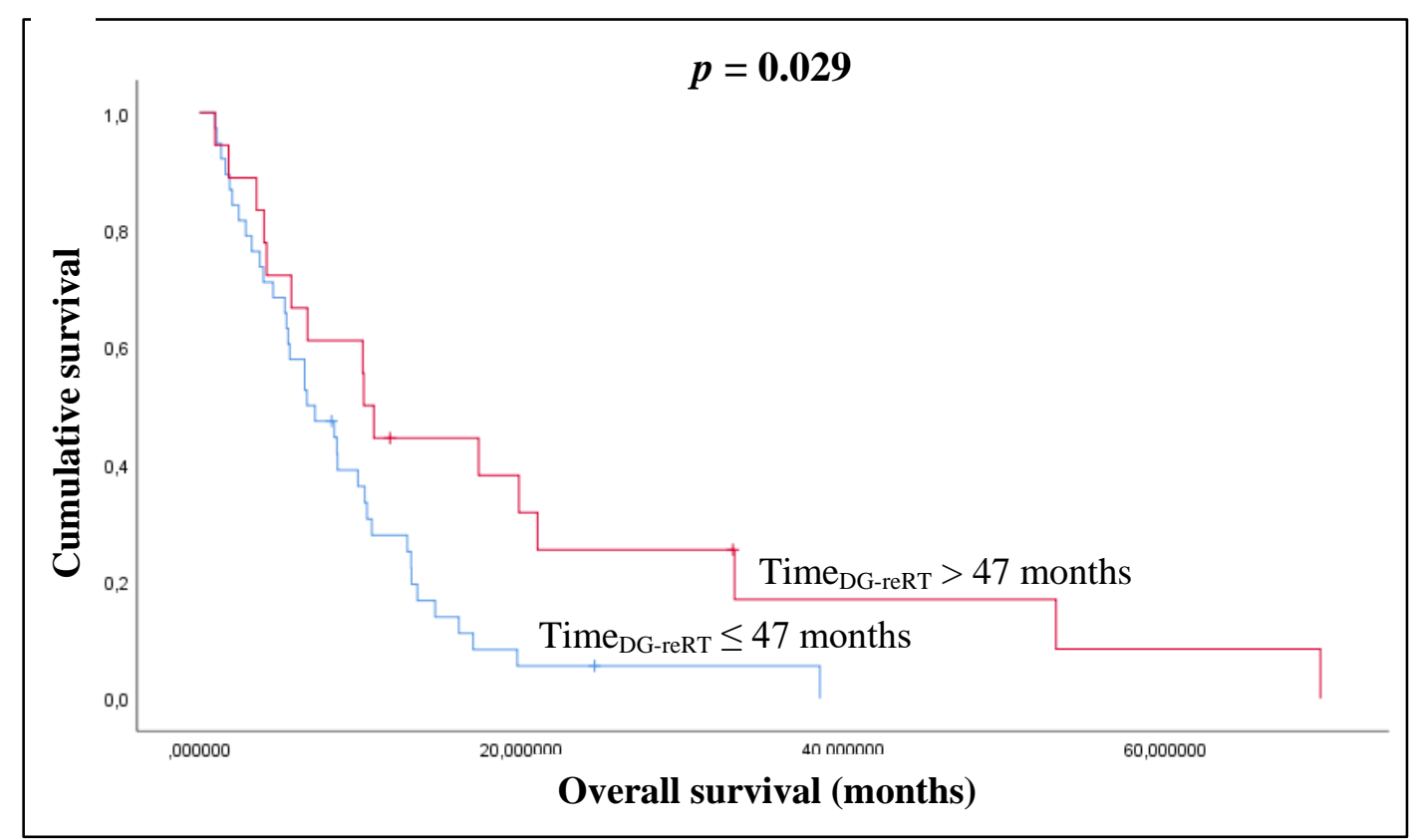

Figure\#4 Kaplan-Meier plot of the correlation between time (DG-reRT) and OS (p=0.029).

Median survival, as calculated from re-irradiation for the entire group was 9.0 months. According to histopathology GBM: 6.0 months, grade 2+3 malignancies 10.0 months; $\mathrm{p}=0.031$.

These factors proved to be significant for OS from re-RT in cox-regression univariate analysis. In multivariate analysis, the smaller GTV and better KPS remained significant influencing factors. The mean length of the interval between the $1^{\text {st }}$ and the $2^{\text {nd }}$ course of RT was 37 months. In multivariate analysis, the survival difference was significant $(p=0,05)$ between the groups of patients having received the re-irradiation in a shorter, or longer time than 37 months after the first full course (chemo)radiation. 
In the present study, no significant interrelation was found between OS and age at re-RT, size of PTV, primary surgical intervention, or whether the second-line bevacizumab therapy preceded or followed the re-irradiation.

Due to the second radiotherapy at progression, amelioration of neurological signs and KPS were experienced in $58 \%$ of our patients. Control radiological imaging detected stable disease or partial remission in 44 cases.

\subsection{Discussion}

In the past, re-irradiation for recurrent malignant gliomas was considered with great reluctance due to the high risk of radiation necrosis. In the recent decades after implementation of advanced RT techniques, several retrospective analyses, reviews, as well a prospective study and meta-analysis were published proving that re-irradiation is useful treatment option for recurrent brain tumours $[24,25,66,67]$.

The present work represents the establishment of a careful, consequent re-RT approach with low fraction size to avoid radiation sequelae using standardised target volume and dose definition even for large volume recurrences. Selected studies on SRS for small volume recurrences of median 6.2 to $28.0 \mathrm{~cm}^{3}[68,69,70]$ showed an improvement on median survival ranging from 5.3 to 13.0 months with associated radionecrosis of $0-31.3 \%$. Others have reported their results for recurrent GBM volumes of median 7-50 $\mathrm{cm}^{3}$ applying FSRT resulted in median survival within the range of 6.5-11 months $[67,71,72,73]$. In contrast to this, small target volumes for re-RT with SRS techniques, lower doses to larger volumes could be applied safely with acceptable efficacy, which was confirmed by the first meta-analysis on re-irradiation published by Kazmi et al [25]. However, highly divergent fractionation schemes and target volume concepts are applied with heterogeneous median survival times between 5 and 18 months. Krauze et al reported a median OS of 6 months after re-irradiation of recurrent glioma with median $30 \mathrm{~Gy}$ [74]. Another recent study revealed that OS after salvage SRS or hypofractionated RT (HFRT) does not significantly $(\mathrm{p}=0.06)$ differ from that after conventionally fractionated re-RT, and the trend towards better OS probably related to smaller target volume [75]. Analysis in a retrospective review has not shown any differences in OS after stereotactic or conventionally fractionated re-RT [76]. The similar outcome (median OS of 9.7 months) using conventional-, hypofractionated or SRS techniques was 
confirmed by another retrospective analysis of re-RT for recurrent malignant glioma [77]. The 9-month mOS with re-RT achieved in our patients with GTV median of $118 \mathrm{~cm}^{3}$ falls within the range of previously reported series $[25,66,73]$. There are only very few prospective reports on the efficacy of re-RT. Shi and colleagues recently published the late results from RTOG 0525 trial [78]. Patients received BSC only had an mOS of 4.8 months versus the groups treated with re-RT only, ChT only or RChT, 8.2, 10.5, 11.3 months, respectively [78]. It should be noted that in this study OS was calculated from the first progression and not from the beginning of re-RT, as it is in our present study.

Well-defined prognostic factors are established for glial tumours; however, the factors influencing the outcome of re-RT are less known. Different factors are considered to influence the efficacy of the survival after Re-RT, such as age, performance status, histological grading and the length of the interval between the $1^{\text {st }}$ and the $2^{\text {nd }}$ course of RT [79, 80]. A recent meta-analysis and appraisal summarizes the radiation parameters and outcomes of fractionated re-RT from studies published from 1999 to 2018 [25, 81]. The re-RT was delivered at a median time interval of 12 months (range: 3.5 to 19 months) with dose of 24 to 36 Gy with a daily fractional size of 1.8 to $6 \mathrm{~Gy}$. In our case, $>7$ months passed after the $1^{\text {st }}$ RT and we applied 1.6 Gy fraction size. The 8.4 months OS of our group is comparable to previous studies, reporting the median OS from re-RT 7.5 to 11 months.

The evaluation of the clinical data in different series of re-RT revealed important factors, which may improve the survival, such as KPS $>70 \%$, age $<50$ years, interval $>12$ months between the first RT and re-RT, target volume $<20-30 \mathrm{~cm}^{3}$, radiation dose $>30-35 \mathrm{~Gy}$.

In our study, significant predictors for a longer survival after re-RT were the better performance status at re-RT, the longer intervals from diagnosis to re-RT and also from the $1^{\text {st }}$ to the $2^{\text {nd }}$ RT and lower tumour grade both at diagnosis and at re-RT. The age at re-RT proved not to be a prognostic factor, however, the mean age was below 40 years. The tumour size (i.e. GTV) was one of the most significant factors for the prognosis of our patients, whilst the PTV exhibited no significant relationship to the OS. Recurrent tumour volume remained the strongest factor in multivariate analysis $(\mathrm{p}=0.038)$. The importance of the interval-factor is in line with former reports of re-RT. It can be assumed that the time of the first relapses after the primary treatment is an indicator of the biological behaviour of the tumour. $[66,79,80]$. In our patient group, the median survival according to the histopathological grade was higher than in other reported studies (the median survival is around 55-60 months for grade 2 and 18-26 
months for grade 3 tumours). [82]. It could be explained with the natural patient selection and the younger age (inclusion of paediatric patients).

In our cases, re-challenge of temozolomide was never applied, hence the primary monotherapy part was not limited in time, and it was administered up to progression. Therefore, the MGMT promoter hypermethylation had less importance, because the reirradiation was delivered when all patients developed resistance to TMZ. The MGMT status defined at the initial diagnosis was available for 27 cases, obviously with no significance on survival after re-RT. Other recent proven biological factors, such as ATRX and IDHmutation were only partially available in our patient group.

Therefore this study is limited by the lack of detailed molecular analysis as well as by the retrospective methodology which could result in a selection bias as well as an underreporting of low-grade toxicities. However, the selection bias could be reduced by the homogenous treatment concept for our cohort of patients. Nevertheless, comparison to BSC-series remains to be difficult, and conclusions about survival benefits due to intervention should be drawn with caution. Furthermore, due to the still short survival after re-irradiation, objective longterm responses after re-RT were not possible to assess for all patients.

Due to the therapy, amelioration of neurological signs and KPS were experienced in 58\% of our patients. Control radiological imaging detected stable disease or partial remission in 44 cases $(78.6 \%)$. Although standards of salvage therapy are not yet defined for recurrent glial tumours, mainly due to paucity of high- level prospective or randomized controlled studies, re-RT of various technique is an established salvage option for selected patients[81]. 


\section{Radiotherapy of brain metastases}

\subsection{Patients}

Between 2005 and 2013, at the Department of Oncotherapy, altogether 468 patients with BMs (arising from various primary malignancies) were subjected to palliative skull irradiation. For the present study, the ethical permission (No. 886/2006) was issued by the Ethical Council of the Faculty of Medicine, University of Szeged.

Unconscious patients or those with serious cognitive deficits, lacking the legal capacity of informed consent made on their own, and also patients with previous prophylactic WBRT, were excluded from the enrolment. All patients included in the present study were treated according to the actual protocol for the histologically proven primary disease and had clinical, radiological, pathological evidence of $\mathrm{BM}$.

\subsection{Methods of brain metastasis}

The total biological effective dose was calculated as equivalent dose in 2 Gy fractions (EQD2: $\alpha / \beta$ value of 2 for normal brain [Gy2] and that of 10 for tumour [Gy10]). The traditional palliative approach of 10x3 Gy WBRT (EQD2 37.5 Gy) was applied for 195 cases (Group A); in 273 cases WBRT combined with boost irradiation were performed. In addition to the $10 x 3$ Gy /18x2Gy WBRT boost dose of 10x2 Gy (EQD2 57,5 Gy/ 56 Gy) to the surgical cavity (if the metastasis had been removed), or to the metastatic lesions for patients in good PS and/or better life expectancy were performed (Group B). Later, simultaneous integrated boost irradiation (SIB: 15x2.2 WBRT+ $15 \times 0.7$ boost, (WBRT EQD2 33,4Gy, metastasis EQD2 46.8 Gy) (Group C) had been given whenever it was applicable with 3D conformal technique planned by XIO TPS [Figure \#5].

Patients were immobilised with a 3-point thermoplastic mask (ORFIT Industries, NL). Radiotherapy was planned according to the ICRU 52 recommendation using subfields additionally to the opposed lateral fields to achieve the required dose homogeneity (95-107\%) for WBRT. Boost using 3 DCRT or IMRT at 10x2 Gy boost was given consecutively or with 2-3 months delay, due to the treatment of either the primary tumour or of the extracranial metastases. Later, we have developed the technique of conformal simultaneous boost, delivered whenever the metastases could be encompassed in a boost volume less than $30 \%$ of 
the brain (in majority of the cases less than 10\%). Boost volume was defined on the basis of planning CT and MRI fusion.
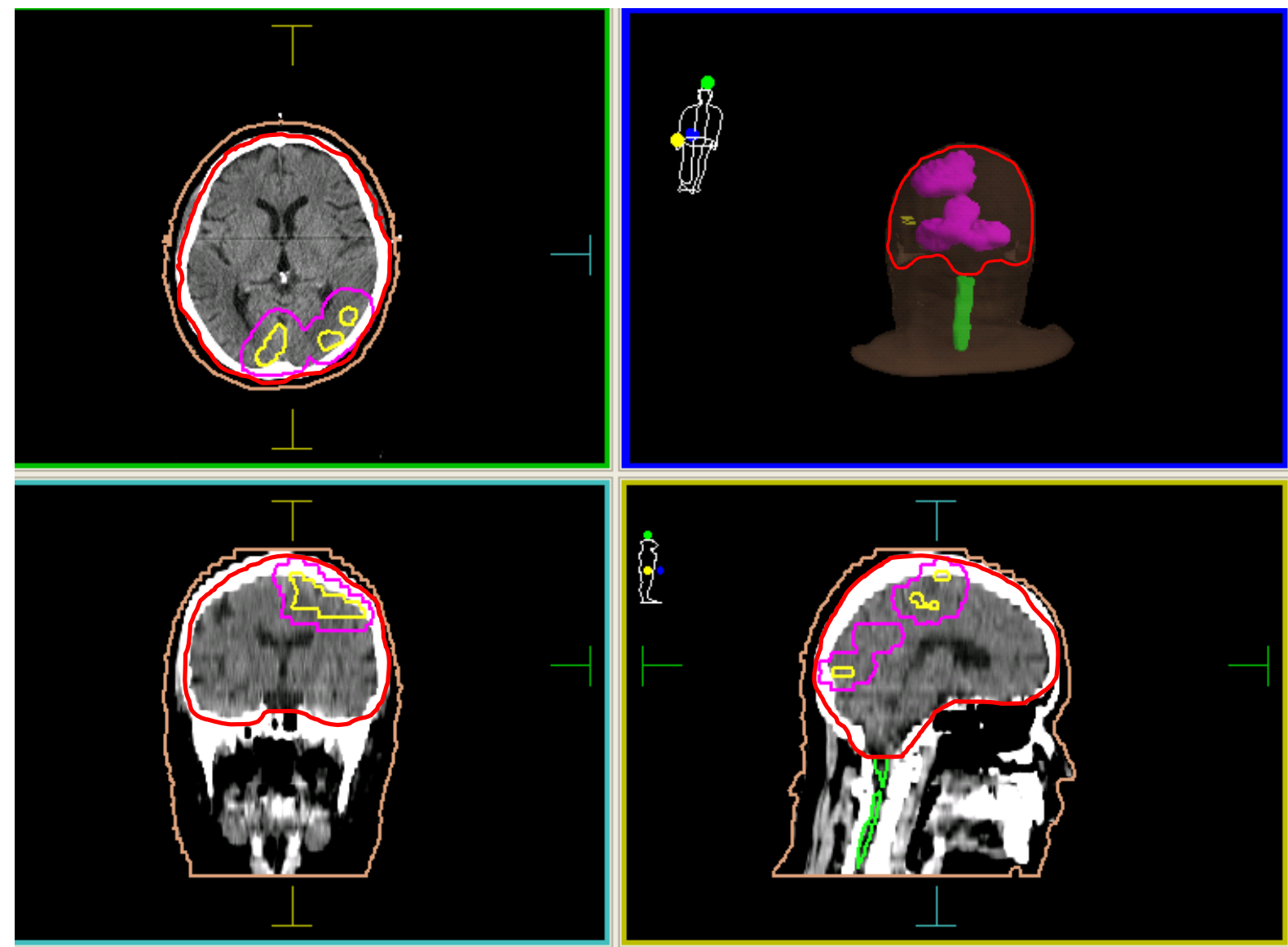

Figure\#5 Contouring of target volumes (PTV, PTV1) and OARs for SIB irradiation of brain metastasis. (yellow line delineates GTV, whereas magenta line encompasses PTVI (boost), red: PTV $($ WBRT))

\subsection{Analysis of the data}

Retrospective assessment of overall survival (OS) according to the recursive partitioning analysis (RPA), Karnofsky performance score (KPS), number of metastases, metastasectomy, localisation and histological features of primary tumour was carried out. The data were evaluated by Kaplan-Meier statistical analysis with IBM SPSS Statistics for Windows, Version 20.0 (Armonk, NY: IBM Corp.) p value <0.05 was considered as statistically significant. Multi-variance analysis of the prognostic factors was performed using the Cox proportional hazard regression model. 
The mean age of the population at the time of BM detection was 60.7 years; $53.3 \%$ of them were male and $46.7 \%$ female. The KPS was in $56.2 \%$ of this population over $70 \%$. The primary neoplasm was that of the lung in $68.9 \%$ (16\% of the latter was small cell lung cancer without prior prophylactic skull irradiation), of the breast in $7.9 \%$, malignant melanoma in $10.6 \%$, of the kidney in $2.1 \%$, of the gastrointestinal tract in $5.4 \%$, or that of other organ in $4.9 \%$ of the assessed population. $36 \%$ of patients with small cell lung cancer received doseescalated radiotherapy; the remaining cases were treated with WBRT.

\begin{tabular}{|c|c|c|c|c|}
\hline Treatment group & $\begin{array}{c}\text { A WBRT } \\
\begin{array}{c}10 x 3 G y \\
n=195\end{array}\end{array}$ & $\begin{array}{c}\text { B WBRT + boost } \\
\begin{array}{c}10 \times 3 / 18 \times 2 \\
n=125\end{array} \\
\quad\end{array}$ & $\begin{array}{c}\text { C SIB } \\
15 x(2.2+0.7) \\
n=148\end{array}$ & $\begin{array}{c}B+C \text { group } \\
n=273\end{array}$ \\
\hline $\begin{array}{l}\text { AGE } \\
\text { Mean } \\
\text { Range } \\
<\mathbf{5 0} \\
\mathbf{5 0 - 7 0} \\
>\mathbf{7 0} \\
\end{array}$ & $\begin{array}{c}60.9 \\
27.6-84.2 \\
20(10.3 \%) \\
135(69.2 \%) \\
40(20.5 \%)\end{array}$ & $\begin{array}{c}58.3 \\
21.6-84.7 \\
28(22.4 \%) \\
78(62.4 \%) \\
19(15.2 \%) \\
\end{array}$ & $\begin{array}{c}63.1 \\
38.3-84.8 \\
10(6.8 \%) \\
103(69.6 \%) \\
35(23.6 \%)\end{array}$ & $\begin{array}{c}60.7 \\
21.6-84.8 \\
38(13 \%) \\
181(66 \%) \\
54(19 \%)\end{array}$ \\
\hline $\begin{array}{l}\text { GENDER } \\
\text { Male } \\
\text { Female }\end{array}$ & $\begin{array}{c}107(54.9 \%) \\
88(45.1 \%)\end{array}$ & $\begin{array}{l}69(55.2 \%) \\
56(44.8 \%)\end{array}$ & $\begin{array}{l}74(50 \%) \\
74(50 \%)\end{array}$ & $\begin{array}{l}143(52 \%) \\
130(48 \%)\end{array}$ \\
\hline $\begin{array}{l}\text { PRIMARY } \\
\text { TUMOUR } \\
\text { Lung (total) } \\
\text {-SCLC } \\
\text {-NSCLC } \\
\text { Breast } \\
\text { MM } \\
\text { Kidney } \\
\text { Colorectal } \\
\text { Other }\end{array}$ & $\begin{array}{c}143(73.3 \%) \\
35(17.9 \%) \\
108(55.3 \%) \\
16(8.2 \%) \\
9(4.6 \%) \\
5(2.6 \%) \\
10(5.1 \%) \\
12(6.2 \%) \\
\end{array}$ & $\begin{array}{c}85(68 \%) \\
7(5.6 \%) \\
78(62.4 \%) \\
7(5.6 \%) \\
18(14.4 \%) \\
3(2.4 \%) \\
8(6.4 \%) \\
4(3.2 \%)\end{array}$ & $\begin{array}{c}97(65.6 \%) \\
13(8.7 \%) \\
84(56.7 \%) \\
15(10.1 \%) \\
19(12.8 \%) \\
2(1.4 \%) \\
7(4.7 \%) \\
8(5.4 \%) \\
\end{array}$ & $\begin{array}{c}182(66 \%) \\
20(7.3 \%) \\
162(59.3 \%) \\
22(8 \%) \\
37(13 \%) \\
5(1.8 \%) \\
15(5.4 \%) \\
12(4.3 \%)\end{array}$ \\
\hline $\begin{array}{r}\text { KPS } \\
>70 \\
<70\end{array}$ & $\begin{array}{c}81(41.5 \%) \\
114(58.5 \%)\end{array}$ & $\begin{array}{l}93(74.4 \%) \\
32(25.6 \%)\end{array}$ & $\begin{array}{l}78(52.7 \%) \\
70(47.3 \%)\end{array}$ & $\begin{array}{l}171(62 \%) \\
102(37 \%)\end{array}$ \\
\hline $\begin{array}{l}\text { STATUS OF } \\
\text { EXTRA-CRANIAL } \\
\text { DISSEMINATION } \\
\text { No. } \\
\text { Regression } \\
\text { Progression } \\
\text { Unknown }\end{array}$ & $\begin{array}{l}67(34.4 \%) \\
10(5.1 \%) \\
70(35.9 \%) \\
48(24.6 \%)\end{array}$ & $\begin{aligned} & 63(50.4 \%) \\
& 8(6.4 \%) \\
& 27(21.6 \%) \\
& 27(21.6 \%)\end{aligned}$ & $\begin{array}{c}19(12.8 \%) \\
5(3.4 \%) \\
74(50 \%) \\
50(33.8 \%)\end{array}$ & $\begin{array}{l}82(30 \%) \\
13(4.7 \%) \\
101(37 \%) \\
77(28 \%)\end{array}$ \\
\hline $\begin{array}{l}\text { RPA } \\
\mathbf{1} \\
\mathbf{2} \\
\mathbf{3}\end{array}$ & $\begin{array}{c}8(4.1 \%) \\
73(37.4 \%) \\
114(58.5 \%)\end{array}$ & $\begin{array}{c}28(22.4 \%) \\
65(52 \%) \\
32(25.6 \%)\end{array}$ & $\begin{array}{c}10(6.8 \%) \\
68(45.9 \%) \\
70(47.3 \%)\end{array}$ & $\begin{array}{c}38(14 \%) \\
133(48 \%) \\
102(38 \%)\end{array}$ \\
\hline
\end{tabular}

Table \#3 Patient characteristics by treatment groups.

At the time of the diagnosis of the cerebral metastasis, the underlying process was controlled in $37.4 \%$, extracranial progression in $35.8 \%$ and was unknown in $26.6 \%$ of this population. 
$11.1 \%$ of all patients belonged to RPA $1,45.1 \%$ to RPA 2, and $43.8 \%$ to RPA 3 class. During the treatments, the data of the patients were registered according to the RPA categories; therefore the graded prognostic assessment (GPA) could not be defined retrospectively in lack of Karnofsky index between 70 and 100. Nevertheless, the treatment outcome could be evaluated according to the number of brain metastases.

Patient distribution according to the age, gender and primary tumour localisation, extracranial metastasis were similar in the 3 groups. The difference of the KPS at the diagnosis and consequently the patient distribution according to the RPA categories shows the patient selection strategy at our Department. In RPA 2, the primary tumour was controlled in 13\%, uncontrolled in $63 \%$, unknown in $24 \%$ of the cases. In RPA 3, this distribution was $10 \%$, $78 \%$, and $12 \%$, respectively [Table \#3].

\subsection{Characteristics of the malignant disease and brain metastases}

Extracranial metastasis was present $53 \%$ in the RPA 2, and 56\% of the cases in the RPA 3 group. Extracranial metastasis was not present in $30 \%$ and $38 \%$, or was unknown in $17 \%$ and $6 \%$ of the cases in RPA 2 and 3 classes, respectively. Higher number of the patients received high dose radiotherapy with good PS, with better prognostic factors and with solitary or oligometastases. The difference according to the KPS and RPA was less pronounced in the Group C, then in the Group B over the Group A. Even the status of extracranial disease was less favourable in the Group C with 50\% progressive disease, in contrast to $36 \%$ in the Group A and $21 \%$ in the Group B.

The time frame of brain metastasis occurrence had a relation to the underlying disease, hence it was similarly distributed between the treatment groups. The development of brain metastases occurred within 1 year after the diagnosis of primary tumour in $71.8 \%$ of the patients in Group A, 66.4\% in Group B and 64.2\% in Group C [Table \#4]. Late occurring brain metastases were diagnosed in $13.8 \%, 14.4 \%$ and $17.6 \%$ in the Groups A, B, C, respectively. The rate of single-/oligometastases was higher than two third of the group when the higher total dose was applied (Groups B and C), and was $42 \%$ of the patients received WBRT only. Consequently, only $10 \%$ of the patients of Group A underwent surgery, meanwhile almost the half of the patients was subjected to neurosurgical removal of the metastases in the other two groups. 


\begin{tabular}{|c|c|c|c|}
\hline Treatment group & $\begin{array}{l}\text { Group A } \\
\text { WBRT } \\
\text { 10x3Gy }\end{array}$ & $\begin{array}{c}\text { Group B } \\
\text { WBRT+ boost } \\
\text { 10x3/18x2 +10X2 }\end{array}$ & $\begin{array}{c}\text { Group C } \\
\text { SIB } \\
15 \times(2.2+0.7)\end{array}$ \\
\hline $\begin{array}{l}\text { DEVELOPMENT OF BM } \\
\text { AFTER THE DIAGNOSIS } \\
\text { OF THE PRIMARY } \\
\text { First manifestation of the } \\
\text { disease or within 1 year } \\
\text { 1-3 years } \\
>4 \text { years }\end{array}$ & $\begin{array}{l}140(71.8 \%) \\
28(14.4 \%) \\
27(13.8 \%)\end{array}$ & $\begin{array}{l}83(66.4 \%) \\
24(19.2 \%) \\
18(14.4 \%)\end{array}$ & $\begin{array}{l}95(64.2 \%) \\
27(18.2 \%) \\
26(17.6 \%)\end{array}$ \\
\hline $\begin{array}{l}\text { NUMBER OF BM } \\
\text { average } \\
1 \\
2-4 \\
>4\end{array}$ & $\begin{array}{c}5.1 \\
38(19.5 \%) \\
44(22.6 \%) \\
113(57.9 \%) \\
\end{array}$ & $\begin{array}{c}2.2 \\
78(62.4 \%) \\
29(23.2 \%) \\
18(14.4 \%) \\
\end{array}$ & $\begin{array}{c}2.9 \\
69(46.6 \%) \\
50(33.8 \%) \\
29(19.6)\end{array}$ \\
\hline $\begin{array}{l}\text { BM SURGERY } \\
\text { no } \\
\text { yes } \\
\end{array}$ & $\begin{array}{c}176(90.3 \%) \\
19(9.7 \%) \\
\end{array}$ & $\begin{array}{l}63(50.4 \%) \\
62(49.6 \%)\end{array}$ & $\begin{array}{l}82(55.4 \%) \\
66(44.6 \%)\end{array}$ \\
\hline $\begin{array}{l}\text { RT VOLUMES OF } \\
\text { INTEREST }\left(\mathrm{cm}^{3}\right) \\
\text { PTV } \\
\text { PTV1 } \\
\text { Brain } \\
\text { GTV }\end{array}$ & $\begin{array}{l}1705 \\
1326\end{array}$ & $\begin{array}{l}1716 \\
153.3 \\
1341 \\
35.9 \\
\end{array}$ & $\begin{array}{l}1686 \\
183.1 \\
1314 \\
59.1\end{array}$ \\
\hline
\end{tabular}

Table \#4 Characteristics of brain metastases by treatment groups.

147 patients were subjected to brain metastasectomy, 90\% of them also received postoperative/ adjuvant radiotherapy, independently from the radiotherapy modality. The planning target volume (PTV) for the WBRT was similar in the three groups. The difference between the boost PTVs of the Groups B $\left(153.3 \pm 27.9 \mathrm{~cm}^{3}\right)$ and C $\left(183.1 \pm 15.7 \mathrm{~cm}^{3}\right)$ was statistically significant $(\mathrm{p}=0.017)$.

\subsection{Results}

Doubling of the survival time was detected in the escalated dose groups over the Group A ( $\mathrm{p}<0.001$ ) [Table \#5]. The OS was 3.2-3.3 months for all tumour types, if only WBRT was applied. OS difference was significant in the case of lung cancer and malignant melanoma between patients treated by WBRT only vs. those receiving escalated total dose. OS difference has not reached the statistical significance level for breast, kidney and gastrointestinal tumours. 
Both in the case of low number of the BM (1-3) and in the case of multiple (>4) metastases, the OS difference between the $30 \mathrm{~Gy}$ and escalated groups were significant. If surgery was performed, statistically no OS benefit could be proven from the boost dose $(p=0.48)$, in contrast to the significantly prolonged survival without neurosurgical removal $(p=0.002)$.

\begin{tabular}{|c|c|c|c|c|c|c|}
\hline & $\begin{array}{c}\text { The } \\
\text { investigated } \\
\text { parameters }\end{array}$ & Type of irradiation & n & OS & $\pm \mathrm{SE}$ & $p$-value \\
\hline & & WBRT (group A) & 195 & 3.3 & 0.29 & $<0.0001 *$ \\
\hline & irradiation & $\begin{array}{l}\text { Escalated dose } \\
\text { (groups B+C) }\end{array}$ & 273 & 6.5 & 0.539 & \\
\hline \multirow{8}{*}{$\begin{array}{l}\text { Primary } \\
\text { tumour }\end{array}$} & \multirow[b]{2}{*}{ Lung cancer } & WBRT (group A) & 144 & 3.3 & 0.314 & \multirow[t]{2}{*}{$<0.0001 *$} \\
\hline & & $\begin{array}{l}\text { Escalated dose } \\
\text { (groups B+C) }\end{array}$ & 184 & 7.1 & 0.698 & \\
\hline & \multirow[b]{2}{*}{ Breast cancer } & WBRT (group A) & 15 & 3.3 & 0.506 & \multirow[t]{2}{*}{0.51} \\
\hline & & $\begin{array}{l}\text { Escalated dose } \\
\text { (groups B+C) }\end{array}$ & 22 & 5.5 & 0.916 & \\
\hline & \multirow[b]{2}{*}{ Melanoma } & WBRT (group A) & 9 & 3.2 & 0.894 & \multirow[t]{2}{*}{$0.03 *$} \\
\hline & & $\begin{array}{l}\text { Escalated dose } \\
\text { (groups B+C) }\end{array}$ & 37 & 6.5 & 1.366 & \\
\hline & \multirow[b]{2}{*}{$\begin{array}{l}\text { Gastro- } \\
\text { intestinal }\end{array}$} & WBRT (group A) & 10 & 3.2 & 0.712 & \multirow[t]{2}{*}{0.13} \\
\hline & & $\begin{array}{l}\text { Escalated dose } \\
\text { (groups B+C) }\end{array}$ & 13 & 5.6 & 0.539 & \\
\hline \multirow{6}{*}{$\begin{array}{c}\text { Number of } \\
\text { brain } \\
\text { metastases }\end{array}$} & \multirow{2}{*}{$\begin{array}{l}\text { Solitary brain } \\
\text { metastases }\end{array}$} & WBRT (group A) & 32 & 4.7 & 1.075 & \multirow[t]{2}{*}{0.1} \\
\hline & & $\begin{array}{l}\text { Escalated dose } \\
\text { (groups B+C) }\end{array}$ & 143 & 7.1 & 0.911 & \\
\hline & \multirow{2}{*}{$\begin{array}{l}\text { Oligo- } \\
\text { metastases }\end{array}$} & WBRT (group A) & 34 & 2.6 & 0.292 & \multirow[t]{2}{*}{$0.002 *$} \\
\hline & & $\begin{array}{l}\begin{array}{l}\text { Escalated dose } \\
\text { (groups B+C) }\end{array}\end{array}$ & 72 & 5.4 & 1.196 & \\
\hline & \multirow[b]{2}{*}{$\begin{array}{c}>4 \text { metastases } \\
\text { (multiplex) }\end{array}$} & WBRT (group A) & 124 & 2.9 & 0.295 & \multirow[t]{2}{*}{$0.00 *$} \\
\hline & & $\begin{array}{l}\text { Escalated dose } \\
\text { (groups B+C) }\end{array}$ & 58 & 5.7 & 0.645 & \\
\hline \multirow{4}{*}{$\begin{array}{c}\text { Brain } \\
\text { surgery }\end{array}$} & \multirow{2}{*}{$\begin{array}{l}\text { Metastas- } \\
\text { ectomy }\end{array}$} & WBRT (group A) & 19 & 8.4 & 2.298 & \multirow[t]{2}{*}{0.48} \\
\hline & & $\begin{array}{l}\text { Escalated dose } \\
\text { (groups B+C) }\end{array}$ & 127 & 9.9 & 0.946 & \\
\hline & \multirow{2}{*}{$\begin{array}{l}\text { NO metastas- } \\
\text { ectomy }\end{array}$} & WBRT (group A) & 176 & 2.9 & 0.252 & \multirow[t]{2}{*}{$0.002 *$} \\
\hline & & $\begin{array}{l}\text { Escalated dose } \\
\text { (groups B+C) }\end{array}$ & 145 & 4.4 & 0.415 & \\
\hline
\end{tabular}

Table \#5 The OS directly related to the type of irradiation, primary tumour, number of brain metastases and metastasectomy. Asterisk denotes significant difference $(p<0.05)$.

The longer treatment with higher total dose (SIB or consecutive boost to WBRT) was significantly more beneficial for the survival of patients both in good and in poor condition. 
The survival data of the Group B and C in RPA classes 2 and 3 were significantly better than in Group A.

\begin{tabular}{|c|c|c|c|c|c|}
\hline $\begin{array}{c}\text { The investigated } \\
\text { parameters }\end{array}$ & Type of irradiation & $\mathbf{n}$ & OS & $\pm \mathrm{SE}$ & p-value \\
\hline \multirow{2}{*}{ Karnofsky $>70 \%$} & $\begin{array}{l}\text { WBRT } \\
\text { SIB }\end{array}$ & $\begin{array}{l}81 \\
78\end{array}$ & $\begin{array}{l}4.1 \\
8.9\end{array}$ & $\begin{array}{l}0.45 \\
0.867\end{array}$ & $0.015 *$ \\
\hline & $\begin{array}{c}\text { WBRT } \\
\text { WBRT+boost }\end{array}$ & $\begin{array}{l}81 \\
93\end{array}$ & $\begin{array}{l}4.1 \\
9.6\end{array}$ & $\begin{array}{l}0.45 \\
0.868\end{array}$ & $<0.0001 *$ \\
\hline \multirow{2}{*}{ Karnofsky $<70 \%$} & $\begin{array}{l}\text { WBRT } \\
\text { SIB }\end{array}$ & $\begin{array}{c}114 \\
70\end{array}$ & $\begin{array}{l}2.6 \\
3.9\end{array}$ & $\begin{array}{l}0.19 \\
0.465\end{array}$ & $0.002 *$ \\
\hline & $\begin{array}{c}\text { WBRT } \\
\text { WBRT+boost }\end{array}$ & $\begin{array}{c}114 \\
32\end{array}$ & $\begin{array}{l}2.6 \\
4.2\end{array}$ & $\begin{array}{c}0.19 \\
0.636\end{array}$ & $0.021 *$ \\
\hline \multirow{2}{*}{ RPA1 } & $\begin{array}{l}\text { WBRT } \\
\text { SIB }\end{array}$ & $\begin{array}{c}8 \\
10\end{array}$ & $\begin{array}{c}6.3 \\
20.2\end{array}$ & $\begin{array}{l}6.223 \\
2.972\end{array}$ & $0.343 *$ \\
\hline & $\begin{array}{c}\text { WBRT } \\
\text { WBRT+boost }\end{array}$ & $\begin{array}{c}8 \\
28\end{array}$ & $\begin{array}{c}6.3 \\
14.6\end{array}$ & $\begin{array}{l}6.223 \\
6.456\end{array}$ & $0.345 *$ \\
\hline \multirow{2}{*}{ RPA2 } & $\begin{array}{l}\text { WBRT } \\
\text { SIB }\end{array}$ & $\begin{array}{l}73 \\
68\end{array}$ & $\begin{array}{l}4.0 \\
7.7\end{array}$ & $\begin{array}{l}0.427 \\
1.052\end{array}$ & $0.034 *$ \\
\hline & $\begin{array}{c}\text { WBRT } \\
\text { WBRT+boost }\end{array}$ & $\begin{array}{l}73 \\
65\end{array}$ & $\begin{array}{l}4.0 \\
8.3\end{array}$ & $\begin{array}{l}0.427 \\
1.875\end{array}$ & $0.003 *$ \\
\hline \multirow{2}{*}{ RPA3 } & $\begin{array}{l}\text { WBRT } \\
\text { SIB }\end{array}$ & $\begin{array}{c}114 \\
70\end{array}$ & $\begin{array}{l}2.6 \\
3.9\end{array}$ & $\begin{array}{c}0.19 \\
0.465\end{array}$ & $0.002 *$ \\
\hline & $\begin{array}{c}\text { WBRT } \\
\text { WBRT+boost }\end{array}$ & $\begin{array}{c}114 \\
32\end{array}$ & $\begin{array}{l}2.6 \\
4.2\end{array}$ & $\begin{array}{l}0.19 \\
0.636\end{array}$ & $0.021 *$ \\
\hline
\end{tabular}

Table \#6 The OS as a function of Karnofsky-scores or RPA. Asterisk denotes significant difference $(\mathbf{p}<0.05)$.

Only a few patients in RPA class 1 were treated with WBRT, therefore in spite of the median survival of Group B (20.2 months) and in Group C (14.6 months) in contrast to the 6.3 months of Group A; it has not reached the statistical significance [Table \#6]. Kaplan-Meier survival analysis detected no significant OS difference between the treatment groups for the patients of RPA 1 category. 
As for the RPA 2 and RPA3 categories, the OS was significantly prolonged in case of patients received escalated dose, 4.0 vs. 7.7 months; ( $\mathrm{p}=0.002)$ in class RPA2 and 2.6 vs. 4.2 months; ( $\mathrm{p}<0.0001)$ in the class RPA 3. If no surgery was performed the SIB resulted in significantly longer OS of 6.5 months in contrast to the 3.9 months survival of the patients received WBRT only for class $1-2(\mathrm{p}=0.05)$.

In RPA class 3, the addition of both the consecutive or delayed boost and the simultaneous boost to the WBRT resulted in significant OS benefit $(\mathrm{p}=0.001)$. The OS of patients with KPS $>70 \%$ and even the OS of patients with KPS $<70 \%$ were equally proven better in case of those receiving the escalated dose vs. WBRT without boost (9.4 vs. 4.2 months; $p<0.0001$ and 4.2 vs. 2.6 months; $\mathrm{p}<0.0001$; respectively).

The multi-variance analysis yielded three, mutually independent prognostic factors for survival: RPA, surgery and therapy method. According to this analysis, the number of metastases, as a prognostic factor, is not independent from the ones mentioned above [Table \#7].

\begin{tabular}{|c|l|c|c|c|}
\multicolumn{2}{|c|}{ Risk factors } & HR & 95\% CI & $p$-value \\
\hline RPA & RPA 3 vs. RPA 1 & & & $<\mathbf{0 . 0 0 1 *}$ \\
\hline & RPA 3 vs. RPA 2 & 3.546 & $2.463-5.102$ & \\
\hline Surgery & NO vs. YES & 1.773 & $1.441-2.183$ & \\
\hline $\begin{array}{c}\text { RT } \\
\text { group }\end{array}$ & Group A vs. Group B,C & 2.072 & $1.643-2.512$ & $<\mathbf{0 . 0 0 1 *}$ \\
\hline
\end{tabular}

Table \#7 RPA, surgery and RT method, as prognostic factors for survival. Asterisk denotes significant difference $(p<0.05)$.

\subsection{Toxicity of the treatment}

In the majority of the cases, the prophylactic dose and escalated dose on demand of the methyl-prednisolone prevented the development of serious brain oedema and the consequent intracranial pressure elevation. We did not see any radiation necrosis in the re-irradiation 
study on the follow up MRIs and no major cognitive deficit was associated to the re-RT assessed with Mini Mental Score (MMS). In the study of brain metastasis in 35\% of the cases, the dehydration had to be intensified, but with appropriate supportive control, $96 \%$ of the patients could complete the planned therapy. Alopecia occurred in all groups equally.

\subsection{Discussion}

There is still a seething debate concerning the optimal management of brain metastases. The main aim that everyone agrees with is to achieve as long time for the patients as possible without physical and psychological signs and symptoms. Historically, the very short survival without treatment, with the symptoms of increasing intracranial pressure and diverse neurological deteriorations including motor-, sensory-, speech- and cognitive dysfunctions led to delivery of palliative 30 Gy WBRT, in 10 fractions [83]. Ten or five consecutive working days were reasonable even for patients in poor condition with short life expectancy and the RT was performed with simple technique (two opposed lateral beams) with relative large dose inhomogeneity in the whole brain. Nevertheless, WBRT resulted in symptom relief in the majority of the patients, and added some months to their survival [84]. Based on that, WBRT became the standard management of brain metastasis [85] and had been also introduced as preventive measure in case of radiosensitive malignancy with high risk for $\mathrm{BM}$ or leptomeningeal dissemination (ALL, SCLC) $[86,87]$. The prophylactic WBRT is performed with conventional fractionation (1.8-2 Gy/fraction). There is no doubt that WBRT is highly effective to prevent metastatic spread in the brain, but severe neurocognitive decline (particularly memory deficit) occurs with high probability after 5x4Gy or 10x3Gy [88]. The introduction of stereotactic radiosurgery technique in the 1960s provided access to highly selective dose delivery method for small $(<3 \mathrm{~cm})$, and low number (1-3) of brain metastases, which was applied as alternative method to neurosurgical intervention. Several clinical studies proved the superiority of the combined treatment, surgery or SRS + WBRT to improve local and central nervous system control $[57,89,90,91,92]$. In the last decade, with the advent of imaging (CT/MRI), development of neurosurgery technique and various SRS solutions, high precision local management of single and oligo-BM became widely available. Recent clinical trials and meta-analyses questioned the necessity of WBRT at all, emphasising the neurocognitive harm of the WBRT [93, 94, 95, 96, 97, 98]. Meanwhile, other authors [99] warn of drawing too early and hasty conclusions leading to general omission of WBRT, without considering the danger of increase of intracranial impairments, and neurocognitive 
decline due to cerebral disease progression. They rather suggest considering the use of selective neuroprotective agent (memantine) and hippocampus-sparing WBRT technique $[100,101]$. Chung et al [102] applied a lower WBRT dose with a boost to the tumour bed after metastasectomy, since WBRT neurotoxicity is associated with the total dose and fractionation [103]. Although no randomized studies have directly compared lower WBRT doses to the traditional WBRT dose of $30 \mathrm{~Gy}$, the advantage of lower WBRT dose has been shown in previous studies on prophylactic cranial irradiation (PCI). For example, a French study compared PCI (24 Gy in 8 fractions, EQD2 26 Gy) vs. no PCI, and observed no significant difference between the groups in terms of neuropsychological function or abnormalities [104]. In another trial performed at MD Anderson Cancer Centre, 30 patients received PCI (25 Gy in 10 fractions, EQD2 $26.04 \mathrm{~Gy}$ ) and no significant deterioration was observed after PCI [105]. Other approach to reduce the decrease of memory function could be the use of lower fraction doses.

Our aim was to find a balance in improving the survival with dose escalation to the macroscopic metastases, maintaining the intracranial control and reducing the probability of treatment-related cognitive decline; meanwhile keeping the treatment duration reasonable for patients even with multiple brain metastases. Therefore, we have applied conventional fractionation for 3D conformal whole brain and consecutive boost irradiation using the classical conventional fractionation scheme, $18 \times 2 \mathrm{~Gy}+10$ to $12 \times 2 \mathrm{~Gy}$ up to $56-60 \mathrm{~Gy}$ total dose for patients with relatively longer life expectancy. Later we have introduced a shortened regime of $15 \times 2.2$ Gy whole brain irradiation and simultaneously 0.7 Gy was delivered to the tumour or tumour bed after surgery. This technique allowed encompassing even 10-12 metastases into the boost volume, and lasted only 3 weeks, considered reasonable for patients with poorer condition. Tiwari and co-workers reported the results of SIB of 19 patients versus WBRT alone (13 patients), demonstrating better local control and improved survival in the SIB group [106]. Another publication from Italian groups emphasises the higher efficacy of the intensified treatment (WBRT and SRS boost), as well, enrolling 134 patients, of whom 21 were treated with SIB [91]. On the basis of high patient number, we could demonstrate the feasibility and clinical usefulness of dose escalation and in particular, the application of SIB in the management of BM, even for patients with unfavourable status. Direct comparison of SRS to SIB was performed in a matched cohort of 178 patients with similar baseline characteristics [107]. However, as for the OS, neither the treatment with SRS nor with SIB did result in any statistically significant difference, the SIB was associated with reduced intracranial impairment, likely due to the WBRT component of the treatment (HR 0.36, 
$\mathrm{p}<0.001)$. Similarly for single and oligometastatic brain spread, several randomised clinical studies have proven the better outcome in terms of local and intracranial disease control with combined treatment approaches, such as surgery +WBRT, SRS+WBRT, or SIB; but in the majority of the cases these encouraging results could not be transformed into significantly improved survival $[89,91,102,107,108,109]$.

In contrast, our retrospective analysis confirmed the significant survival benefit for the whole group of patients including multiple metastases from intensified treatments without difference between the long and the shortened (SIB) regimes. This relevant survival difference was achieved not only for oligometastatic diseases, but for patients with multiple metastases $(>4)$, as well. Hence, in the group that received SIB, one fifth of the patients had multiple metastases, in which the simultaneous boost was technically performable. No serious adverse event was detected during the treatment. The majority of evidence-based data derived from randomised clinical studies concerns patient population with single or oligometastases only, without progressing extracranial disease and in good status. Nevertheless, patients with worse initial parameters could not be enrolled - by forming homogeneous groups- into randomised trials. In fact, the design of clinical investigation on the management of brain metastasis is a highly challenging task. The application of the suggested recommendations of the Response Assessment in Neuro-Oncology (RANO) brain metastases group [110,111] supposes patients in good condition and good cooperation, what is frequently not the case with patients of progressing extracranial cancer and/or low performance status. In our current study population, around half of the patients in the SIB arm had progressive disease and bad performance status $(<70 \%)$, according to Karnofsky score.

Our study has evident limitations. Its retrospective nature and consequent patient heterogeneity may have biased the results. Our effort to compare the outcome of the different treatment schemes by retrospectively dividing the patient population amongst similar prognostic groups could not completely compensate the lack of prospective patient enrolment. Furthermore, no objective assessment of late neurotoxicity has been performed. However, this study has several strengths. The large number of the patients allowed relevant statistical evaluation, and the three treatment approaches were clearly defined. Our aim to study the feasibility of SIB in 15 fractions even for patients, who cannot be enrolled into prospective clinical trials due to their bad prognostics, could be investigated. Conclusion could be drawn from this analysis on the applicability of lower WBRT fraction dose approach with a boost RT. 
The improvement in the systemic treatment of disseminated malignancies urges the establishment of optimal management of patients with brain metastasis of different clinical and tumour parameters. Meanwhile, some open questions could be hopefully answered soon by the results of the on-going trials on radiation technique and via combination of radiotherapy with targeted agents for patients with low number of BMs.

Still, novel RT approaches are highly required to decrease the potential neurocognitive decline as a consequence of WBRT, since the majority of the patients belong to less favourable prognostic groups (i.e. with progressive extracranial status and multiple BMs). Therefore, retrospective analyses could provide valuable conclusions, even though they should be assessed critically.

Therefore, considering all the limitations, our study on large patient series in RPA2 and RPA3 categories seems to document survival advantage of intensified irradiation schemes, which has high importance for the daily clinical decisions, even for patients in poor condition (KPS $<70 \%)$. The novel generation of linear accelerators allow the introduction of hippocampal-avoidance WBRT technique, smaller fraction size of WBRT simultaneously to fSRT boost. Furthermore, the use of neuroprotective agents and optimisation of RT combination by molecular systemic therapeutic modalities [34-51, 100-101, 112] are to be considered for clinical investigation.

\section{Findings and conclusion}

\subsection{Main points derived from the analysis of glial tumour re-irradiation}

As for the first goal of the present thesis, during the optimising of radiotherapy, I investigated the question, whether the re-irradiation of glial tumours is plausible while keeping the adverse effects and complications at theirs minimum and respecting the quality of life of patients at the same time. The literature is not unanimous about the proper target volume size of the recurrent tumour to be contoured during radiotherapy planning. In case of reoperation, by encompassing the surgical cavity into the target volume, the possibility of large volume reirradiation has been also examined, in addition to how to choose the appropriate patient group for re-irradiation. 
(1) Smaller recurrent tumour size, better PS, longer intervals from the diagnosis to re-RT and also from primary RT to the re-RT and lower tumour grade predict better outcome from re-RT.

(2) No radiation-associated serious adverse events were observed and the re-RT improved the performance status and neurologic symptoms in the majority of the cases.

(3) Re-irradiation with low fraction dose in large volume recurrent gliomas proved to be safe and seems to be clinically beneficial in selected patient group.

\subsection{Main points of dose escalation in the radiation treatment of brain metastases}

In the second part of the current thesis, we aimed to define the right total radiation dose for brain metastases and whether boost treatment is necessary in these cases. Further, if we opted for boost treatment, we investigated whether should it be performed together with WBRT or with certain latency. The shortest delivery of WBRT+boost using the technique of SIB proved to be the most efficient, and gentle method.

(1) From our large series of evaluation, the applicability and safety of intensification of RT in the management of brain metastases could be confirmed.

(2) Patients with primary lung cancer or melanoma malignum achieved significant benefit from SIB.

(3) For RPA2, 3 and if no metastasectomy was performed, the higher total dose to the metastases yielded increased OS.

(4) The RT intensification improved the outcome of the total patient group suffering from brain metastases.

(5) The concept of dose escalation proved to be feasible and beneficial for patients with good and poor performance status equally. 


\section{Acknowledgements}

First of all I am most grateful to my supervisor, Professor Katalin Hideghéty, whose encouragement and generous support helped me in the completion of this thesis. Her patience, guidance and motivation helped me all the time during the research and writing this dissertation.

I wish to express my special thanks to Professor Zsuzsanna Kahán the former, and to Professor Judit Oláh, the current director of the Department of Oncotherapy, University of Szeged, who provided excellent working condition for me at the institute.

I would like to express my sincere gratitude to Ms Barbara Darázs and Zoltán Varga for the support in statistical analysis and to all of our fantastic physicist team, especially to $\boldsymbol{M} \boldsymbol{s}$ Emese Fodor, for her invaluable help that significantly contributed my scientific work.

I am also obliged to the radiologists, Dr Adrienne Cserháti and Dr Angéla Csomor, for their professional work and scrutiny when evaluating and re-evaluating the radiological images of our patients, and to their guidance for contouring for the radiotherapy treatments.

My definite thank is due to all my colleagues at our Department of Oncotherapy, to the specialist physicians, residents and interns, to our assistants and nurses, for their participation and always kind help in the diagnostic-therapeutic processes of our patients.

I am grateful for the contribution of all my colleagues at the neuro-oncoteam, especially to my neurosurgeon colleagues, for their cooperation in the multi-modal treatment of our brain metastatic patients.

Lastly, but most importantly, my heartfelt gratitude is due to my family and friends for their unconditional love, care and measureless patience; and to my husband, Dr Roland Weiczner, for his precious support and help that enabled me the completion of my present doctoral thesis. 


\section{References}

1) Stupp R, Tonn J-C, Brada M, Pentheroudakis G (2010) High-grade malignant glioma: ESMO Clinical Practice Guidelines for diagnosis, treatment and follow-up. Ann Oncol 21: v190-v193.

2) Nayak L, Lee EQ, Wen PY. (2012) Epidemiology of brain metastases. Curr Oncol Rep 14(1): 48-54.

3) Singh M, Manoranjan B, Mahendram S, McFarlane N, Venugopal C, Singh SK. (2014) Brain Metastasis-Initiating Cells: Survival of the Fittest. Int J Mol Sci 15(5): 91179133.

4) Brinkman, T. M. et al. (2016) Long-term neurocognitive functioning and social attainment in adult survivors of paediatric CNS tumours: results from the St Jude Lifetime Cohort Study. J Clin Oncol 34, 1358-1367.

5) Chemaitilly W., Armstrong GT, Gajjar A, Hudson MM. (2016) Hypothalamic-pituitary axis dysfunction in survivors of childhood CNS tumours: importance of systematic follow-up and early endocrine consultation. J Clin Oncol 34, 4315-4319.

6) Mackay, A. et al. (2017) Integrated molecular meta-analysis of 1,000 paediatric highgrade and diffuse intrinsic pontine glioma. Cancer Cell 32, 520-537.

7) Quail DF, Joyce JA. (2017) The microenvironmental landscape of brain tumours. Cancer Cell 31, 326-341.

8) Gilbertson, R. J. (2011) Mapping cancer origins. Cell 145, 25-29.

9) Jacus, MO et al. (2016) Pharmacokinetic properties of anticancer agents for the treatment of central nervous system tumours: update of the literature. Clin Pharmacokinet 55, 297-311.

10) Dolocek TA , Propp JM, Stroup NE, et al (2012) CBTRUS statistical report: primary brain and central nervous system tumours diagnosed in the United States in 2005-2009. Neuro Oncol 14 Suppl 5:1-49.

11) Wem PY, Kesari S (2008) Malignant gliomas in adults. New England Med 359:492507.

12) Sherriff J, Tamangani J, Senthil L, Cruickshank G, Spooner D, Jones B, et al (2013) Patterns of relapse in glioblastoma multiforme following concomitant chemoradiotherapy with temozolomide. Br J Radiol 86:20120414. 
13) Pichlmeier U, Bink A, Schackert G, et al (2008) Resection and survival in glioblastoma multiforme: an RTOG recursive partitioning analysis of ALA study patients. Neuro Oncology 10:1025-34.

14) Studio R, Hegi ME, Mason WP, et al. (2009) Effects of radiotherapy with concomitant and adjuvant temozolomide versus radiotherapy alone on survival in glioblastoma in a randomised phase III study: 5 year analysis of the EORTC-NCIC trial. Lancet Oncol 10:459-66.

15) Dirks P, Bernstein M, Muller PJ, Tucker WS (1993) The value of reoperation for recurrent glioblastoma. Can J Surg 36:271-5.

16) Barbagallo GM, Jenkinson MD, Brodbelt AR (2008) "Recurrent" glioblastoma multiforme, when should we reoperate? Br J Neurosurg 22:452-455.

17) Perry JR et al (2010) Phase II trial of continuous dose-intense temozolomide in recurrent malignant glioma: RESCUE study. Clin Oncol 28(12):2051-2057.

18) Aktan M, Koc M, Kanyilmaz G (2015) Survival following re-irradiation using intensitymodulated radiation therapy with temozolomide in selected patients with recurrent high grade gliomas. Ann Transl Med 3(20):304.

19) Wang X, Guo G, Guan H, Yu Y, Lu J, Yu J. (2019) Challenges and potential of PD1/PD-L1checkpoint blockade immunotherapy for glioblastoma. J Exp Clin Cancer Res $38: 87$

20) Phuphanich S, Wheeler CJ, Rudnick JD, Mazer M, Wang H, Nuño MA, et al (2013) Phase I trial of a multi-epitope-pulsed dendritic cell vaccine for patients with newly diagnosed glioblastoma. Cancer Immunol Immunother 62:125-35.

21) Liau LM, Ashkan K, Tran DD, Campian JL, Trusheim JE, Cobbs CS, et al (2018) First results on survival from a large Phase 3 clinical trial of an autologous dendritic cell vaccine in newly diagnosed glioblastoma. J Transl Med 16:142

22) Jain KK (2018) Critical overview of targeted therapies for glioblastoma. Front Oncol $8: 419$.

23) Taunk NK, Moraes FY, Escorcia FE, Mendez LC, Beal K, Marta GN (2016) External beam re-irradiation, combination chemoradiotherapy, and particle therapy for the treatment of recurrent glioblastoma. Expert Rev Anticancer Ther. 16(3): 347-358.

24) Amichetti M, Amelio D (2011) A Review of the role of the Re-irradiation in recurrent high-grade glioma (HGG). Cancers (Basel) 3:4061-89. 
25) Kazmi F, Soon YY, Leong YH, Koh WY, Vellayappan B. (2018) Re-irradiation for recurrent glioblastoma (GBM) a systematic review and meta-analyis. J Neurooncol 142(1):79-90.

26) Minniti GC, Scaringi V, De Sanctis G, Lanzetta T, Falco D, Di Stefano, et al (2013) Hypofractionated stereotactic radiotherapy and continuous low- dose temozolomide in patients with recurrent or progressive malignant gliomas. J Neurooncol 111:187-194.

27) Grosu AL, Weber WA, Franz M, Stärk S, Piert M, Thamm R, et al (2005) Reirradiation of recurrent high- grade gliomas using amino acid PET (SPECT)/CT/MRI image fusion to determine gross tumour volume for stereotactic fractionated radiotherapy. Int J Radiat Oncol Biol Phys 63:511-519.24.

28) Ernst-Stecken A, Ganslandt O, Lambrecht U, Sauer R, Grabenbauer G (2007) Survival and quality of life after hypofractionated stereotactic radiotherapy for recurrent malignant glioma. J Neurooncol 81:287-294.25.

29) Wuthrick EJ, Curran WJ, Camphausen K, Lin A, Glass J, Evans J, et al (2014) A pilot study of hypofractionated stereotactic radiation therapy and sunitinib in previously irradiated patients with recurrent high- grade glioma. Int J Radiat Oncol Biol Phys 90:369-375.26.

30) Patel M, Siddiqui F, Jin JY, Mikkelsen T, Rosenblum M, Movsas B, et al (2009) Salvage re-irradiation for recurrent glioblastoma with radiosurgery: radiographic response and improved survival. J Neurooncol 92:185-191.

31) Taillibert S, Le Rhun É. (2015) Epidemiology of brain metastases. Cancer Radiother 19(1):3-9.

32) Liu Q, Tong X, Wang J (2019) Management of brain metastases: history and the present. Chinese Neurosurgical Journal DOI: 10.1186/s41016-018-0149-0

33) Ellis TL, Neal MT, Chan MD. (2012) The role of surgery, radiosurgery and whole brain radiation therapy in the management of patients with metastatic brain tumours. Int $\mathbf{J}$ Surg Oncol 952345.

34) Kotecha R, Gondi V, Ahluwalia MS, Brastianos PK, Mehta MP. (2018) Recent advances in managing brain metastasis. F1000Res. 2018 Nov 9;7:F1000 Faculty Rev1772 .

35) Gadgeel SM, Shaw AT, Govindan R, et al. (2016) Pooled analysis of CNS response to alectinib in two studies of pretreated patients with ALK-positive non-small-cell lung cancer. J Clin Oncol 34(34):4079-85. 
36) Crinò L, Ahn MJ, De Marinis F, et al. (2016) Multicenter phase II study of whole-body and intracranial activity with ceritinib in patients with ALK-rearranged non-small-cell lung cancer previously treated with chemotherapy and crizotinib: results from ASCEND-2. J Clin Oncol 34(24):2866-73.

37) Gettinger S, Kim D, Tiseo M. (2016) Brigatinib activity in patients with ALK+ NSCLC and intracranial CNS metastases in two clinical trials. International Association for the Study of Lung Cancer 17th World Conference on Lung Cancer Vienna, Austria

38) Camidge DR, Kim HR, Ahn MJ, et al. (2018) Brigatinib versus crizotinib in ALKpositive non-small-cell lung cancer. N Engl J Med. F1000 Recommendation

39) Venur VA, Ahluwalia MS (2016) Targeted therapy in brain metastases: ready for primetime? Am Soc Clin Oncol Educ Book. 35:e123-30.

40) Venur VA, Leone JP (2016) Targeted therapies for brain metastases from breast cancer. Int J Mol Sci. 17(9): pii: E1543.

41) Lin NU, Diéras V, Paul D, et al. (2009) Multicenter phase II study of lapatinib in patients with brain metastases from HER2-positive breast cancer. Clin Cancer Res. 2009;15(4):1452-9.

42) Lin NU, Carey LA, Liu MC, et al. (2008) Phase II trial of lapatinib for brain metastases in patients with human epidermal growth factor receptor 2-positive breast cancer. J Clin Oncol. 2008;26(12):1993-9.

43) Bachelot T, Romieu G, Campone M, et al. (2013) Lapatinib plus capecitabine in patients with previously untreated brain metastases from HER2-positive metastatic breast cancer (LANDSCAPE): a single-group phase 2 study. Lancet Oncol. 14(1):6471.

44) Freedman RA, Gelman RS, Wefel JS, et al. (2016) Translational breast cancer research consortium (TBCRC) 022: A phase II trial of neratinib for patients with human epidermal growth factor receptor 2-positive breast cancer and brain metastases. J Clin Oncol 34(9):945-52.

45) Freedman R, Gelman R, Melisko M, et al. (2017) TBCRC 022: Phase II trial of neratinib + capecitabine for patients (Pts) with human epidermal growth factor receptor 2 (HER2+) breast cancer brain metastases (BCBM). J Clin Oncol. 2017;35(15_suppl):1005

46) McArthur GA, Maio M, Arance A, et al. (2017) Vemurafenib in metastatic melanoma patients with brain metastases: An open-label, single-arm, phase 2, multicentre study. Ann Oncol. 28(3):634-41. 
47) Long GV, Trefzer U, Davies MA, et al. (2012) Dabrafenib in patients with Val600Glu or Val600Lys BRAF-mutant melanoma metastatic to the brain (BREAK-MB): a multicentre, open-label, phase 2 trial. Lancet Oncol. 13(11):1087-95.

48) Davies MA, Saiag P, Robert C, et al. (2017) Dabrafenib plus trametinib in patients with BRAF V600-mutant melanoma brain metastases (COMBI-MB): A multicentre, multicohort, open-label, phase 2 trial. Lancet Oncol. 18(7):863-73.

49) Tawbi H, Forsyth P, Algazi A, et al. (2017) Efficacy and safety of nivolumab (NIVO) plus ipilimumab (IPI) in patients with melanoma (MEL) metastatic to the brain: Results of the phase II study CheckMate 204. J Clin Oncol. 35(15_suppl):9507 10.1200/JCO.2017.35.15_suppl.9507

50) Long G, Atkinson V, Menzies A, et al. (2017) A randomized phase II study of nivolumab or nivolumab combined with ipilimumab in patients (pts) with melanoma brain metastases (mets): The Anti-PD1 Brain Collaboration (ABC). J Clin Oncol. 2017;35(15_suppl):9508 10.1200/JCO.2017.35.15_suppl.9508

51) Tawbi HA, Forsyth PA, Algazi A, et al. (2018) Combined Nivolumab and Ipilimumab in Melanoma Metastatic to the Brain. N Engl J Med. 379(8):722-30.

52) Brastianos PK, Carter SL, Santagata S, et al. (2015) Genomic Characterization of Brain Metastases Reveals Branched Evolution and Potential Therapeutic Targets. Cancer Discov. 5(11):1164-77.

53) Khuntia D, Brown P, Li J, et al. (2006) Whole-brain radiotherapy in the management of brain metastasis. J Clin Oncol 24:1295-1304.

54) Patchell RA, Tibbs PA, Walsh JW, et al. (1990) A randomized trial of surgery in the treatment of single metastases to the brain. N Engl J Med 322:494-500.

55) Weber DC, Caparrotti F, Laouiti M, Malek K. (2011) Simultaneous in-field boost for patients with 1 to 4 brain metastasis/es treated with volumetric modulated arc therapy: A prospective study on quality-of-life. Radiat Oncol 6:79.

56) Linskey ME, Andrews DW, Asher AL, et al. (2010) The role of stereotactic radiosurgery in the management of patients with newly diagnosed brain metastases: a systematic review and evidence-based clinical practice guideline. J Neurooncol 96(1):45-68.

57) Gaspar LE, Mehta MP, Patchell RA, et al. (2010) The role of whole brain radiation therapy in the management of newly diagnosed brain metastases: a systematic review and evidence-based clinical practice guideline. J Neurooncol 96(1):17-32. 
58) Kalkanis SN, Kondziolka D, Gaspar LE, et al. (2010) The role of surgical resection in the management of newly diagnosed brain metastases: a systematic review and evidence-based clinical practice guideline. J. Neurooncol 96(1):33-43.

59) Casanova N, Mazouni Z, Bieri S, Combescure C, Pica A, Weber DC. (2010) Whole brain radiotherapy with a conformational external beam radiation boost for lung cancer patients with 1-3 brain metastasis: A multi institutional study. Radiat Oncol 5:13.

60) Weber DC, Caparrotti F, Laouiti M, Malek K. (2011) Simultaneous in-field boost for patients with 1 to 4 brain metastasis/es treated with volumetric modulated arc therapy: A prospective study on quality-of-life. Radiat Oncol 6:79.

61) Bruzzaniti V, Abate A, Pedrini M, Benassi M, Strigari L. (2011) IsoBED: A tool for automatic calculation of biologically equivalent fractionation schedules in radiotherapy using IMRT with a simultaneous integrated boost (SIB) technique. J Exp Clin Cancer Res 30:52.

62) Borghetti P, Pedretti S, Spiazzi L et al. (2016) Whole brain radiotherapy with adjuvant or concomitant boost in brain metastasis: dosimetric comparison between helical and volumetric IMRT technique. Radiat Oncol 11:59.

63) Hall EJ, Brenner DJ. (1993) The radiobiology of radiosurgery: rationale for different treatment regimes for AVMs and malignancies. Int J Radiat Oncol Biol Phys. 5:381-5.

64) Lin NU, Lee EQ et al. (2015) Response assessment criteria for brain metastases: proposal from the RANO group. Lancet Oncology 16: e270-78

65) Bratengeier K, Oechsner M, Gainey M, Flentje M. (2009) Remarks on reporting and recording consistent with the ICRU reference dose. Radiat Oncol. 4:44.

66) Straube C, Elpula G, Gempt J et al. (2017) Re-irradiation after gross total resection of recurrent glioblastoma. Strahlenther Onkol 193, 897-909

67) Fokas E, Wacker U, Gross MW, Henzel M, Encheva E, Engenhart- Cabillic R (2009) Hypofractionated stereotactic re-irradiation of recurrent glioblastomas. Strahlenther Onkol 185:235-240.

68) Niyazi M, Siefert A, Schwarz SB et al (2011) Therapeutic options for recurrent malignant glioma. Radiother Oncol 98:1-14

69) Amelio D, Amichetti M (2012) Radiation therapy for the treatment of recurrent glioblastoma: an overview. Cancers (Basel) 4:257-280

70) Redmond KJ, Mehta M (2015) Stereotactic radiosurgery for glioblastoma. Cureus 7:e413 
71) Fogh SE, Andrews DW, Glass J et al (2010) Hypofractionated stereotactic radiation therapy: an effective therapy for recurrent high-grade gliomas. J Clin Oncol 28:3048-3053

72) Chatzikonstantinou G, Zamboglou N, Archavlis E et al. (2018) CT-guided interstitial HDR-brachytherapy for recurrent glioblastoma multiforme: a 20-year single-institute experience Strahlenther Onkol. 194(12):1171-1179.

73) Combs SE, Niyazi M, Adeberg S et al. (2018) Re-irradiation of recurrent gliomas: pooled analysis and validation of an established prognostic score-report of the Radiation Oncology Group (ROG) of the German Cancer Consortium (DKTK), Cancer Med. 7(5): 1742-1749

74) Krauze AV, Peters C, Cheng J, et al. (2017) Re-irradiation for recurrent glioma- the NCI experience in tumour control, OAR toxicity and proposal of a novel prognostic scoring system. Radiat Oncol Lond Engl. 12(1):191.

75) Zwirner K, Paulsen F, Schittenhelm J, et al. (2017) Prognostic parameters and outcome after re-irradiation for progressive glioblastoma. Acta Neurol Scand 136:23945

76) Klobukowski L, Falkov A, Chelimo C, et al. (2018) A retrospective review of reirradiating patients' recurrent high-grade gliomas. Clin Oncol (R Coll Radiol) 30:56370.

77) Post CCB, Kramer MCA, Smid EJ, et al. (2019) Patterns of re- irradiation for recurrent gliomas and validation of a prognostic score. Radiother Oncol 130:156-63.

78) Shi W, Scannell BM, Gilbert MR, et al. (2017) Investigating the effect of reirradiation or systemic therapy in patients with glioblastoma after tumour progression: a secondary analysis of NRG oncology/radiation therapy oncology group trial 0525. Int J Radiat Oncol Biol Phys 100:38-44.

79) Combs SE, Edler L, Rausch R et al. (2013) Generation and validation of a prognostic score to predict outcome after re-irradiation of recurrent glioma. Acta Oncol 52:147152.

80) Kessel KA, Hesse J, Straube C, et al. (2017) Modification and optimization of an established prognostic score after re-irradiation of recurrent glioma. PLoS ONE 12:e0180457.

81) Kim IH (2019) Appraisal of re-irradiation for the recurrent glioblastoma in the era of MGMT promoter methylation. Radiat Oncol J 37(1):1-12. 
82) Tunthanathip T, Ratanalert S, Sae-heng S, et al. (2020) Prognostic Factors and Nomogram Predicting Survival in Diffuse Astrocytoma. J Neurosci Rural Pract 11(1): $135-143$.

83) Chao JH, Phillips R, Nickson JJ. (1954) Roentgen-ray therapy of cerebral metastases. Cancer 7:682-689.

84) Nieder C, Spanne O, Mehta MP, Grosu AL, Geinitz H. (2011) Presentation, patterns of care, and survival in patients with brain metastases: what has changed in the last 20 years? Cancer 117(11):2505-2512.

85) Kocher, M., Soffietti, R., Abacioglu, U., et al. (2011) Adjuvant Whole-Brain Radiotherapy Versus Observation After Radiosurgery or Surgical Resection of One to Three Cerebral Metastases: Results of the EORTC 22952-26001 Study. J Clin Oncol 29(2), 134-141.

86) Tsao MN. (2015) Brain metastases: advances over the decades. Ann Palliat Med 4(4):225-232.

87) Andrews DW, Scott CB, Sperduto PW, et al. (2004) Whole brain radiation therapy with or without stereotactic radiosurgery boost for patients with one to three brain metastases: phase III results of the RTOG 9508 randomised trial. Lancet 363:16651672 .

88) Kondziolka D, Patel A, Lunsford LD, Kassam A, Flickinger JC. (1999) Stereotactic radiosurgery plus whole brain radiotherapy versus radiotherapy alone for patients with multiple brain metastases. Int J Radiat Oncol Biol Phys 45:427-434.

89) Aoyama H, Shirato H, Tago M et al. (2006) Stereotactic radiosurgery plus whole-brain radiation therapy vs stereotactic radiosurgery alone for treatment of brain metastases: a randomized controlled trial. JAMA 295:2483-2491.

90) Kocher M, Soffietti R, Abacioglu U et al. (2011) Adjuvant whole-brain radiotherapy versus observation after radiosurgery or surgical resection of one to three cerebral metastases: results of the EORTC 22952-26001 study. J Clin Oncol 29:134-141.

91) Buglione M, Pedretti S, Gipponi S et al. (2015) The treatment of patients with 1-3 brain metastases: is there a place for whole brain radiotherapy alone, yet? A retrospective analysis. Radiol Med 120(12):1146-1152.

92) Brown PD, Asher AL, Ballman KV et al. (2015) NCCTG N0574 (Alliance): A phase III randomized trial of whole brain radiation therapy (WBRT) in addition to radiosurgery (SRS) in patients with 1 to 3 brain metastases. J Clin Oncol 33(15_suppl):LBA4. 
93) Sahgal A, Aayama H, Kocher M, et al. (2015) Phase 3 trials of stereotactic radiosurgery with or without whole-brain radiation therapy for 1 to 4 brain metastasis: individual patient data meta-analysis. Int J Radiat Oncol Biol Phys 91(4):710-717.

94) Meyers CA, Smith JA, Bezjak A et al. (2004) Neurocognitive function and progression in patients with brain metastases treated with whole-brain radiation and motexafin gadolinium: results of a randomized phase III trial. J Clin Oncol 22:157-165.

95) Weiss SE, Kelly PJ. (2010) Neurocognitive function after WBRT plus SRS or SRS alone. Lancet Oncol 11:220-221.

96) Soffietti R, Kocher M, Abacioglu UM et al. (2013) A European Organisation for Research and Treatment of Cancer phase III trial of adjuvant whole-brain radiotherapy versus observation in patients with one to three brain metastases from solid tumours after surgical resection or radiosurgery: quality-of-life results. J Clin Oncol 31:65-72.

97) Tsao M, Xu W, Sahgal A. (2012) A meta-analysis evaluating stereotactic radiosurgery, whole-brain radiotherapy, or both for patients presenting with a limited number of brain metastases. Cancer 118:2486-2493.

98) Soliman H, Das S, Larson DA, Sahgal A. (2016) Stereotactic radiosurgery (SRS) in the modern management of patients with brain metastases. Oncotarget 7(11):12318-30.

99) Mehta M. (2015) The controversy surrounding the use of whole-brain radiotherapy in brain metastases patients Neuro-Oncology 17(7):919-923

100) Dye NB, Gondi V, Mehta MP. (2015) Strategies for preservation of memory function in patients with brain metastases. Chin Clin Oncol 4(2):24.

101) Brown PD, Pugh S, Laack NN et al. (2013) Memantine for the prevention of cognitive dysfunction in patients receiving whole-brain radiotherapy: a randomized, double-blind, placebo-controlled trial. Neuro Oncol 15(10):1429-1437.

102) Chung SY, Chang JH, Kim HR, et al. (2017) Optimal dose and volume for postoperative radiotherapy in brain oligometastases from lung cancer: a retrospective study Radiat Oncol J 35(2):153-162

103) Filley CM , Kleinschmidt-DeMasters BK. (2001) Toxic leukoencephalopathy. N Engl J Med 345:425-32.

104) Arriagada R, Le Chevalier T, Borie F, et al. (1995) Prophylactic cranial irradiation for patients with small-cell lung cancer in complete remission. J Natl Cancer Inst 87:18390. 
105) Komaki R, Meyers CA, Shin DM, et al. (1995) Evaluation of cognitive function in patients with limited small cell lung cancer prior to and shortly following prophylactic cranial irradiation. Int J Radiat Oncol Biol Phys 33:179-82.

106) Tiwari V, Pande SC, Verma K, Goel S. (2015) Simultaneous_integrated boost with intensity modulated radiation therapy in brain oligometastases: A feasible technique for developing countries. South Asian J Cancer 4(1):11-14.

107) Rodrigues G, Zindler J, Warner A, Bauman G, Senan S, Lagerwaard F. (2013) Propensity-score matched pair comparison of whole brain with simultaneous in-field boost radiotherapy and stereotactic radiosurgery. Radiother Oncol 106(2):206-209.

108) Patchell RA, Tibbs PA, Regine WF et al. (1998) Postoperative radiotherapy in the treatment of single metastases to the brain: a randomized trial. JAMA 280(17):14851489.

109) Wang TJ, Saad S, Qureshi YH et al. (2015) Outcomes of gamma knife radiosurgery, bimodality \&amp; tri-modality treatment regimens for patients with one or multiple brain metastases: the Columbia University Medical Center experience. J Neurooncol 122(2):399-408.

110) Lin NU, Lee EQ, Aoyama $\mathrm{H}$ et al. (2013) Challenges relating to solid tumour brain metastases in clinical trials, part 1: patient population, response, and progression. A report from the RANO group. Lancet Oncol 14:e396-406.

111) Lin NU, Wefel JS, Lee EQ et al. (2013) Challenges relating to solid tumour brain metastases in clinical trials, part 2: neurocognitive, neurological, and quality-of-life outcomes. A report from the RANO group. Lancet Oncol 14:e407-416.

112) Voronova V, Lebedeva S, Sekacheva M, Helmlinger G, Peskov K. (2020) Quantification of Scheduling Impact on Safety and Efficacy Outcomes of Brain Metastasis Radio- and Immuno-Therapies: A Systematic Review and Meta-Analysis. Front Oncol. 10:1609. 


\title{
Boost Irradiation Integrated to Whole Brain Radiotherapy in the Management of Brain Metastases
}

\author{
Ágnes Dobi ${ }^{1} \cdot$ Emese Fodor ${ }^{1}$ - Anikó Maráz ${ }^{1} \cdot$ Zsófia Együd $^{1} \cdot$ Adrienne Cserháti $^{1} \cdot$ László Tiszlavicz $^{2} \cdot$ Zita Reisz $^{2}$. \\ Pál Barzó $^{3} \cdot$ Zoltán Varga $^{1} \cdot$ Katalin Hideghéty ${ }^{1}$
}

Received: 4 June 2017 / Accepted: 10 January 2018

(C) Arányi Lajos Foundation 2018

\begin{abstract}
Our retrospective analysis aimed to evaluate the clinical value of dose intensification schemes: WBRT and consecutive, delayed, or simultaneous integrated boost (SIB) in brain metastasis (BM) management. Clinical data and overall survival (OS) of 468 patients with BM from various primaries treated with $10 \times 3$ Gy WBRT $(n=195)$, WBRT $+10 \times 2$ Gy boost $(n=125)$, or simultaneously $15 \times 2.2$ Gy WBRT +0.7 Gy boost $(n=148)$ during a 6-year period were statistically analysed. Significant difference in OS could be detected with additional boost to WBRT (3.3 versus 6.5 months) and this difference was confirmed for BMs of lung cancer and melanoma and both for oligo- and multiplex lesions. The OS was prolonged for the RPA 2 and RPA3 categories, if patients received escalated dose, 4.0 vs. 7.7 months; $(p=0.002)$ in class RPA2 and 2.6 vs. 4.2 months; $(p<0.0001)$ in the class RPA 3 respectively. The significant difference in OS was also achieved with SIB. The shortened overall treatment time of SIB with lower WBRT fraction dose exhibited survival benefit over WBRT alone, and could be applied for patients developing BM even with unfavourable prognostic factors. These results warrant for further study of this approach with dose escalation using the lately available solutions for hippocampus sparing and fractionated stereotactic irradiation. The simultaneous delivery of WBRT with reduced fraction dose and boost proved to be advantageous prolonging the OS with shortened treatment time and reduced probability for cognitive decline development even for patients with poor performance status and progressing extracranial disease.
\end{abstract}

Keywords WBRT $\cdot$ Simultaneous integrated boost $\cdot$ Brain metastasis $\cdot 3$ DCRT $\cdot$ IMRT

\section{Introduction}

Alongside the improved efficacy of systemic treatments, the incidence of brain metastases (BMs) steadily increases, ranging 9-40\% worldwide [1,2]. The most common cancers that metastasise to the brain include lung, breast, melanoma, renal cell, and colorectal cancers [3]. The recent advances in chemotherapy and the fast growing introduction of diverse molecular targeted approaches (including EGFR-, VEGFR-,

Ágnes Dobi

dobiagnes@gmail.com

1 Department of Oncotherapy, University of Szeged, Korányi fasor 12, Szeged H-6720, Hungary

2 Department of Pathology, University of Szeged, Állomás utca 1, Szeged H-6725, Hungary

3 Department of Neurosurgery, University of Szeged, Semmelweis utca 8, Szeged H-6725, Hungary multikinase, B-RAF, MEK, ERK and immunoresponse CTLA-4, PD-1, PD-L1 inhibitors) into the management of these metastatic cancers lead to remarkable improvement in the outcome of disseminated stage of these frequent tumours. In the case of brain metastasis, though, the overall prognosis remains poor: without any treatment $1-2$ months, with palliative methods, 4-6 months of median survival can be expected [4], depending (1) on the age and functional status of the patient, (2) the extent of the underlying systemic disease, and (3) the number of metastases [5]. Moreover, in 15\% of the cases, the primary tumour is still unknown at the time when BMs are already diagnosed [4].

The common therapeutic mean is the palliative irradiation with different possible methods to choose from. In case of multiple BMs, the whole-brain irradiation (WBRT) is usually performed with the dose of $10 \times 3$ Gy [6], whilst the cases with less than three metastatic lesions (i.e. oligometastases) were considered for surgery and/or radiosurgery with or without WBRT [7, 8]. In the last decade, conclusions from relevant clinical studies demonstrated the superiority of multimodal 
approaches over the single treatment method of neurosurgery, stereotactic radiosurgery (SRS), and WBRT [9-11]. More recently, in order to decrease the cognitive decline attributed to the standard WBRT, the possibility of omitting the WBRT came again into focus. The ASCO recommendation in 2014 did not include the routine addition of WBRT to SRS for limited brain metastases, based on meta-analysis of published clinical research $[12,13]$. However, it could be substantially criticised and several arguments (including survival benefit, notable increase of intracerebral impairments, and more serious neurocognitive decline due to metastatic progression in the brain) support the further application of combined approaches including the WBRT $[14,15]$.

At the same time, any mean to mitigate the treatmentrelated brain toxicities, such as the use of radioprotective agents, and/or hippocampus-sparing advanced radiation technique and/or alternative fractionation of WBRT, is highly required. The conformational fractionated external beam boost, instead of SRS for BMs arising from lung cancer (as it has been recently demonstrated in a multi-institutional study [16]), results in a remarkable estimated 1-year local control rate of $>75 \%$. Such dose escalation can be also carried out with intensity-modulated radiotherapy (IMRT) or volumetric modulated arc therapy (VMAT), using the simultaneous integrated boost (SIB) technique $[8,17]$, or, if the above mentioned techniques are not available, with external beam radiotherapy boost (RTB) [16].

Several technical and logistical advantages of SIB over other modalities (such as radiosurgery) makes SIB a plausible choice. SIB includes WBRT and boost on BM in the same session with optimised dose distribution, requires a single simulation protocol, reducing the waiting and dose delivery time, therefore costs and inconvenience, as well [18]. Using single fraction protocols, the re-oxygenation and re-assortment benefits accompanying fractionated modalities, cannot be exploited. The treatment of more than 3 metastases with radiosurgery may require long or multiple sessions, or may lead to the impossibility of radiosurgery, as well. The substantial time break between radiosurgery and WBRT may enhance the probability of tumour cell repopulation or subletal repair processes [19].

From 2005 on, the dose escalation with 3D conformal technique was introduced for patients presented with brain metastasis at our Department, in the lack of SRS availability before 2016. The standard WBRT and the new approaches were performed parallel; therefore we could evaluate the results of the different radiation schemes in a single institutional retrospective analysis.

\section{Materials and Methods}

Between 2005 and 2013, at the Department of Oncotherapy, altogether 468 patients with BMs (arising from various primary malignancies) were subjected to palliative skull irradiation. The present study has been carried out in accordance with The Code of Ethics of the World Medical Association (Declaration of Helsinki) for experiments involving humans. Informed consent was obtained from the patients at their first clinical admission for the anonymised use of their patient data for research purposes. For the present study, the ethical permission (No. 886/2006) was issued by the Ethical Council of the Faculty of Medicine, University of Szeged. The treatment schemes were thoroughly discussed with every single patient, independently from their actual performance status. The fractionation was agreed by signed informed consent. Unconscious patients or those with serious cognitive deficits, lacking the legal capacity of informed consent made on their own, and also patients with previous prophylactic WBRT, were excluded from the enrolment. All patients included in the present study were treated according to the actual protocol for the histologically proven primary disease and had clinical, radiological, pathological evidence of BM.

The total biological effective dose was calculated as equivalent dose in 2 Gy fractions (EQD2: $\alpha / \beta$ value of 2 for normal brain [Gy2] and that of 10 for tumour [Gy10]). The traditional palliative approach of $10 \times 3$ Gy WBRT (EQD2 37.5 Gy) was applied for 195 cases (Group A); in 273 cases WBRT combined with boost irradiation were performed. In addition to the $10 \times 3$ Gy $/ 18 \times 2$ Gy WBRT boost dose of $10 \times 2$ Gy $($ EQD2 $57,5 \mathrm{~Gy} / 56 \mathrm{~Gy}$ ) to the surgical cavity (if the metastasis had been removed), or to the metastatic lesions for patients in good PS and/or better life expectancy were performed (Group B). Later, simultaneous integrated boost irradiation (SIB: $15 \times 2.2$ WBRT $+15 \times 0.7$ boost, (WBRT EQD2 33,4Gy, metastasis EQD2 46.8 Gy) (Group C) had been given whenever it was applicable with 3D conformal technique planned by XIO TPS.

Patients were immobilised with a 3-point thermoplastic mask (ORFIT Industries, NL). Radiotherapy was planned according to the ICRU 52 recommendation using subfields additionally to the opposed lateral fields to achieve the required dose homogeneity (95-107\%) for WBRT. Boost using 3 DCRT or IMRT at $10 \times 2$ Gy boost was given consecutively or with 2-3 months delay, due to the treatment of either the primary tumour or of the extracranial metastases. Later, we have developed the technique of conformal simultaneous boost, delivered whenever the metastases could be encompassed in a boost volume less than $30 \%$ of the brain (in majority of the cases less than $10 \%$ ). Boost volume was defined on the basis of planning CAT and MRI fusion. During brain irradiation patients received $12 \mathrm{mg}$ methylprednisolone for prevention of brain oedema, with gradually decreased dosing after radiotherapy. The dose of methylprednisolone was adjusted according to the symptoms of intracranial pressure elevation due to brain oedema. Retrospective assessment of overall survival (OS) according to the recursive partitioning analysis (RPA), Karnofsky performance score 
(KPS), number of metastases, metastasectomy, localisation and histological features of primary tumour was carried out. The data were evaluated by Kaplan-Meier statistical analysis with IBM SPSS Statistics for Windows, Version 20.0 (Armonk, NY: IBM Corp.) $p$ value $<0.05$ was considered as statistically significant. Multi-variance analysis of the prognostic factors was performed using the Cox proportional hazard regression model.

\section{Results}

\section{Patient Characteristics}

The mean age of the population at the time of BM detection was 60.7 years; $53.3 \%$ of them was male and $46.7 \%$ female. The KPS was in $56.2 \%$ of this population over $70 \%$. The primary neoplasm was that of the lung in $68.9 \%$ (16\% of the latter was small cell lung cancer without prior prophylactic skull irradiation), of the breast in $7.9 \%$, malignant melanoma in $10.6 \%$, of the kidney in $2.1 \%$, of the gastrointestinal tract in $5.4 \%$, or that of other organ in $4.9 \%$ of the assessed population. $36 \%$ of patients with small cell lung cancer received dose-escalated radiotherapy, the remaining cases were treated with WBRT. At the time of the diagnosis of the cerebral metastasis, the underlying process was controlled in $37.4 \%$, extracranial progression in $35.8 \%$ and was unknown in $26.6 \%$ of this population. $11.1 \%$ of all patients belonged to RPA 1 , $45.1 \%$ to RPA 2, and $43.8 \%$ to RPA 3 class. During the treatments, the data of the patients were registered according to the RPA categories; therefore the graded prognostic assessment (GPA) could not be defined retrospectively in lack of Karnofsky index between 70 and 100 . Nevertheless, the treatment outcome could be evaluated according to the number of brain metastases.

Table 1 summarises the patient characteristics according to the three different methods of treatment. Patient distribution according to the age, gender and primary tumour localisation, extracranial metastasis were similar in the 3 groups. The difference of the KPS at the diagnosis and consequently the patient distribution according to the RPA categories shows the patient selection strategy at our Department. In RPA 2, the primary tumour was controlled in $13 \%$, uncontrolled in $63 \%$, unknown in $24 \%$ of the cases. In RPA 3, this distribution was $10 \%, 78 \%$, and $12 \%$, respectively.

\section{Characteristics of the Malignant Disease and Brain Metastases}

Extracranial metastasis was present $53 \%$ in the RPA 2, and $56 \%$ of the cases in the RPA 3 group. Extracranial metastasis was not present in $30 \%$ and $38 \%$, or was unknown in $17 \%$ and $6 \%$ of the cases in RPA 2 and 3 classes, respectively. Higher number of the patients received high dose radiotherapy with good PS, with better prognostic factors and with solitary or oligometastases. The difference according to the KPS and RPA was less pronounced in the Group C, then in the Group B over the Group A. Even the status of extracranial disease was less favourable in the Group $\mathbf{C}$ with $50 \%$ progressive disease, in contrast to $36 \%$ in the Group A and $21 \%$ in the Group B. Table 2 characterises the brain metastases further. The time frame of brain metastasis occurrence had a relation to the underlying disease, hence were similarly distributed between the treatment groups. The development of brain metastases occurred within 1 year after the diagnosis of primary tumour in $72 \%$ of the patients in Group A, $66 \%$ in Group B and $64 \%$ in Group C. Late occurring brain metastases were diagnosed in $13.8 \%, 14.4 \%$ and $17.6 \%$ in the Groups A, B, C, respectively. The rate of single-/oligometastases was higher than two third of the group when the higher total dose was applied (Groups B and C), and was $42 \%$ of the patients received WBRT only. Consequently, only $10 \%$ of the patients of Group A underwent surgery, meanwhile almost the half of the patients was subjected to neurosurgical removal of the metastases in the other two groups. 147 patients were subjected to brain metastasectomy, $90 \%$ of them also received postoperative/ adjuvant radiotherapy, independently from the radiotherapy modality. The planning target volume (PTV) for the WBRT was similar in the three groups. The difference between the boost PTVs of the Groups B (153.3 $\left.\pm 27.9 \mathrm{~cm}^{3}\right)$ and $\mathrm{C}\left(183.1 \pm 15.7 \mathrm{~cm}^{3}\right)$ was statistically significant $(p=0.017)$.

\section{Survival Analysis}

The analysis of OS according to different factors is summarised in Table 3. Doubling of the survival time was detected in the escalated dose groups over the Group A. $(p<0.001)$ The OS was 3.2-3.3 months for all tumour types, if only WBRT was applied. OS difference was significant in the case of lung cancer and malignant melanoma between patients treated by WBRT only vs. those receiving escalated total dose. OS difference has not reached the statistical significance level for breast, kidney and gastrointestinal tumours. Both in the case of low number of the BM (1-3) and in the case of multiple $(>4)$ metastases, the OS difference between the $30 \mathrm{~Gy}$ and escalated groups were significant. If surgery was performed, statistically no OS benefit could be proven from the boost dose $(p=0.48)$, in contrast to the significantly prolonged survival without neurosurgical removal $(p=$ 0.002). The longer treatment with higher total dose (SIB or consecutive boost to WBRT) was significantly more beneficial for the survival of patients both in good and in poor condition (Table 4). The survival data of the Group B and C in RPA classes 2 and 3 were significantly better than in Group A. Only a few patients in RPA class 1 were treated with WBRT, therefore in spite of the median survival of Group B 
Table 1 Patient characteristics by treatment groups

\begin{tabular}{|c|c|c|c|c|}
\hline Treatment group & $\begin{array}{l}\text { A WBRT } \\
10 \times 3 \text { Gy } \\
n=195\end{array}$ & $\begin{array}{l}\text { B WBRT }+ \text { boost } \\
10 \times 3 / 18 \times 2+10 \times 2 \\
n=125\end{array}$ & $\begin{array}{l}\text { C SIB } \\
15 \times(2.2+0.7) \\
n=148\end{array}$ & $\begin{array}{l}\mathrm{B}+\mathrm{C} \text { group } \\
n=273\end{array}$ \\
\hline \multicolumn{5}{|l|}{ Age } \\
\hline Mean & 60.9 & 58.3 & 63.1 & 60.7 \\
\hline Range & $27.6-84.2$ & $21.6-84.7$ & $38.3-84.8$ & $21.6-84.8$ \\
\hline$<50$ & $20(10.3 \%)$ & $28(22.4 \%)$ & $10(6.8 \%)$ & $38(13 \%)$ \\
\hline $50-70$ & $135(69.2 \%)$ & $78(62.4 \%)$ & $103(69.6 \%)$ & $181(66 \%)$ \\
\hline$>70$ & $40(20.5 \%)$ & $19(15.2 \%)$ & $35(23.6 \%)$ & $54(19 \%)$ \\
\hline \multicolumn{5}{|l|}{ Gender } \\
\hline Male & $107(54.9 \%)$ & $69(55.2 \%)$ & $74(50 \%)$ & $143(52 \%)$ \\
\hline Female & $88(45.1 \%)$ & $56(44.8 \%)$ & $74(50 \%)$ & $130(48 \%)$ \\
\hline \multicolumn{5}{|l|}{ Primary tumour } \\
\hline Lung (total) & $143(73.3 \%)$ & $85(68 \%)$ & $97(65.6 \%)$ & $182(66 \%)$ \\
\hline$-S C L C$ & $35(17.9 \%)$ & $7(5.6 \%)$ & $13(8.7 \%)$ & $20(7.3 \%)$ \\
\hline$-N S C L C$ & $108(55.3 \%)$ & $78(62.4 \%)$ & $84(56.7 \%)$ & $162(59.3 \%)$ \\
\hline Breast & $16(8.2 \%)$ & $7(5.6 \%)$ & $15(10.1 \%)$ & $22(8 \%)$ \\
\hline MM & $9(4.6 \%)$ & $18(14.4 \%)$ & $19(12.8 \%)$ & $37(13 \%)$ \\
\hline Kidney & $5(2.6 \%)$ & $3(2.4 \%)$ & $2(1.4 \%)$ & $5(1.8 \%)$ \\
\hline Colorectal & $10(5.1 \%)$ & $8(6.4 \%)$ & $7(4.7 \%)$ & $15(5.4 \%)$ \\
\hline Other & $12(6.2 \%)$ & $4(3.2 \%)$ & $8(5.4 \%)$ & $12(4.3 \%)$ \\
\hline \multicolumn{5}{|l|}{ KPS } \\
\hline$>70$ & $81(41.5 \%)$ & $93(74.4 \%)$ & $78(52.7 \%)$ & $171(62 \%)$ \\
\hline$<70$ & $114(58.5 \%)$ & $32(25.6 \%)$ & $70(47.3 \%)$ & $102(37 \%)$ \\
\hline \multicolumn{5}{|c|}{ Status of extracranial dissemination } \\
\hline No. & $67(34.4 \%)$ & $63(50.4 \%)$ & $19(12.8 \%)$ & $82(30 \%)$ \\
\hline Regression & $10(5.1 \%)$ & $8(6.4 \%)$ & $5(3.4 \%)$ & $13(4.7 \%)$ \\
\hline Progression & $70(35.9 \%)$ & $27(21.6 \%)$ & $74(50 \%)$ & $101(37 \%)$ \\
\hline Unknown & $48(24.6 \%)$ & $27(21.6 \%)$ & $50(33.8 \%)$ & $77(28 \%)$ \\
\hline \multicolumn{5}{|l|}{ RPA } \\
\hline 1 & $8(4.1 \%)$ & $28(22.4 \%)$ & $10(6.8 \%)$ & $38(14 \%)$ \\
\hline 2 & $73(37.4 \%)$ & $65(52 \%)$ & $68(45.9 \%)$ & $133(48 \%)$ \\
\hline 3 & $114(58.5 \%)$ & $32(25.6 \%)$ & $70(47.3 \%)$ & $102(38 \%)$ \\
\hline
\end{tabular}

$\mathrm{MM}=$ malignant melanoma

(20.2 months) and in Group C (14.6 months) in contrast to the 6.3 months of Group A; it has not reached the statistical significance (Table 4). Kaplan-Meier survival analysis detected no significant OS difference between the treatment groups for the patients of RPA 1 category. As for the RPA 2 and RPA3 categories, the OS was significantly prolonged in case of patients received escalated dose, 4.0 vs. 7.7 months; $(p=0.002)$ in class RPA2 and 2.6 vs. 4.2 months; $(p<0.0001)$ in the class RPA 3. If no surgery was performed the SIB resulted in significantly longer OS of 6.5 months in contrast to the 3.9 months survival of the patients received WBRT only for class $1-2(p=0.05)$. In RPA class 3 , the addition of both the consecutive or delayed boost and the simultaneous boost to the WBRT resulted in significant OS benefit $(p=0.001)$. The
OS of patients with KPS $>70 \%$ and even the OS of patients with KPS $<70 \%$ were equally proven better in case of those receiving the escalated dose vs. WBRT without boost (9.4 vs. 4.2 months; $p<0.0001$ and 4.2 vs. 2.6 months; $\mathrm{p}<0.0001$; respectively). The multi-variance analysis yielded three, mutually independent prognostic factors for survival: RPA, surgery and therapy method. According to this analysis, the number of metastases, as a prognostic factor, is not independent from the ones mentioned above (as shown in Table 5).

\section{Toxicity of the Treatment}

In the majority of the cases in each group, the prophylactic dose of the methyl-prednisolone prevented the development 
Table 2 Characteristics of brain metastases by treatment groups

\begin{tabular}{|c|c|c|c|}
\hline Treatment group & $\begin{array}{l}\text { A WBRT } \\
10 x 3 \mathrm{~Gy}\end{array}$ & $\begin{array}{l}\text { B WBRT }+ \text { boost } \\
10 \times 3 / 18 \times 2+10 \mathrm{X} 2\end{array}$ & $\begin{array}{l}\text { C SIB } \\
15 \times(2.2+0.7)\end{array}$ \\
\hline \multicolumn{4}{|l|}{ Development of BM after the diagnosis of the primary } \\
\hline First manifestation of the disease or within 1 year & $140(71.8 \%)$ & $83(66.4 \%)$ & $95(64.2 \%)$ \\
\hline $1-3$ years & $28(14.4 \%)$ & $24(19.2 \%)$ & $27(18.2 \%)$ \\
\hline$>4$ years & $27(13.8 \%)$ & $18(14.4 \%)$ & $26(17.6 \%)$ \\
\hline \multicolumn{4}{|l|}{ Number of BM } \\
\hline average & 5,1 & 2,2 & 2,9 \\
\hline 1 & $38(19.5 \%)$ & $78(62.4 \%)$ & $69(46.6 \%)$ \\
\hline $2-4$ & $44(22.6 \%)$ & $29(23.2 \%)$ & $50(33.8 \%)$ \\
\hline$>4$ & $113(57.9 \%)$ & $18(14.4 \%)$ & $29(19.6)$ \\
\hline \multicolumn{4}{|l|}{ BM surgery } \\
\hline no & $176(90.3 \%)$ & $63(50.4 \%)$ & $82(55.4 \%)$ \\
\hline yes & $19(9.7 \%)$ & $62(49.6 \%)$ & $66(44.6 \%)$ \\
\hline \multicolumn{4}{|l|}{ RT volumes of interest } \\
\hline PTV & 1705 & 1716 & 1686 \\
\hline PTV1 & & 153.3 & 183.1 \\
\hline Brain & 1326 & 1341 & 1314 \\
\hline GTV & & 35.9 & 59.1 \\
\hline
\end{tabular}

of serious brain oedema, the consequent intracranial pressure elevation, and the aggravation of the neurological symptoms. In $35 \%$ of the cases, the dehydration had to be intensified, but with appropriate supportive control, $96 \%$ of the patients could complete the planned therapy. Alopecia occurred in all groups equally.

\section{Discussion}

There is still a seething debate concerning the optimal management of brain metastases. The main aim that everyone agrees with is to achieve as long time for the patients as possible without physical and psychological signs and symptoms.

Table 3 The OS directly related to the type of irradiation, primary tumour, number of brain metastases and metastasectomy




Table 4 The OS as a function of Karnovsky-scores or RPA

\begin{tabular}{llllll}
\hline The investigated parameters & Type of irradiation & $\mathrm{n}$ & OS & \pm SE & $p$-value \\
\hline Karnofsky $>70 \%$ & WBRTSIB & 81 & 4.1 & 0.45 & 0.015 \\
& WBRTWBRT+boost & 81 & 4.1 & 0.45 & $<0.0001$ \\
& & 93 & 9.6 & 0.868 & \\
Karnofsky $<70 \%$ & WBRTSIB & 114 & 2.6 & 0.19 & 0.002 \\
& WBRTWBRT+boost & 70 & 3.9 & 0.465 & \\
& & 114 & 2.6 & 0.19 & 0.021 \\
RPA1 & WBRTSIB & 8 & 4.2 & 0.636 & \\
& & 6.3 & 6.223 & 0.343 \\
& WBRTWBRT+boost & 8 & 6.3 & 6.223 & 0.345 \\
RPA2 & WBRTSIB & 28 & 14.6 & 6.456 & \\
& & 73 & 4.0 & 0.427 & 0.034 \\
& WBRTWBRT+boost & 73 & 4.0 & 0.427 & 0.003 \\
RPA3 & WBRTSIB & 65 & 8.3 & 1.875 & \\
& & 114 & 2.6 & 0.19 & 0.002
\end{tabular}

Historically, the very short survival without treatment, with the symptoms of increasing intracranial pressure and diverse neurological deteriorations including motor-, sensory-, speech- and cognitive dysfunctions led to delivery of palliative 30 Gy WBRT, in 10 fractions [20]. Ten or five consecutive working days were reasonable even for patients in poor condition with short life expectancy and the RT was performed with simple technique (two opposed lateral beams) with relative large dose inhomogeneity in the whole brain. Nevertheless, WBRT resulted in symptom relief in the majority of the patients, and added some months to their survival [21]. Based on that, WBRT became the standard management of brain metastasis [22] and had been also introduced as preventive measure in case of radiosensitive malignancy with high risk for BM or leptomeningeal dissemination (ALL, SCLC) $[23,24]$. The prophylactic WBRT is performed with conventional fractionation (1.8-2 Gy/fraction). There is no doubt that WBRT is highly effective to prevent metastatic spread in the brain, but severe neurocognitive decline

Table 5 RPA, surgery and RT method, as prognostic factors for survival

\begin{tabular}{lllll}
\hline Risk factors & HR & $95 \%$ CI & $p$-value \\
\hline RPA & & & & $<0.001$ \\
& RPA 3 vs. RPA 1 & 3.546 & $2.463-5.102$ & \\
& RPA 3 vs. RPA 2 & 1.773 & $1.441-2.183$ & \\
Surgery & NO vs. YES & 2.072 & $1.643-2.512$ & $<0.001$ \\
RT group & Group A vs. Group B,C & 1.256 & $1.021-1.546$ & 0.031 \\
\hline
\end{tabular}

(particularly memory deficit) occurs with high probability after $5 \times 4$ Gy or $10 \times 3$ Gy [25]. The introduction of stereotactic radiosurgery technique in the 1960 s provided access to highly selective dose delivery method for small $(<3 \mathrm{~cm})$, and low number (1-3) of brain metastases, which was applied as alternative method to neurosurgical intervention. Several clinical studies proved the superiority of the combined treatment, surgery or SRS + WBRT to improve local and central nervous system control [10, 26-29]. In the last decade, with the advent of imaging (CAT/MRI), development of neurosurgery technique and various SRS solutions, high precision local management of single and oligo-BM became widely available. Recent clinical trials and meta-analyses questioned the necessity of WBRT at all, emphasising the neurocognitive harm of the WBRT [12, 30-34]. Meanwhile, other authors [35] warn of drawing too early and hasty conclusions leading to general omission of WBRT, without considering the danger of increase of intracranial impairments, and neurocognitive decline due to cerebral disease progression. They rather suggest considering the use of selective neuroprotective agent (memantine) and hippocampus-sparing WBRT technique [36, 37]. Chung et al. [15]. applied a lower WBRT dose with a boost to the tumour bed after metastasectomy, since WBRT neurotoxicity is associated with the total dose and fractionation [38]. Although no randomized studies have directly compared lower WBRT doses to the traditional WBRT dose of $30 \mathrm{~Gy}$, the advantage of lower WBRT dose has been shown in previous studies on prophylactic cranial irradiation (PCI). For example, a French study compared PCI (24 Gy in 8 fractions, EQD2 26 Gy) vs. no PCI, and observed no significant 
difference between the groups in terms of neuropsychological function or abnormalities [39]. In another trial performed at MD Anderson Cancer Centre, 30 patients received PCI (25 Gy in 10 fractions, EQD2 $26.04 \mathrm{~Gy}$ ) and no significant deterioration was observed after PCI [40]. Other approach to reduce the decrease of memory function could be the use of lower fraction doses.

Our aim was to find a balance in improving the survival with dose escalation to the macroscopic metastases, maintaining the intracranial control and reducing the probability of treatment-related cognitive decline; meanwhile keeping the treatment duration reasonable for patients even with multiple brain metastases. Therefore, we have applied conventional fractionation for $3 \mathrm{D}$ conformal whole brain and consecutive boost irradiation using the classical conventional fractionation scheme, $18 \times 2$ Gy +10 to $12 \times 2$ Gy up to $56-60$ Gy total dose for patients with relatively longer life expectancy. Later we have introduced a shortened regime of $15 \times 2.2$ Gy whole brain irradiation and simultaneously 0.7 Gy was delivered to the tumour or tumour bed after surgery. This technique allowed encompassing even 10-12 metastases into the boost volume, and lasted only 3 weeks, considered reasonable for patients with poorer condition. Tiwari and co-workers reported the results of SIB of 19 patients versus WBRT alone (13 patients), demonstrating better local control and improved survival in the SIB group [41]. Another publication from Italian groups emphasises the higher efficacy of the intensified treatment (WBRT and SRS boost), as well, enrolling 134 patients, of whom 21 were treated with SIB [28]. On the basis of high patient number, we could demonstrate the feasibility and clinical usefulness of dose escalation and in particular, the application of SIB in the management of BM, even for patients with unfavourable status. Direct comparison of SRS to SIB was performed in a matched cohort of 178 patients with similar baseline characteristics [42]. However, as for the OS, neither the treatment with SRS nor with SIB did result in any statistically significant difference, the SIB was associated with reduced intracranial impairment, likely due to the WBRT component of the treatment (HR $0.36, p<0.001$ ). Similarly for single and oligometastatic brain spread, several randomised clinical studies have proven the better outcome in terms of local and intracranial disease control with combined treatment approaches, such as surgery +WBRT, SRS + WBRT, or SIB; but in the majority of the cases these encouraging results could not be transformed into significantly improved survival [13, 15, 28, 42-44].

In contrast, our retrospective analysis confirmed the significant survival benefit for the whole group of patients including multiple metastases from intensified treatments without difference between the long and the shortened (SIB) regimes. This relevant survival difference was achieved not only for oligometastatic diseases, but for patients with multiple metastases ( $>4)$, as well. Hence, in the group that received SIB, one fifth of the patients had multiple metastases, in which the simultaneous boost was technically performable. The majority of evidence-based data derived from randomised clinical studies concerns patient population with single or oligometastases only, without progressing extracranial disease and in good status. Nevertheless, patients with worse initial parameters could not be enrolled - by forming homogeneous groups- into randomised trials. In fact, the design of clinical investigation on the management of brain metastasis is a highly challenging task. The application of the suggested recommendations of the Response Assessment in Neuro-Oncology (RANO) brain metastases group [45, 46] supposes patients in good condition and good cooperation, what is frequently not the case with patients of progressing extracranial cancer and/or low performance status. In our current study population, around half of the patients in the SIB arm had progressive disease and bad performance status $(<70 \%)$, according to Karnofsky score.

Our study has evident limitations. Its retrospective nature and consequent patient heterogeneity may have biased the results. Our effort to compare the outcome of the different treatment schemes by retrospectively dividing the patient population amongst similar prognostic groups could not completely compensate the lack of prospective patient enrolment. Furthermore, no objective assessment of late neurotoxicity has been performed. However, this study has several strengths. The large number of the patients allowed relevant statistical evaluation, and the three treatment approaches were clearly defined. Our aim to study the feasibility of SIB in 15 fractions even for patients, who cannot be enrolled into prospective clinical trials due to their bad prognostics, could be investigated. Conclusion could be drawn from this analysis on the applicability of lower WBRT fraction dose approach with a boost RT.

Therefore, considering all the limitations, our study on large patient series in RPA2 and RPA3 categories seems to document survival advantage of intensified irradiation schemes, which has high importance for the daily clinical decisions, even for patients in poor condition (KPS $<70 \%$ ). The novel generation of linear accelerators allow the introduction of fractionated stereotactic irradiation of the boost volumes simultaneously to the low fraction size $(<2.5 \mathrm{~Gy})$ WBRT.

\section{Conclusion}

The improvement in the systemic treatment of disseminated malignancies urges the establishment of optimal management of patients with brain metastasis with different clinical and tumour parameters. Meanwhile, some open questions could be hopefully answered soon by the results of the on-going trials on radiation technique and on combination of radiotherapy with targeted agents for patients with low number of BMs. 
Still, novel approaches are highly required to decrease the potential neurocognitive decline as a consequence of WBRT, since the majority of the patients belong to less favourable prognostic groups (i.e. with progressive extracranial status and multiple BMs). Therefore, retrospective analyses could provide valuable conclusions, even though they should be assessed critically. From our large series of evaluation, the intensive radiation approach for groups of BM patients seems to yield clinical benefit; and the feasibility of SIB in the management of BMs could be confirmed. Together with the use of neuroprotective agents and hippocampal-avoidance WBRT technique, smaller fraction size of WBRT simultaneously to fSRT boost is to be considered for further clinical investigation.

Contributions The contributions of the authors to the present study are as follows: (1) the conception and design of the study (Á.D., K.H.), (2) examination, therapy plans and follow-up of the patients (Á.D., Zs.E., A.M., K.H.), (4) radiological assessments (A.Cs.), (5) histopathological diagnostics (L.T., Z.R.), (6) neurosurgical treatment (P.B.), (7) radiotherapy planning physicist (E.F.), (8) collection and acquisition of data (Á.D.), (9) statistical analysis of data (Z.V.), (10) interpretation of data (Á.D., K.H.), (11) drafting the article (Á.D., K.H), (12) revising it critically for important intellectual content (K.H.).

All authors have approved the final version of the submission.

Funding This project was supported by Analytic Healthcare Quality User Information Programme of the National Research, Development and Innovation Fund, Hungarian Government, Grant No. VKSZ 12-12013-0012.

\section{Compliance with Ethical Standards}

Ethical Approval For this type of study (i.e. retrospective) formal consent is not required.

Informed Consent Informed consent was obtained from all individual participants included in the study.

Conflict of Interest The authors declare that they have no conflict of interest.

\section{References}

1. Nayak L, Lee EQ, Wen PY (2012) Epidemiology of brain metastases. Curr Oncol Rep 14(1):48-54

2. Singh M, Manoranjan B, Mahendram S, McFarlane N, Venugopal C, Singh SK (2014) Brain metastasis-initiating cells: survival of the fittest. Int J Mol Sci 15(5):9117-9133

3. Taillibert S, Le Rhun É (2015) Epidemiology of brain metastases. Cancer Radiother 19(1):3-9 (Article in French)

4. Soffietti R, Rudā R, Mutani R (2002) Management of brain metastases. J Neurol 249(10):1357-1369

5. Ellis TL, Neal MT, Chan MD (2012) The role of surgery, radiosurgery and whole brain radiation therapy in the management of patients with metastatic brain tumors. Int J Surg Oncol 952345

6. Khuntia D, Brown P, Li J et al (2006) Whole-brain radiotherapy in the management of brain metastasis. J Clin Oncol 24:1295-1304
7. Patchell RA, Tibbs PA, Walsh JW et al (1990) A randomized trial of surgery in the treatment of single metastases to the brain. N Engl J Med 322:494-500

8. Weber DC, Caparrotti F, Laouiti M, Malek K (2011) Simultaneous in-field boost for patients with 1 to 4 brain metastasis/es treated with volumetric modulated arc therapy: a prospective study on qualityof-life. Radiat Oncol 6:79

9. Linskey ME, Andrews DW, Asher AL et al (2010) The role of stereotactic radiosurgery in the management of patients with newly diagnosed brain metastases: a systematic review and evidencebased clinical practice guideline. J Neuro-Oncol 96(1):45-68

10. Gaspar LE, Mehta MP, Patchell RA et al (2010) The role of whole brain radiation therapy in the management of newly diagnosed brain metastases: a systematic review and evidencebased clinical practice guideline. J Neuro-Oncol 96(1):17-32

11. Kalkanis SN, Kondziolka D, Gaspar LE et al (2010) The role of surgical resection in the management of newly diagnosed brain metastases: a systematic review and evidencebased clinical practice guideline. J Neuro-Oncol 96(1):33-43

12. Sahgal A, Aayama H, Kocher M et al (2015) Phase 3 trials of stereotactic radiosurgery with or without whole-brain radiation therapy for 1 to 4 brain metastasis: individual patient data meta-analysis. Int J Radiat Oncol Biol Phys 91(4):710-717

13. Aayoma H, Tago M, Shirato H (2015) Stereotactic radiosurgery with or without upfront whole brain radiation therapy for one to four brain metastases. Secondary analysis of the diagnosis-specific graded prognostic assessment. JAMA Oncol 1(4):457-464

14. Yuan X, Liu WJ, Li B, Shen ZT, Shen JS, Zhu XX (2017) A Bayesian network meta-analysis of whole brain radiotherapy and stereotactic radiotherapy for brain metastasis. Medicine (Baltimore) 96(34):e7698. https://doi.org/10.1097/MD.0000000000007698

15. Chung SY, Chang JH, Kim HR, Cho BC, Lee CG, Suh CO (2017) Optimal dose and volume for postoperative radiotherapy in brain oligometastases from lung cancer: a retrospective study. Radiat Oncol J 35(2):153-162

16. Casanova N, Mazouni Z, Bieri S, Combescure C, Pica A, Weber DC (2010) Whole brain radiotherapy with a conformational external beam radiation boost for lung cancer patients with 1-3 brain metastasis: a multi institutional study. Radiat Oncol 5:13

17. Bruzzaniti V, Abate A, Pedrini M, Benassi M, Strigari L (2011) IsoBED: a tool for automatic calculation of biologically equivalent fractionation schedules in radiotherapy using IMRT with a simultaneous integrated boost (SIB) technique. J Exp Clin Cancer Res 30: 52

18. Borghetti P, Pedretti S, Spiazzi L, Avitabile R, Urpis M, Foscarini F, Tesini G, Trevisan F, Ghirardelli P, Pandini SA, Triggiani L, Magrini SM, Buglione M (2016) Whole brain radiotherapy with adjuvant or concomitant boost in brain metastasis:dosimetric comparison between helical and volumetric IMRT technique. Radiat Oncol 11:59. https://doi.org/10.1186/s13014-016-0634-6

19. Hall EJ, Brenner DJ (1993) The radiobiology of radiosurgery: rationale for different treatment regimes for AVMs and malignancies. Int J Radiat Oncol Biol Phys 25:381-385

20. Chao JH, Phillips R, Nickson JJ (1954) Roentgen-ray therapy of cerebral metastases. Cancer 7:682-689

21. Nieder C, Spanne O, Mehta MP, Grosu AL, Geinitz H (2011) Presentation, patterns of care, and survival in patients with brain metastases: what has changed in the last 20 years? Cancer 117(11): 2505-2512

22. Kocher M, Soffietti R, Abacioglu U et al (2011) Adjuvant wholebrain radiotherapy versus observation after radiosurgery or surgical resection of one to three cerebral metastases: results of the EORTC 22952-26001 study. J Clin Oncol 29(2):134-141

23. Tsao MN (2015) Brain metastases: advances over the decades. Ann Palliat Med 4(4):225-232 
24. Andrews DW, Scott CB, Sperduto PW et al (2004) Whole brain radiation therapy with or without stereotactic radiosurgery boost for patients with one to three brain metastases: phase III results of the RTOG 9508 randomised trial. Lancet 363:1665-1672

25. Kondziolka D, Patel A, Lunsford LD, Kassam A, Flickinger JC (1999) Stereotactic radiosurgery plus whole brain radiotherapy versus radiotherapy alone for patients with multiple brain metastases. Int J Radiat Oncol Biol Phys 45:427-434

26. Aoyama H, Shirato H, Tago M et al (2006) Stereotactic radiosurgery plus whole-brain radiation therapy vs stereotactic radiosurgery alone for treatment of brain metastases: a randomized controlled trial. JAMA 295:2483-2491

27. Kocher M, Soffietti R, Abacioglu U et al (2011) Adjuvant wholebrain radiotherapy versus observation after radiosurgery or surgical resection of one to three cerebral metastases: results of the EORTC 22952-26001 study. J Clin Oncol 29:134-141

28. Buglione M, Pedretti S, Gipponi S et al (2015) The treatment of patients with 1-3 brain metastases: is there a place for whole brain radiotherapy alone, yet? A retrospective analysis. Radiol Med 120(12):1146-1152

29. Brown PD, Asher AL, Ballman KV et al (2015) NCCTG N0574 (Alliance): A phase III randomized trial of whole brain radiation therapy (WBRT) in addition to radiosurgery (SRS) in patients with 1 to 3 brain metastases. J Clin Oncol 33(15 suppl):LBA4

30. Meyers CA, Smith JA, Bezjak A et al (2004) Neurocognitive function and progression in patients with brain metastases treated with whole-brain radiation and motexafin gadolinium: results of a randomized phase III trial. J Clin Oncol 22:157-165

31. Weiss SE, Kelly PJ (2010) Neurocognitive function after WBRT plus SRS or SRS alone. Lancet Oncol 11:220-221

32. Soffietti R, Kocher M, Abacioglu UM et al (2013) A European Organisation for Research and Treatment of Cancer phase III trial of adjuvant whole-brain radiotherapy versus observation in patients with one to three brain metastases from solid tumors after surgical resection or radiosurgery: quality-of-life results. J Clin Oncol 31: 65-72

33. Tsao M, Xu W, Sahgal A (2012) A meta-analysis evaluating stereotactic radiosurgery, whole-brain radiotherapy, or both for patients presenting with a limited number of brain metastases. Cancer 118:2486-2493

34. Soliman H, Das S, Larson DA, Sahgal A (2016) Stereotactic radiosurgery (SRS) in the modern management of patients with brain metastases. Oncotarget 7(11):12318-12330
35. Mehta M (2015) The controversy surrounding the use of wholebrain radiotherapy in brain metastases patients. Neuro-Oncology 17(7):919-923

36. Dye NB, Gondi V, Mehta MP (2015) Strategies for preservation of memory function in patients with brain metastases. Chin Clin Oncol 4(2):24

37. Brown PD, Pugh S, Laack NN et al (2013) Memantine for the prevention of cognitive dysfunction in patients receiving wholebrain radiotherapy: a randomized, double-blind, placebocontrolled trial. Neuro-Oncology 15(10):1429-1437

38. Filley CM, Kleinschmidt-DeMasters BK (2001) Toxic leukoencephalopathy. N Engl J Med 345:425-432

39. Arriagada R, Le Chevalier T, Borie F et al (1995) Prophylactic cranial irradiation for patients with small-cell lung cancer in complete remission. J Natl Cancer Inst 87:183-190

40. Komaki R, Meyers CA, Shin DM et al (1995) Evaluation of cognitive function in patients with limited small cell lung cancer prior to and shortly following prophylactic cranial irradiation. Int J Radiat Oncol Biol Phys 33:179-182

41. Tiwari V, Pande SC, Verma K, Goel S (2015) Simultaneous integrated boost with intensity modulated radiation therapy in brain oligometastases: a feasible technique for developing countries. South Asian J Cancer 4(1):11-14

42. Rodrigues G, Zindler J, Warner A, Bauman G, Senan S, Lagerwaard F (2013) Propensity-score matched pair comparison of whole brain with simultaneous in-field boost radiotherapy and stereotactic radiosurgery. Radiother Oncol 106(2):206-209

43. Patchell RA, Tibbs PA, Regine WF et al (1998) Postoperative radiotherapy in the treatment of single metastases to the brain: a randomized trial. JAMA 280(17):1485-1489

44. Wang TJ, Saad S, Qureshi YH et al (2015) Outcomes of gamma knife radiosurgery, bi-modality \&amp; tri-modality treatment regimens for patients with one or multiple brain metastases: the Columbia University Medical Center experience. J Neuro-Oncol 122(2):399-408

45. Lin NU, Lee EQ, Aoyama $\mathrm{H}$ et al (2013) Challenges relating to solid tumour brain metastases in clinical trials, part 1: patient population, response, and progression. A report from the RANO group. Lancet Oncol 14:e396-e406

46. Lin NU, Wefel JS, Lee EQ et al (2013) Challenges relating to solid tumour brain metastases in clinical trials, part 2: neurocognitive, neurological, and quality-of-life outcomes. A report from the RANO group. Lancet Oncol 14:e407-e416 
II 


\title{
Low Fraction Size Re-irradiation for Large Volume Recurrence of Glial Tumours
}

\author{
Ágnes Dobi ${ }^{1}$ - Barbara Darázs ${ }^{1} \cdot$ Emese Fodor $^{1} \cdot$ Adrienne Cserháti $^{1} \cdot$ Zsófia Együd $^{1} \cdot$ Anikó Maráz $^{1} \cdot$ Szilvia László $^{1}$. \\ Leopold Dodd ${ }^{1} \cdot$ Zita Reisz $^{2} \cdot$ Pál Barzó $^{3} \cdot$ Judit Oláh $^{1} \cdot$ Katalin Hideghéty ${ }^{1}$
}

Received: 29 April 2020 / Accepted: 30 June 2020 / Published online: 9 July 2020

(C) The Author(s) 2020

\begin{abstract}
The aim of the present study was to evaluate the efficacy of re-irradiation (re-RT) in patients with advanced local relapses of glial tumours and to define the factors influencing the result of the hyper-fractionated external beam therapy on progression after primary management. We have analysed the data of 55 patients with brain tumours (GBM: 28) on progression, who were reirradiated between January 2007 and December 2018. The mean volume of the recurrent tumour was $118 \mathrm{~cm}^{3}$, and the mean planning target volume (PTV) was $316 \mathrm{~cm}^{3}$, to which $32 \mathrm{~Gy}$ was delivered in 20 fractions at least 7.7 months after the first radiotherapy, using 3D conformal radiotherapy (CRT) or intensity modulated radiotherapy (IMRT). The median overall survival (mOS) from the re-RT was 8.4 months, and the 6-month and the 12-month OS rate was 64\% and 31\%, respectively. The most important factors by univariate analysis, which significantly improved the outcome of re-RT were the longer time interval between the diagnosis and second radiotherapy $(p=0.029)$, the lower histology grade $(p=0.034)$, volume of the recurrent tumour $(p=0.006)$ and Karnofsky performance status (KPS) $(p=0.009)$ at the re-irradiation. Our low fraction size re-irradiation $\geq 8$ months after the first radiotherapy proved to be safe and beneficial for patients with large volume recurrent glial tumours.
\end{abstract}

Keywords Re-irradiation $\cdot$ Multiform glioblastoma $\cdot$ Glioma

\section{Introduction}

Gliomas, with incidence of 5/100 000 in adults, are the most common primary central nervous system malignancies, peaking between the fifth and sixth decades of life [1]. After initial multimodal treatment, at least $70 \%$ recurrence rate of gliomas can be expected [2-4]. By surgical therapy alone, the disease has a very poor prognosis (median survival 4-6 months [5], whereas surgery accompanied by radiotherapy (RT) ameliorates the median survival data to 8-9 months. Together with concomitant and sequential TMZ, better median survival values can be expected,

Ágnes Dobi

dobiagnes@gmail.com

1 Department of Oncotherapy, University of Szeged, Korányi fasor 12, Szeged H-6720, Hungary

2 Department of Pathology, University of Szeged, Állomás utca 1, Szeged H-6725, Hungary

3 Department of Neurosurgery, University of Szeged, Semmelweis utca 6, Szeged H-6725, Hungary such as 15 months for glioblastomas, or even 2-5 years for anaplastic gliomas [6].

In the case of recurrence with its considerable limitations, and only if it is possible, surgical treatment has the highest efficacy [7]. In certain good performance status patients with good anatomical access to tumours, surgery is applicable, but the resection outcome could be definitely limited by considerable infiltration of nervous tissue and by higher morbidity risk [8,9]. As for other low grade and grade 3 cases, temozolamide (TMZ) is the treatment of choice, if it was not administered during the initial management. Thereafter and for GBM second-line systemic treatment (such as chemo- or biological therapy) and re-irradiation is optional, in the lack of standardised treatment for recurrent gliomas [10]. Recently, Tumour Treating Field (TTF), a novel therapeutic option emerged prolonging the survival with further 6 months [1]. For systemic treatment, monoclonal antibody (bevacizumab), chemotherapy (nitrosurea, lomustine, dose dense TMZ [9], immune checkpoint blockade (nivolumab, pembrolizumab) [11], or even vaccines (DCVax) [12-14] are options to consider. For recurrent tumours, salvage re-irradiation could be selected. The typical re-irradiation techniques and strategies 
for recurrent gliomas are conventionally fractionated RT, brachytherapy, hypofractionated stereotactic radiosurgery (FSRT), stereotactic radiosurgery (SRS) alone, or combination treatment with RT and systemic therapy, and palliative RT $[15,16]$.

On reviewing several clinical trials, the 6- and 12-month overall survival (OS-6 and OS-12), calculated from the time of re-irradiation, were $73 \%$ and $36 \%$, respectively, whereas the 6- and 12-month of progression free survival (PFS-6 and PFS12) were $43 \%$ and $17 \%$, respectively [17]. Median OS (mOS) was 7.4-12.7 months in other studies [18-22].

\section{Materials and Methods}

Between 2007 and 2018, at the Department of Oncotherapy, altogether 55 patients with recurrent glial tumours were subjected to re-irradiation. The present study has been carried out in accordance with The Code of Ethics of the World Medical Association (Declaration of Helsinki) for experiments involving humans. Informed consent was obtained from the patients at their first clinical admission for the anonymised use of their patient data for research purposes. According to Sect. 20/Q of No. 23/2002 Decree of the Ministry of Health, Hungary, the present study is considered as a non-interventional clinical study. The whole present study was carried out according to the ethical permission No. 4209/2018-SZTE, issued by the Ethical Committee of our University. The treatment schemes were thoroughly discussed with every single patient, independently from their actual performance status. The re-irradiation was agreed by signed informed consent. The initial care consisted of surgery in each case. The patients with grade 2 and grade 3 brain tumours received radiotherapy only postoperatively and for GBM we applied adjuvant chemoradiation therapy followed by temozolamide monotherapy up to progression. Magnetic resonance imaging (MRI) were performed three monthly. Disease progression was defined by two independent experts. At the time of diagnosis, the tumour grading was based on histological assessment. At the time of re-RT, histological evaluation was performed only in the re-operated cases, in the case of the remaining patients (without re-operation), the grading was based on clinical and radiological evaluation. The re-irradiation volume was defined on the basis of planning CT (computed tomography) and MRI fusion. Patients were immobilised with a 3-point thermoplastic mask (ORFIT Industries, NL). The planning target volume encompassed the GTV (gross tumour volume) plus $0.3-1 \mathrm{~cm}$ margin. The shapes of the recurrent tumours were frequently highly irregular, sometimes with multiple manifestations, and with spread to the contralateral hemisphere through the corpus callosum; or spreading along the wall of the previous surgical cavity and/or ventricle wall, resulting in larger PTV (planning target volume). The normal structures were contoured including the lens, optic chiasm, optic nerve, brain, and brainstem. Treatment planning was performed with Eclipse (version 5, Varian Medical Systems, Palo Alto, USA). The re-RT dose was 32 Gy in 1.6 Gy daily fractions in all cases, in order to avoid serious neurotoxicity. Dependent on the location and extent of the recurrent glioma, 3 DCRT or IMRT or VMAT (Rapid Arch) therapy-plans (VMAT) were generated according to the ICRU (International Commission on Radiation Units \& Measurements, Inc.) 52 recommendation. [23].

During brain irradiation, patients received $12 \mathrm{mg}$ methylprednisolone for prevention of brain oedema, with gradually decreased dosing after radiotherapy. The dose of methylprednisolone was adjusted according to the symptoms of intracranial pressure elevation due to brain oedema. The majority of the patients ( 32 over 23 ) received bevacizumab therapy after the re-RT, and these patients were controlled in a biweekly fashion, with physical examination up to progression and 3-months intervals MRIs were performed, whereas for the remaining group without bevacizumab treatment after re-RT, the check-ups were scheduled in 4-6 weeks. Two experts evaluated the images according to the RANO HGG (Response Assessment in Neuro-Oncology High-grade glioma) criteria [24]. We included all patients with a recurrent glial tumour who completed the 32 Gy re-irradiation in 20 fractions to the present analysis. We assessed retrospectively the overall survival (OS) from the diagnosis, and from the first day of the re-irradiation according to the, age, Karnofsky performance score (KPS), primary tumour grade and histopathology type, the type of the primary tumour removal, size of GTV, size of PTV, time interval between two irradiations, time elapsed between diagnosis and 2nd RT, second line bevacizumab treatment. The data were evaluated by KaplanMeier statistical analysis with IBM SPSS Statistics for Windows, Version 20.0 (Armonk, NY: IBM Corp.) p value $<0.05$ was considered as statistically significant. COX regression was used for univariate, as well as multivariate analysis. Factors with significance in univariate analysis were included into a multivariate analysis. After the re-irradiation we recorded the KPS, Mini Mental Score (MMS) and daily activity in every visit.

\section{Results}

\subsection{Patient Characteristics}

Table 1 summarises the patient characteristics. The mean age of the population at the time of the primary diagnosis detection was 39 years (range: $11-71$ years); $49 \%$ of them was male and $51 \%$ female. The mean age at the time of the re-irradiation was 42 years (range: $13-72$ years). The KPS was in $40 \%$ of this population over $70 \%$. At the beginning of the reirradiation, 
Table 1 Summary of the patient characteristics

\begin{tabular}{ll}
\hline Variables & No. of the patients \\
\hline Number of the patients & 55 \\
Sex & \\
Male & 27 \\
Female & 28 \\
KPS & \\
$>70 \%$ & 22 \\
$\leq 70 \%$ & 33 \\
Primary histopathology type & \\
astrocytoma grade 2 & 15 \\
oligodendroglioma grade 3 & 6 \\
anaplastic astrocytoma grade 3 & 6 \\
glioblastoma multiforme & 28 \\
Salvage surgery & 23 \\
Prior temozolomid treatment & 55 \\
MGMT methylation status & \\
methylated & 18 \\
unmethylated & 9 \\
unknown & 28 \\
\hline
\end{tabular}

majority of the patients had minor neurological symptoms, such as hemiparesis, facial paresis, focal seizure partly controlled by antiepileptic medication, more frequently motor and sensory aphasia. Besides these symptoms, the patients preserved the ability of self-caring, except 5 patients with serious paresis needing regular help in their daily life. Out of 23 cases with repeated surgery, only four initially grade 2-3 tumours showed malignant transformation to grade $3-4$. In the majority of the cases, though, reoperation took place relatively early during the course of the disease. Usually in the case of initially low grade tumours, surgery was performed prior to the first oncological management; and also grade 3 tumours were as well as re-operated some years prior to reirradiation. In $84 \%$ of the cases, based on the clinical behaviour of the tumour, their malignant transformation was highly probable at the time of reirradiation, but no regular biopsy was performed in order to confirm it. The average time interval between the diagnosis and re-irradiation was 47.4 months (range: $7.3-228$ months) first and the re-irradiation was 36 months (range: 7.7232 months) respectively. All patients received first-line systemic temozolomide treatment, either as part of initial postoperative management (GBM), or at the first relapse. 23 patients were treated with bevacizumab monotherapy, as second-line treatment. The re-irradiation was performed after the first-line systemic treatment in 45 cases, and after second-line therapy in 10 cases. The primary histological type was grade 2 astrocytoma in 15 cases, grade 3 glial tumour (anaplastic astrocytoma or oligodendroglioma) in 12 cases, and glioblastoma multiforme (GBM) in 28 cases. MGMT (O-6-
methylguanine-DNA methyltransferase) methylation status was known in 26 cases. 16 patients were methylated, 9 patients borderline methylated and in one case MGMT was nonmethylated.

\subsection{Survival Analysis}

Median survival was altogether 42.6 months, as calculated from the date of the first diagnosis. The Table 2 shows the survival data. Regarding histology, cases with lower, grade 2 malignancies had the most favourable survival values (111.0 months), whereas this value was 23 months $(\mathrm{p}<0.001)$ in cases with GBM. We found a strong correlation to histological type: grade 2 astrocytoma cases had the longest survival (114.8 months), whereas the worst survival was detected of grade 4 cases $(30.7$ months; $\mathrm{p} \leq 0.001)$.

The most important factors significantly influencing the outcome of re-RT were the time interval between the first and second radiotherapy, histology grade, GTV, and KPS at the re-irradiation.

\subsection{Survival from the Beginning of Re-irradiation}

The mOS from the re-RT of the entire cohort was 8.4 months; 6 patients survived more than 10 months and 2 patients more than 2 years. The 6-month and the 12 -month OS rate was $64 \%$ and $31 \%$ respectively.

The mean volume of GTV, as contoured during Re-RT, was $118.0 \mathrm{~cm}^{3}$ (range: $4.5-304 \mathrm{~cm}^{3}$ ). Patients with lesser than average GTV at re-RT had 12.9 months, patients with greater than average GTV at re-RT had 5.5 month of median survival $(\mathrm{p}=0.006)$ (Fig. 1).

Patients with KPS $>70 \%$ at the beginning of re-RT had significantly better survival values (10.4 months, $p=0.009)$, than those ones with poorer general conditions (5.6 months) (Fig. 2).

Comparing time interval (between diagnosis and second radiotherapy, reRT) with OS on univariate analysis, patients with an interval of more than 47 months from 1 st to the 2 nd course of RT (mOS 10.2 vs. 6.7 months, hazard ratio (HR) $0.99,95 \%$ confidence interval (CI) $\mathrm{p}=0.029$. (Fig. 3).

Median survival, as calculated from re-irradiation for the entire group was 9.0 months. According to histopathology GBM: 6.0 months, grade $2+3$ malignancies 10.0 months; $\mathrm{p}=0.031$.

These factors proved to be significant for OS from re-RT in cox-regression univariate analysis. In multivariate analysis, the smaller GTV and better KPS remained significant influencing factors.

In the present study, no significant interrelation was found between OS and age at re-RT, size of PTV, type of primary surgical intervention, or whether the second-line bevacizumab therapy preceded or followed the re-irradiation. 
Table 2 Survival data. Significant correlations between investigated factors are highlighted with bold characters

\begin{tabular}{|c|c|c|c|c|}
\hline Variable & $\mathrm{n}$ & OS (months) & $\pm \mathrm{SE}$ & p-value \\
\hline & & from initial di & & \multirow{7}{*}{$\mathrm{p}<0.001$} \\
\hline Entire group & 55 & 42.6 & 2.6 & \\
\hline \multicolumn{5}{|l|}{ initial histopathology type } \\
\hline grade 2 & 15 & 114.8 & 40.2 & \\
\hline grade 3 & 12 & 52.2 & 9.8 & \\
\hline \multirow[t]{2}{*}{ grade 4} & 28 & 30.7 & 1.3 & \\
\hline & & \multicolumn{2}{|l|}{ from re-RT } & \\
\hline entire group & 55 & 8.37 & 1.9 & \\
\hline \multicolumn{5}{|l|}{ histopathology type at re-irradiation } \\
\hline $\operatorname{grade} 2(n=12)+\operatorname{grade} 3(n=14)$ & 26 & 10 & 1.2 & \multirow[t]{2}{*}{$p=0.031$} \\
\hline grade 4 & 29 & 6 & 2 & \\
\hline \multicolumn{5}{|l|}{ GTV re-RT mean $118 \mathrm{~cm}^{3}$} \\
\hline$\leq$ mean & 29 & 12.9 & 3.9 & \multirow[t]{2}{*}{$p=0.006$} \\
\hline$>$ mean & 23 & 5.5 & 0.3 & \\
\hline \multicolumn{5}{|l|}{ KPS at re-RT } \\
\hline$\leq 70 \%$ & 33 & 5.6 & 0.7 & \multirow[t]{2}{*}{$p=0.009$} \\
\hline$>70 \%$ & 22 & 10.4 & 1.9 & \\
\hline \multicolumn{5}{|c|}{ Time between diagnosis (DG) and re-RT } \\
\hline$\leq 47$ months & 18 & 6.7 & & \multirow[t]{2}{*}{$p=0.029$} \\
\hline$>47$ months & 37 & 10.2 & & \\
\hline \multicolumn{5}{|l|}{ PTV re-RT $316 \mathrm{~cm}^{3}$} \\
\hline$\leq$ mean & 33 & 10.1 & 1.5 & \multirow[t]{2}{*}{$\mathrm{p}=0.246$} \\
\hline$>$ mean & 22 & 5.5 & 0.4 & \\
\hline \multicolumn{5}{|l|}{ Age at re-irradiation } \\
\hline$\leq 40$ year & 27 & 8.3 & 2.2 & \multirow[t]{2}{*}{$\mathrm{p}=0.704$} \\
\hline$>40$ year & 28 & 6.6 & 2.7 & \\
\hline \multicolumn{5}{|l|}{ bevacizumab therapy before re-RT } \\
\hline no & 32 & 6.5 & 1.1 & \multirow[t]{2}{*}{$\mathrm{p}=0.35$} \\
\hline yes & 23 & 10.2 & 0.3 & \\
\hline
\end{tabular}

\subsection{Outcome and Toxicity of the Treatment}

Due to the second radiotherapy at progression, amelioration of neurological signs and KPS were experienced in $58 \%$ of our patients. Control radiological imaging detected stable disease or partial remission in 44 cases.

In the majority of the cases, the prophylactic dose and escalated dose on demand of the methyl-prednisolone prevented the development of serious brain oedema and the consequent intracranial pressure elevation. We did not see any radiation necrosis on the follow up MRIs and no major cognitive deficit was associated to the re-RT assessed with MMS.

\section{Discussion}

In the past, re-irradiation for recurrent malignant gliomas was considered with great reluctance due to the high risk of radiation necrosis. In the recent decades after implementation of advanced RT techniques, several retrospective analyses, reviews, as well a prospective study and meta-analysis were published proving that re-irradiation is useful treatment option for recurrent brain tumours [16, 17, 25, 26].

The present work represents the establishment of a careful, consequent re-RT approach with low fraction size to avoid radiation sequelae using standardised target volume and dose definition even for large volume recurrences. Selected studies on SRS for small volume recurrences of median 6.2 to $28.0 \mathrm{~cm}^{3}$ [27-29] showed an improvement on median survival ranging from 5.3 to 13.0 months with associated radionecrosis of $0-31.3 \%$. Others have reported their results for recurrent GBM volumes of median 7-50 $\mathrm{cm}^{3}$ applying FSRT resulted in median survival within the range of 6.5-11 months [26, 30-32]. In contrast to these small target volumes for re-RT with SRS techniques, lower doses to larger volumes could be applied safely with acceptable efficacy, which was confirmed by the first meta-analysis on re-irradiation published by Kazmi et al. [17]. However, highly divergent 


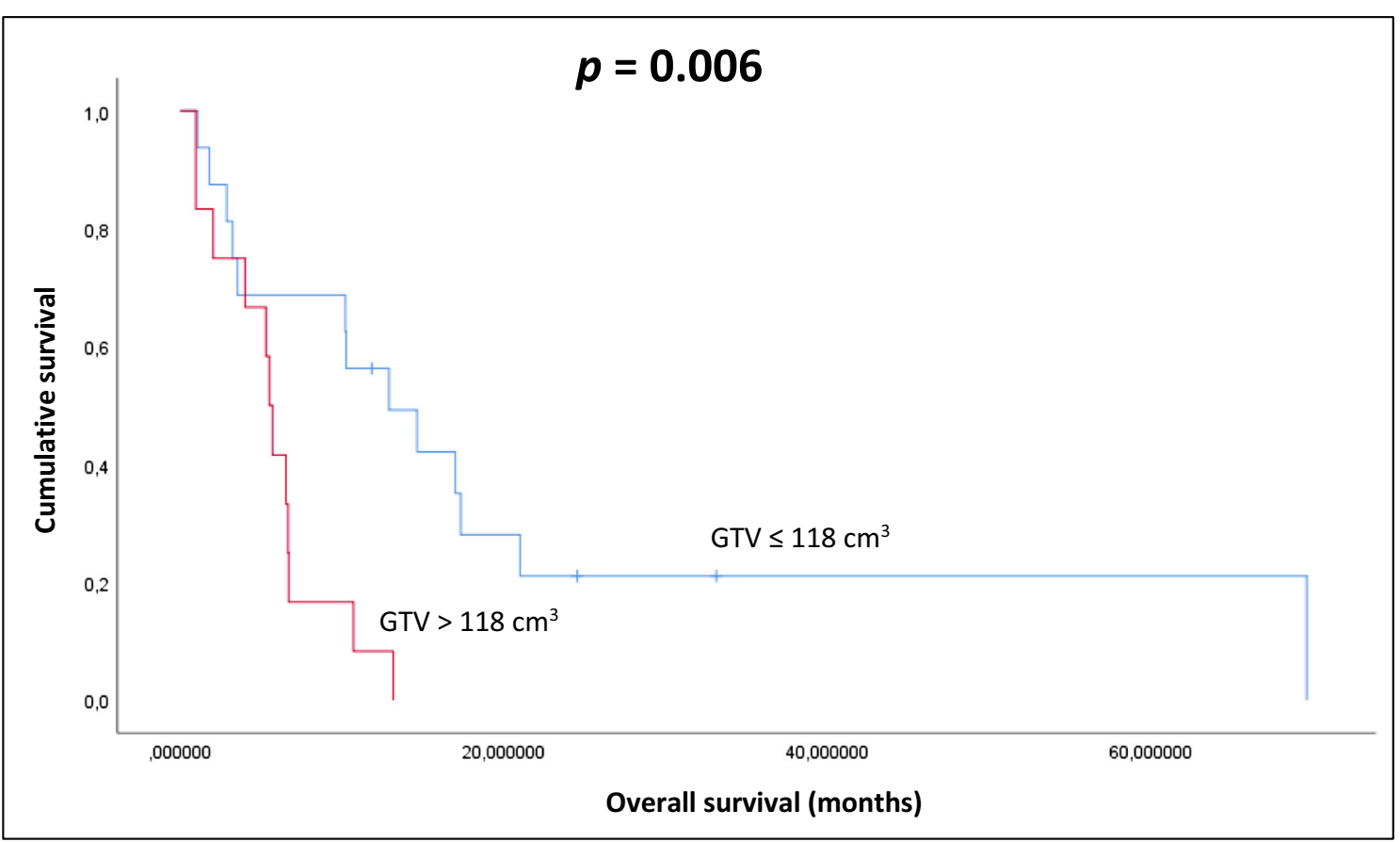

Fig. 1 Kaplan-Meier plot of the correlation between GTV-re-irradiation and OS ( $p=0.006)$

fractionation schemes and target volume concepts are applied with heterogeneous median survival times between 5 and 18 months. Krauze et al. reported a mOS of 6 months after reirradiation of recurrent glioma with median 30 Gy [33]. Another recent study revealed that OS after salvage SRS or hypofractionated RT (HFRT) does not significantly $(\mathrm{p}=0.06)$ differs from that after conventionally fractionated re-RT, and the trend towards better OS probably related to smaller target volume [34]. Analysis in a retrospective review has not shown any differences in OS after stereotactic or conventionally fractionated re-RT [35]. The similar outcome (mOS of 9.7 months) using conventional-, hypofractionated or SRS techniques was confirmed by another retrospective analysis of reRT for recurrent malignant glioma [36]. The 9-month mOS with re-RT achieved in our patients with GTV median of $118 \mathrm{~cm}^{3}$ falls within the range of previously reported series

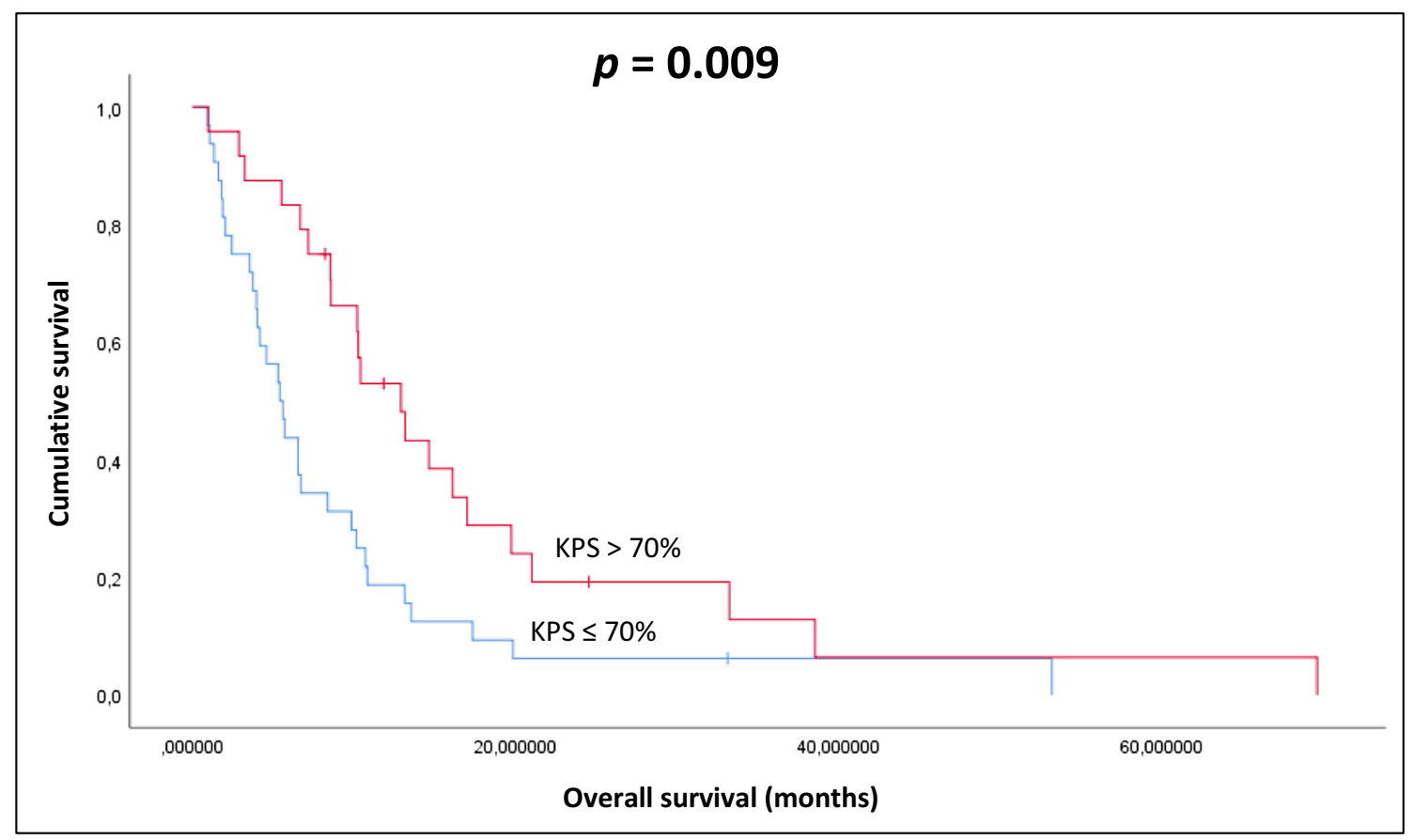

Fig. 2 Kaplan-Meier plot of the correlation between KPS and OS ( $\mathrm{p}=0.009)$ 


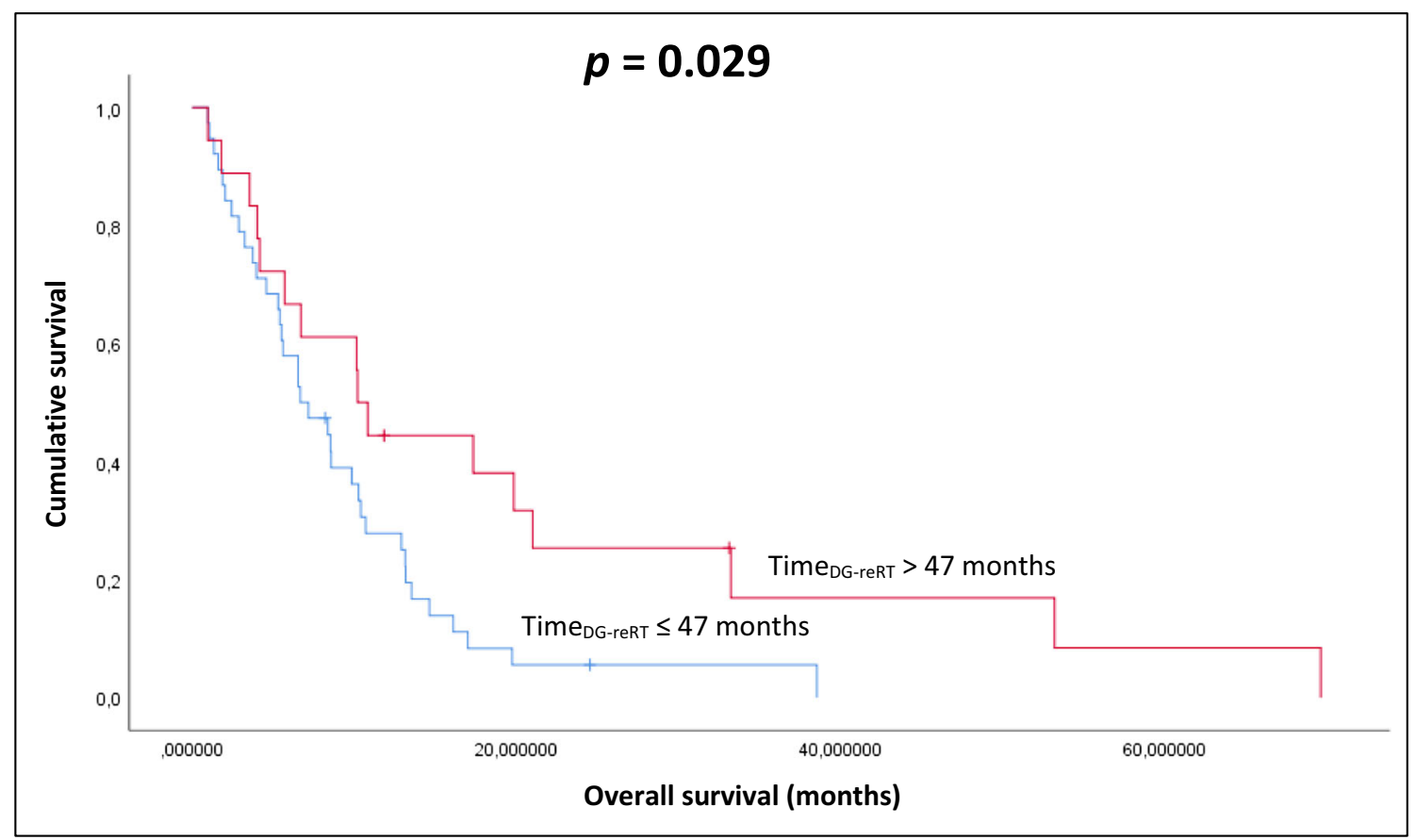

Fig. 3 Kaplan-Meier plot of the correlation between time (DG-reRT) and OS (DG=diagnosis; $\mathrm{p}=0.029$ )

$[17,25,32]$. There are only very few prospective reports on the efficacy of re-RT. Shi and colleagues recently published the late results from RTOG 0525 trial [37]. Patients received BSC only had an mOS of 4.8 months versus the groups treated with re-RT only, chemotherapy only or radiochemotherapy, $8.2,10.5,11.3$ months, respectively [37]. It should be noted that in this study OS was calculated from the first progression and not from the beginning of re-RT, as it is in our present study. Well-defined prognostic factors are established for glial tumours; however, the factors influencing the outcome of reRT are less known. Different factors are considered to influence the efficacy of the survival after re-RT, such as age, performance status, histological grading and the length of the interval between the 1st and the 2nd course of RT [38, 39]. A recent meta-analysis and appraisal summarizes the radiation parameters and outcomes of fractionated re-RT from studies published from 1999 to 2018 [17, 40]. The re-RT was delivered at a median time interval of 12 months (range: 3.5 to 19 months) with dose of 24 to 36 Gy with a daily fractional size of 1.8 to $6 \mathrm{~Gy}$. In our case, $>7$ months passed after the 1 st RT and we applied 1.6 Gy fraction size. The 8.4 months OS of our group is comparable to previous studies, reporting the mOS from re-RT 7.5 to 11 months.

The evaluation of the clinical data in different series of reRT revealed important factors, which may improve the survival, such as KPS $>70 \%$, age $<50$ years, interval $>$ 12 months between the first RT and re-RT, target volume $<$ 20-30 $\mathrm{cm}^{3}$, radiation dose $>30-35 \mathrm{~Gy}$.

In our study, significant predictors for a longer survival after re-RT were the better performance status at re-RT, the longer interval from 1st line treatment to re-RT and lower tumour grade both at diagnosis and at re-RT. The age at reRT proved not to be a prognostic factor, however, the mean age was below 40 years. The tumour size (i.e. GTV) was one of the most significant factors for the prognosis of our patients, whilst the PTV exhibited no significant relationship to the OS. Recurrent tumour volume remained the strongest factor in multivariate analysis $(p=0.038)$. The importance of the interval-factor is in line with former reports of re-RT. It can be assumed that the time of the first relapses after the primary treatment is an indicator of the biological behaviour of the tumour [25, 38, 39]. In our patient group, the median survival according to the histopathological grade was higher than in other reported studies (the median survival is around 5560 months for grade 2 and 18-26 months for grade $3 \mathrm{tu}-$ mours). [41]. It could be explained with the natural patient selection and the younger age (inclusion of paediatric patients).

In our cases, re-challenge of temosolomide was never applied, hence the primary monotherapy part was not limited in time, it was administered up to progression. Therefore, the MGMT promoter hypermethylation had less importance, because the re-irradiation was delivered when all patients developed resistance to TMZ. The MGMT status defined at the initial diagnosis was available for 27 cases, obviously with no significance on survival after re-RT. Other recent proven biological factors, such as ATRX and IDH- mutation were only partially available in our patient group.

Therefore this report is limited by the lack of detailed molecular analysis as well as by the retrospective methodology 
which could result in a selection bias as well as an underreporting of low-grade toxicities. However, the selection bias could be reduced by the homogenous treatment concept for our cohort of patients. Nevertheless, comparison to BSCseries remains to be difficult, and conclusions about survival benefits due to intervention should be drawn with caution. Furthermore, due to the still short survival after re-irradiation, objective long-term responses after re-RT were not possible to assess for all patients.

Due to the therapy, amelioration of neurological signs and KPS were experienced in $58 \%$ of our patients. Control radiological imaging detected stable disease or partial remission in 44 cases $(78.6 \%)$.

Although standards of salvage therapy are not yet defined for recurrent glial tumours, mainly due to paucity of highlevel prospective or randomized controlled studies, re-RT of various technique is an established salvage option for selected patients [42].

\section{Conclusion}

Smaller recurrent tumour size, better PS, longer interval from 1st line treatment to re-RT and lower tumour grade predict better outcome from re-RT. No radiation-associated serious adverse events were observed and the re-RT improved the performance status and neurologic symptoms in the majority of the cases. Re-irradiation with low fraction size in large volume recurrent gliomas proved to be safe and seems to be clinically beneficial in selected patient group.

Author contributions The contributions of the authors to the present study are as follows: (1) the conception and design of the study (Á.D., K.H.), (2) examination, therapy plans and follow-up of the patients (Á.D., Zs.E., A.M., K.H.), (4) radiological assessments (A.Cs.), (5) histopathological diagnostics (Z.R.), (6) neurosurgical treatment (P.B.), (7) radiotherapy planning physicist (E.F.), (8) collection and acquisition of data (Sz.L, L.D., Á.D.), (9) statistical analysis of data (B.D.), (10) interpretation of data (Á.D., K.H.), (11) drafting the article (Á.D., K.H), (12) revising it critically for important intellectual content (J.O., K.H.).

Funding Information Open access funding provided by University of Szeged. The authors confirm independence from the sponsors; the content of the article has not been influenced by the sponsors.

\section{Compliance with Ethical Standards}

Conflict of Interest The authors declare that they have no conflict of interest.

Open Access This article is licensed under a Creative Commons Attribution 4.0 International License, which permits use, sharing, adaptation, distribution and reproduction in any medium or format, as long as you give appropriate credit to the original author(s) and the source, provide a link to the Creative Commons licence, and indicate if changes were made. The images or other third party material in this article are included in the article's Creative Commons licence, unless indicated otherwise in a credit line to the material. If material is not included in the article's Creative Commons licence and your intended use is not permitted by statutory regulation or exceeds the permitted use, you will need to obtain permission directly from the copyright holder. To view a copy of this licence, visit http://creativecommons.org/licenses/by/4.0/.

\section{References}

1. Stupp R, Tonn J-C, Brada M, Pentheroudakis G (2010) High-grade malignant glioma: ESMO Clinical Practice Guidelines for diagnosis, treatment and follow-up. Annal of Oncology 21:v190-v193. https://doi.org/10.1093/annonc/mdq187

2. Dolocek TA, Propp JM, Stroup NE et al (2012) CBTRUS statistical report: primary brain and central nervous system tumors diagnosed in the United States in 2005-2009. Neuro Oncol 14(Suppl 5):1-49

3. Wem PY, Kesari S (2008) Malignant gliomas in adults. New England Med 359:492-507

4. Sherriff J, Tamangani J, Senthil L, Cruickshank G, Spooner D, Jones B et al (2013) Patterns of relapse in glioblastoma multiforme following concomitant chemoradiotherapy with temozolomide. $\mathrm{Br}$ J Radiol 86:20120414

5. Pichlmeier U, Bink A, Schackert G et al (2008) Resection and survival in glioblastoma multiforme: an RTOG recursive partitioning analysis of ALA study patients. Neuro Oncology 10: $1025-1034$

6. Studio R, Hegi ME, Mason WP et al (2009) Effects of radiotherapy with concomitant and adjuvant temozolomide versus radiotherapy alone on survival in glioblastoma in a randomised phase III study: 5 year analysis of the EORTC-NCIC trial. Lancet Oncol 10:459-466

7. Dirks P, Bernstein M, Muller PJ, Tucker WS (1993) The value of re-operation for recurrent glioblastoma. Can J Surg 36:271-275

8. Barbagallo GM, Jenkinson MD, Brodbelt AR (2008) "Recurrent" glioblastoma multiforme, when should we reoperate? Br J Neurosurg 22:452-455

9. Perry JR et al (2010) Phase II trial of continuous dose-intense temozolomide in recurrent malignant glioma: RESCUE study. Clin Oncol 28(12):2051-2057

10. Meryem Aktan M, Koc, Gul Kanyilmaz (2015) Survival following re-irradiation using intensity-modulated radiaton therapy with temozolomide in selected patients with recurrent high grade gliomas. Ann Transl Med 3(20):304. https://doi.org/10.3978/j.issn.23055839.2015.11.29

11. Wang 13X, Guo G, Guan H, Yu Y, Lu J, Jinming Yu (2019) Challenges and potential of PD-1/PD-L1checkpoint blockade immunotherapy for glioblastoma. J Exp Clin Cancer Res 38:87. https://doi.org/10.1186/s13046-019-1085-3

12. Phuphanich S, Wheeler CJ, Rudnick JD, Mazer M, Wang H, Nuño MA et al (2013) Phase I trial of a multi-epitope-pulsed dendritic cell vaccine for patients with newly diagnosed glioblastoma. Cancer Immunol Immunother 62:125-135

13. Liau LM, Ashkan K, Tran DD, Campian JL, Trusheim JE, Cobbs CS et al (2018) First results on survival from a large Phase 3 clinical trial of an autologous dendritic cell vaccine in newly diagnosed glioblastoma. J Transl Med 16:142

14. Jain KK (2018) Critical overview of targeted therapies for glioblastoma. Front Oncol 8:419

15. Taunk NK, Moraes FY, Escorcia FE, Mendez LC, Beal K, Marta GN (2016) External beam re-irradiation, combination chemoradiotherapy, and particle therapy for the treatment of recurrent glioblastoma. Expert Rev Anticancer Ther 16(3):347-358 
16. Amichetti M, Amelio D (2011) A Review of the role of the Reirradiation in recurrent high-grade glioma (HGG). Cancers (Basel) 3:4061-4089

17. Kazmi F, Soon YY, Leong Y, Koh WY, Vellayappan B (2018) Reirradiation for recurrent glioblastoma (GBM) a systematic review and meta-analyis. Journal of Neuro-Oncology 142(1):79-90

18. Minniti G, Scaringi C, De Sanctis V, Lanzetta G, Falco T, Di Stefano D et al (2013) Hypofractionated stereotactic radiotherapy and continuous low- dose temozolomide in patients with recurrent or progressive malignant gliomas. J Neurooncol 111:187-194

19. Grosu AL, Weber WA, Franz M, Stärk S, Piert M, Thamm R et al (2005) Re-irradiation of recurrent high- grade gliomas using amino acid PET (SPECT)/CT/MRI image fusion to determine gross tumor volume for stereotactic fractionated radiotherapy. Int J Radiat Oncol Biol Phys 63:511-519.24

20. Ernst-Stecken A, Ganslandt O, Lambrecht U, Sauer R, Grabenbauer G (2007) Survival and quality of life after hypofractionated stereotactic radiotherapy for recurrent malignant glioma. J Neurooncol 81:287-294.25

21. Wuthrick EJ, Curran WJ, Camphausen K, Lin A, Glass J, Evans J et al (2014) A pilot study of hypofractionated stereotactic radiation therapy and sunitinib in previously irradiated patients with recurrent high- grade glioma. Int J Radiat Oncol Biol Phys 90:369-375.26

22. Patel M, Siddiqui F, Jin J-Y, Mikkelsen T, Rosenblum M, Movsas $\mathrm{B}$ et al (2009) Salvage re-irradiation for recurrent glioblastoma with radiosurgery: radiographic response and improved survival. J Neurooncol 92:185-191

23. Bratengeier K, Oechsner M, Gainey M, Flentje M (2009) Remarks on reporting and recording consistent with the ICRU reference dose. Radiat Oncol 4:44. https://doi.org/10.1186/1748-717X-4-44

24. Lin NU, Lee EQ et al (2015) Response assessment criteria for brain metastases: proposal from the RANO group. Lancet Oncology 16: e270-e278

25. Straube C, Elpula G, Gempt J, Gerhardt J, Bette S, Zimmer C, Schmidt-Graf F, Meyer B, Combs SE (2017) Re-irradiation after gross total resection of recurrent glioblastoma. Strahlenther Onkol. https://doi.org/10.1007/s00066-017-1161-6

26. Fokas E, Wacker U, Gross MW, Henzel M, Encheva E, EngenhartCabillic R (2009) Hypofractionated stereotactic re-irradiation of recurrent glioblastomas. Strahlenther Onkol 185:235-240. https:// doi.org/10.1007/s00066-009-1753-x

27. Niyazi M, Siefert A, Schwarz SB et al (2011) Therapeutic options for recurrent malignant glioma. Radiother Oncol 98:1-14

28. Amelio D, Amichetti M (2012) Radiation therapy for the treatment of recurrent glioblastoma: an overview. Cancers (Basel) 4:257-280

29. Redmond KJ, Mehta M (2015) Stereotactic radiosurgery for glioblastoma. Cureus 7:e413

30. Fogh SE, Andrews DW, Glass J et al (2010) Hypofractionated stereotactic radiation therapy: an effective therapy for recurrent high-grade gliomas. J Clin Oncol 28:3048-3053

31. Chatzikonstantinou G, Zamboglou N, Archavlis E, Strouthos I, Zoga E, Milickovic N, Hilaris B, Baltas D, Rödel C, Tselis N. (2018) CT-guided interstitial HDR-brachytherapy for recurrent glioblastoma multiforme: a 20 -year single-institute experience
Strahlenther Onkol. 194(12):1171-1179. https://doi.org/10.1007/ s00066-018-1358-3

32. Combs SE, Niyazi M, Adeberg S, Bougatf N, Kaul D et al (2018) Re-irradiation of recurrent gliomas: pooled analysis and validation of an established prognostic score-report of the Radiation Oncology Group (ROG) of the German Cancer Consortium (DKTK). Cancer Med 7(5): 1742-1749

33. Krauze AV, Peters C, Cheng J et al (2017) Re-irradiation for recurrent glioma- the NCI experience in tumor control, OAR toxicity and proposal of a novel prognostic scoring system. Radiat Oncol Lond Engl 12(1):191. https://doi.org/10.1186/s13014-017-0930-9

34. Zwirner K, Paulsen F, Schittenhelm J et al (2017) Prognostic parameters and outcome after re-irradiation for progressive glioblastoma. Acta Neurol Scand 136:239-245

35. Klobukowski L, Falkov A, Chelimo C et al (2018) A retrospective review of re-irradiating patients' recurrent high-grade gliomas. Clin Oncol (R Coll Radiol) 30:563-570

36. Post CCB, Kramer MCA, Smid EJ et al (2019) Patterns of reirradiation for recurrent gliomas and validation of a prognostic score. Radiother Oncol 130:156-163

37. Shi W, Scannell Bryan M, Gilbert MR, Mehta MP, Blumenthal DT, Brown PD, Valeinis E, Hopkins K, Souhami L, Andrews DW, Tzuk-Shina T, Howard SP, Youssef EF, Lessard N, Dignam JJ, Werner-Wasik M (2017) Investigating the effect of reirradiation or systemic therapy in patients with glioblastoma after tumor progression: a secondary analysis of NRG oncology/radiation therapy oncology group trial 0525. Int J Radiat Oncol Biol Phys 100:38-44. https://doi.org/10.1016/j.ijrobp.2017.08.038

38. Combs SE, Edler L, Rausch R, Welzel T, Wick W, Debus J (2013) Generation and validation of a prognostic score to predict outcome after re-irradiation of recurrent glioma. Acta Oncol 52:147-152. https://doi.org/10.3109/0284186X.2012.692882

39. Kessel KA, Hesse J, Straube C, Zimmer C, Schmidt-Graf F, Schlegel J, Meyer B, Combs SE (2017) Modification and optimization of an established prognostic score after re-irradiation of recurrent glioma. PLoS ONE 12:e0180457. https://doi.org/10.1371/ journal.pone. 0180457

40. Kim IH (2019) Appraisal of re-irradiation for the recurrent glioblastoma in the era of MGMT promotor methylation. Radiat Oncol $\mathrm{J}$ 37(1):1-12. https://doi.org/10.3857/roj.2019.00171T

41. Tunthanathip T, Ratanalert S, Sae-heng S, Oearsakul T, Sakaruncchai I, Kaewborisutsakul A, Chotsampancharoen T, Intusoma U, Kitkhuandee A, Vaniyapong T (2020) Prognostic Factors and Nomogram Predicting Survival in Diffuse Astrocytoma. J Neurosci Rural Pract 11(1):135-143. https://doi. org/10.1055/s-0039-3403446

42. Guyotat J, Signorelli F, Frappaz D, Madarassy G, Ricci AC, Bret P (2000) Is re-operation for recurrence of glioblastoma justified? Oncol Rep 7:899-904

Publisher's Note Springer Nature remains neutral with regard to jurisdictional claims in published maps and institutional affiliations. 